\section{Pacific Northwest}

National Laboratory

Operated by Battelle for the

U.S. Department of Energy

\title{
Release Fraction Evaluation
}

J. A. Bamberger

J. A. Glissmeyer

January 2004

Prepared for the U.S. Department of Energy under Contract DE-AC06-76RL01830

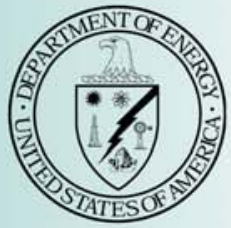




\title{
DISCLAIMER
}

This report was prepared as an account of work sponsored by an agency of the United States Government. Neither the United States Government nor any agency thereof, nor Battelle Memorial Institute, nor any of their employees, makes any warranty, express or implied, or assumes any legal liability or responsibility for the accuracy, completeness, or usefulness of any information, apparatus, product, or process disclosed, or represents that its use would not infringe privately owned rights. Reference herein to any specific commercial product, process, or service by trade name, trademark, manufacturer, or otherwise does not necessarily constitute or imply its endorsement, recommendation, or favoring by the United States Government or any agency thereof, or Battelle Memorial Institute. The views and opinions of authors expressed herein do not necessarily state or reflect those of the United States Government or any agency thereof.

\author{
PACIFIC NORTHWEST NATIONAL LABORATORY \\ operated by \\ BATTELLE \\ for the \\ UNITED STATES DEPARTMENT OF ENERGY \\ under Contract DE-AC06-76RLO 1830
}

\author{
Printed in the United States of America \\ Available to DOE and DOE contractors from the \\ Office of Scientific and Technical Information, P.O. Box 62, Oak Ridge, TN 37831; \\ prices available from (615) 576-8401. \\ Available to the public from the National Technical Information Service, \\ U.S. Department of Commerce, 5285 Port Royal Rd., Springfield, VA 22161
}

This document was printed on recycled paper. 
PNNL-14545

\title{
Release Fraction Evaluation
}

\author{
J. A. Bamberger \\ J. A. Glissmeyer
}

January 2004

Prepared for the U.S. Department of Energy under Contract DE-AC06-76RLO 1830

Pacific Northwest National Laboratory

Richland, Washington 99352 


\section{Summary}

This document presents results of experiments conducted to measure release fractions during certain tank retrieval processes. The tests were performed in a $1 / 4$ - scale model of a $75-\mathrm{ft}(22.9-\mathrm{m})$ diameter million gallon $\left(3785 \mathrm{~m}^{3}\right.$ ) waste storage tank. The retrieval processes simulated were:

1. Discharging liquid or slurry from the mouth of a vertically oriented 2-in. Schedule 40 pipe [ID2.067 in. $(5.25 \mathrm{~cm})]$. The discharging material was in free-fall from the mouth of the pipe near the top of the tank into a liquid or slurry pool at the bottom of the tank, a distance of $11.4 \mathrm{ft}$ (3.48 $\mathrm{m})$.

2. The jet from a 9/16-in. - (1.43 cm-) diameter nozzle transferring liquid or slurry waste from one side of the tank to the other. The discharging liquid was aimed at the opposite side of the tank from the nozzle and either impacted the tank wall or fell into a liquid or slurry pool in the bottom of the tank.

3. A high pressure fan jet of liquid striking a steel plate or simulated waste from a stand-off distance of a few inches.

For each process, a water-soluble fluorescent dye was added to the liquid fraction as a tracer. Kaolin clay was used to represent the solids. The tank was covered and there was no forced ventilation in the tank during the tests.

Six air samples were collected during each test. The air samples were collected at fixed positions in the tank. The air sample filters were dried and weighed to determine the solids collection. The fluorescent dye was then leached from each filter and quantified with a fluorometer to determine the collection of liquid. Samples of the slurry and liquid simulants were also collected to determine the quantities of simulant used in each test.

To calculate the release fraction, the quantity collected on each air sample was adjusted for the fraction of the tank volume sampled and divided by the quantity of material exposed in the simulation. The method was not as sensitive for the solids content as it was for the liquid content; but in those instances where a solids release fraction was determined, it was in agreement with that of the liquid phase.

Release fractions are commonly used to make conservative estimates of emissions from processes. Usually, rather gross assumptions are made in such estimates, such as the total failure of abatement equipment and the use of maximum inventory values. Consequently, it is common practice to report bounding release fraction values with single digit accuracy. The release fractions for the top of the unventilated tank ranged from $9 \times 10^{-7}$ to $8 \times 10^{-5}$ depending on the process simulated. The particle size distribution was determined to be log-normally distributed with geometric mean diameters ranging from 3 to $8 \mu \mathrm{m}$. Thus, all particles are conservatively considered "respirable." 


\section{Contents}

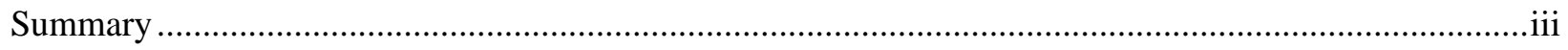

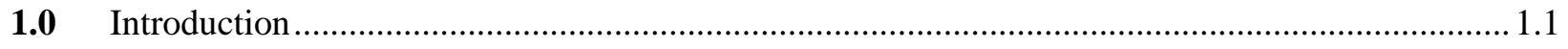

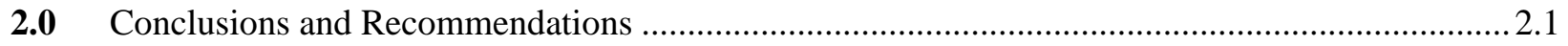

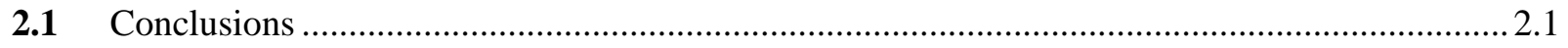

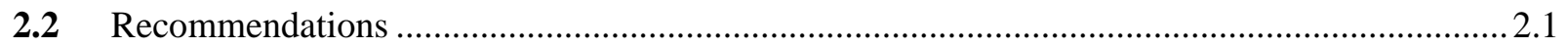

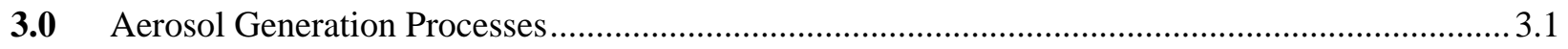

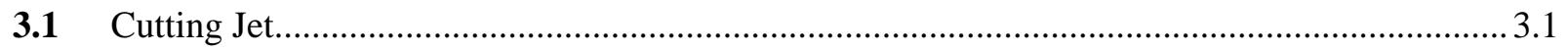

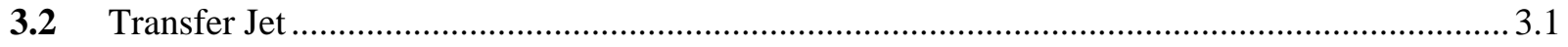

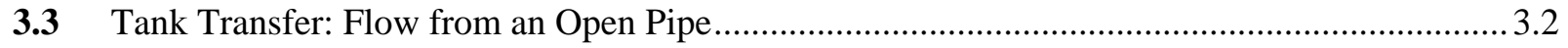

3.4 Aerosol Generation Experiment Configuration................................................................... 3.3

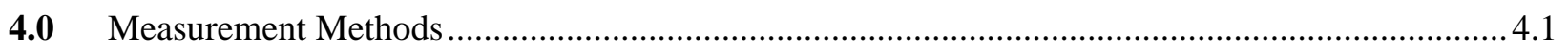

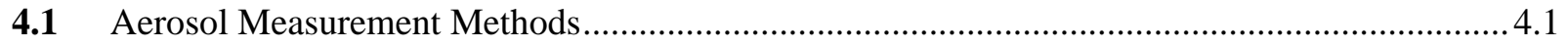

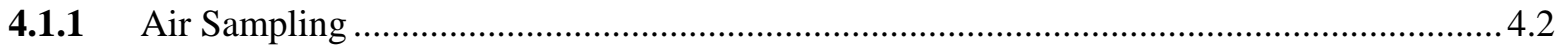

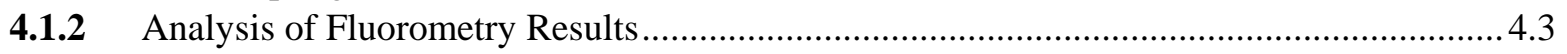

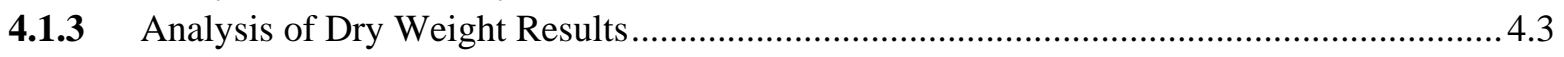

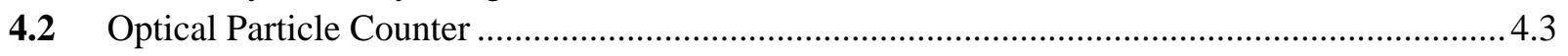

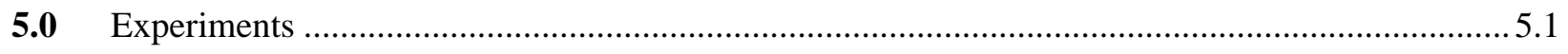

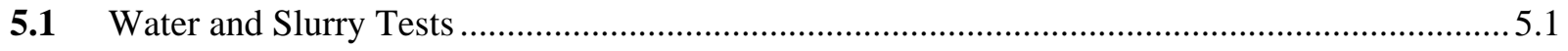

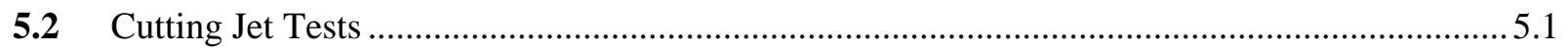

5.3 Cutting Jet Aerosol Generation Tests .................................................................................... 5.2

5.3.1 Run 7: Cutting Jet Impacting Steel Plate at Low Pressure............................................... 5.2

5.3.2 Run 8: Cutting Jet Impacting Simulant at Low Pressure ................................................. 5.3

5.3.3 Run 9: Cutting Jet Impacting Simulant at High Pressure .................................................5.4

5.4 Tank Transfer Aerosol and Solids Generation Tests............................................................ 5.5

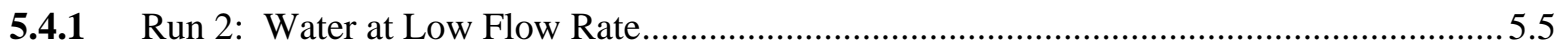

5.4.2 Run 3: Water at High Flow Rate.............................................................................. 5.7

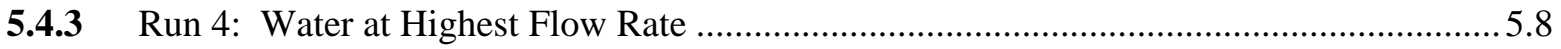

5.4.4 Run 11: Slurry Transfer at Low Flow Rate.................................................................... 5.9

5.4.5 Run 12: Slurry Transfer at High Flow Rate .....................................................................10

5.5 Transfer Jet Aerosol Generation Tests ............................................................................... 5.11

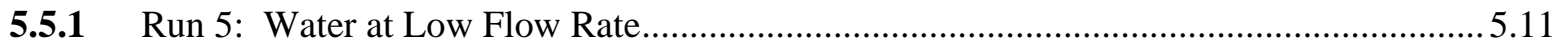

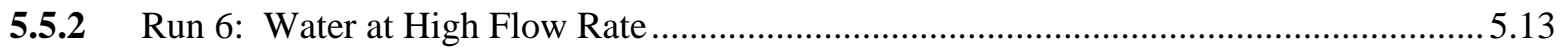

5.5.3 Run 10: Slurry at Low Flow Rate ........................................................................... 5.14

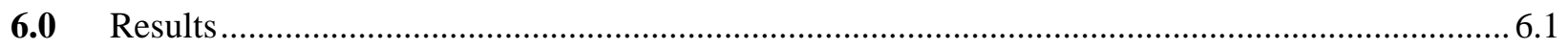

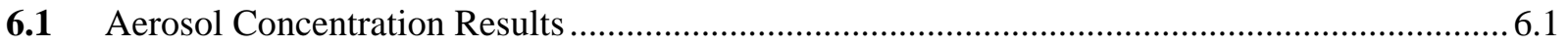

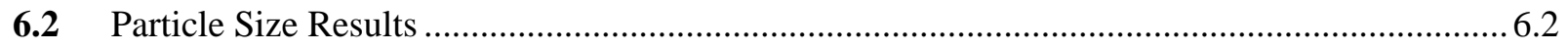

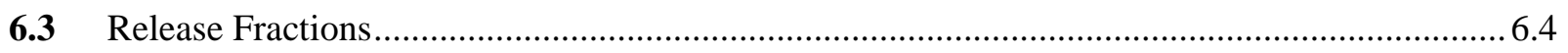

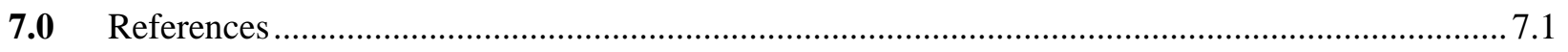




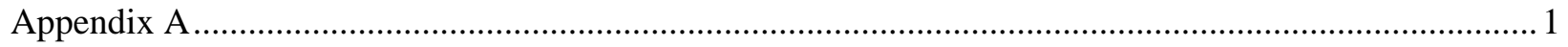

Air Sampling Procedure for Suspension Experiment ............................................................................. 1

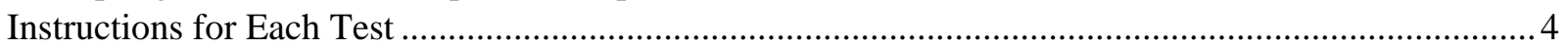

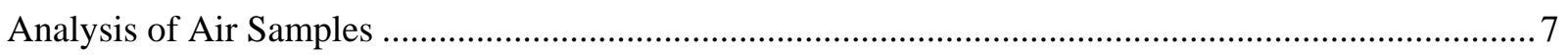

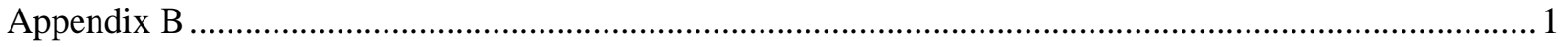

Optical Particle Counter Measured Concentration as a Function of Time ................................................ 1

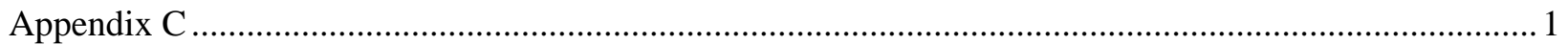

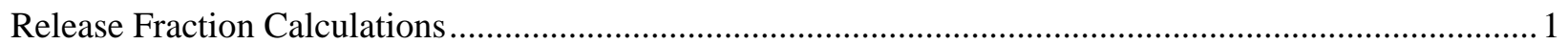




\section{Figures}

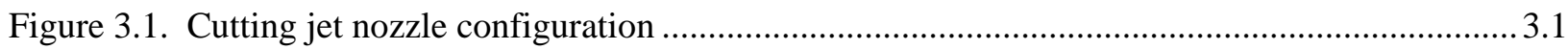

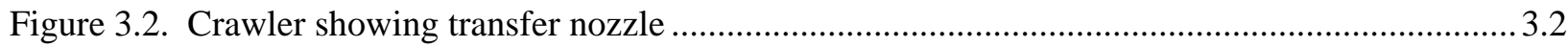

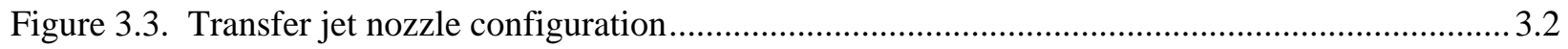

Figure 3.4. Pipe transfer nozzle configuration used to model flow from tank transfers .......................... 3.3

Figure 5.1. Photos from Run 7 showing the jet pattern on the steel plate............................................ 5.2

Figure 5.2. Photos from Run 8 showing the cutting jet impacting the sludge simulant at low pressure .. 5.4

Figure 5.3. Photos from Run 9 showing the cutting jet impacting the sludge simulant at high pressure .5 .5

Figure 5.4. Photos from Run 2 showing water transfer from a discharge pipe at low flow rate...............5.7

Figure 5.5. Photos from Run 3 showing water transfer from a discharge pipe at high flow rate ............ 5.7

Figure 5.6. Photos from Run 4 showing water transfer from a discharge pipe at highest flow rate .........5.9

Figure 5.7. Photos from Run 11 showing slurry transfer through a discharge pipe at low flow rate .....5.10

Figure 5.8. Photos from Run 12 showing slurry transfer through a discharge pipe at high flow rate .... 5.11

Figure 5.9. Photos from Run 5 showing water transfer jet test sequence at low flow rate ..................... 5.13

Figure 5.10. Photos from Run 6 showing water transfer jet test sequence at high flow rate .................. 5.14

Figure 5.11. Photos from Run 10 showing slurry transfer jet test sequence at low flow rate.................5.16

Figure 6.1. Example plot of real-time aerosol concentration data ....................................................... 6.1

Figure 6.2. Run 2 particle size plot during the background measurement ${ }^{\prime}$............................................ 6.3

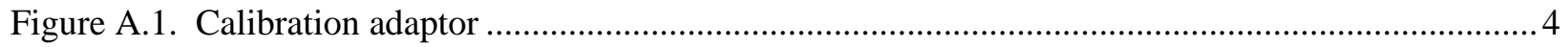

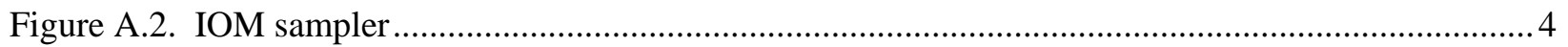

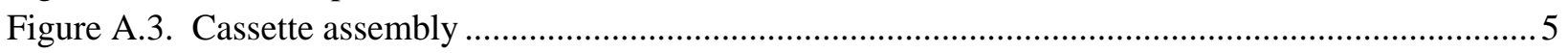

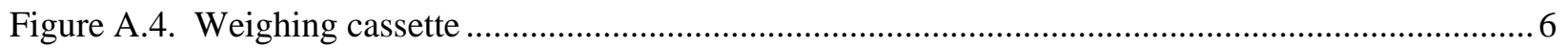

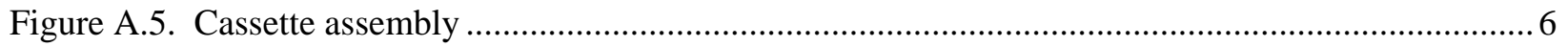

Figure B.1. Run 1 Optical Particle Counter Background Concentration .................................................. 3

Figure B.2. Run 2 Optical Particle Counter concentration pipe discharge with water .............................. 3

Figure B.3. Run 3-4 Optical Particle Counter concentration for pipe discharge with water at high flow

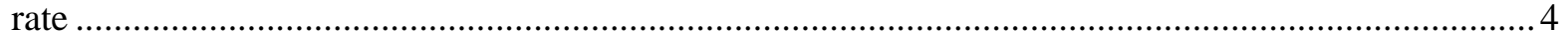

Figure B.4. Run 5 Optical Particle Counter concentration for transfer jet with water................................ 4

Figure B.5. Run 6 Optical Particle Counter concentration for transfer jet with Water............................... 5

Figure B.6. Run 7 Optical Particle Counter concentration for cutting jet impacting steel plate at low

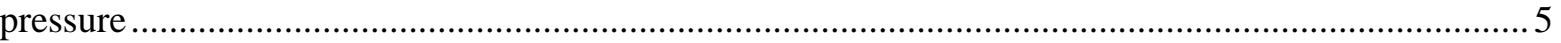

Figure B.7. Run 8 Optical Particle Counter concentration for cutting jet impacting simulant at low

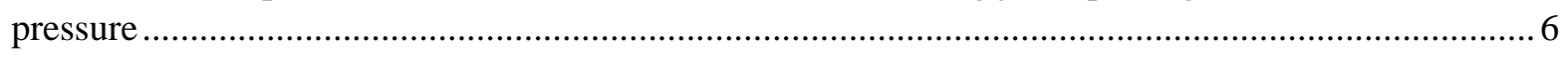

Figure B.8. Run 9 Optical Particle Counter concentration for cutting jet impacting simulant at high

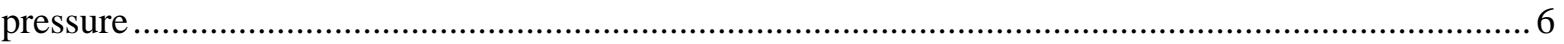

Figure B.9. Run 10 Optical Particle Counter Concentration for transfer jet slurry discharge .................... 7 Figure B.10. Run 11 Optical Particle Counter concentration for slurry discharge from a pipe at low flow

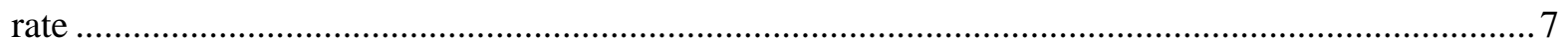

Figure B.11. Run 12 Optical Particle Counter concentration for slurry transfer at high flow rate ..............8 


\section{Tables}

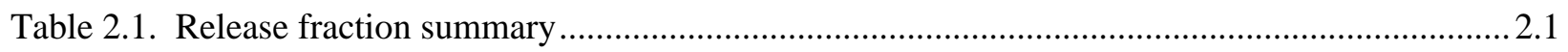

Table 3.1. Locations of hardware and sampling equipment .................................................................. 3.4

Table 5.1. Run 7 flow rate data through the cutting jet...................................................................... 5.2

Table 5.2 Run 8 flow rate data through the cutting jet........................................................................... 5.3

Table 5.3. Run 9 flow rate data through the cutting jet........................................................................ 5.4

Table 5.4. Run 2 flow rate data through a discharge pipe at low flow rate ..........................................5.6

Table 5.5. Run 3 flow rate data through a discharge pipe at high flow rate .......................................... 5.7

Table 5.6. Run 4 flow rate data through a discharge pipe at highest flow rate...................................... 5.8

Table 5.7. Run 11 slurry flow rate data through discharge pipe at low flow rate ................................... 5.9

Table 5.8. Run 12 slurry flow rate data through a discharge pipe at high flow rate ............................ 5.11

Table 5.9. Run 5 flow rate data through a transfer jet at low flow rate ................................................ 5.12

Table 5.10. Run 6 flow rate data through a transfer jet at high flow rate ............................................ 5.13

Table 5.11. Run 10 slurry flow rate data through a transfer jet at low flow rate .................................. 5.15

Table 6.1. Sampling cycles for OPC data to return to background and maximum/background

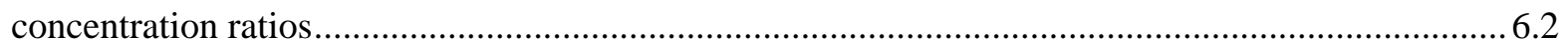

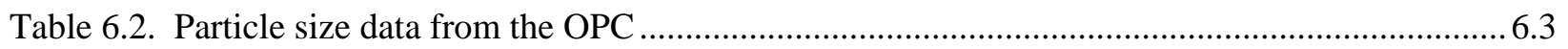

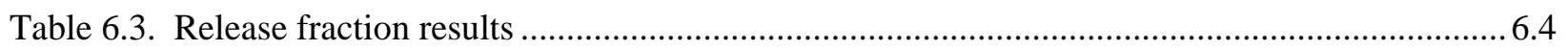

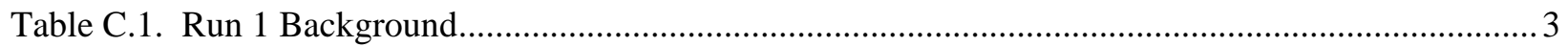

Table C.2. Run 2 Pipe transfer tests with water at low flow rate.......................................................... 4

Table C.3. Run 5 Transfer jet tests with water................................................................................ 5

Table C.4. Run 7 Cutting jet tests with water on steel at low pressure.................................................... 6

Table C.5. Run 8 Cutting jet tests on simulant at low pressure ........................................................ 7

Table C.6. Run 9 Cutting jet tests on simulant at high pressure ........................................................... 8

Table C.7. Run 10 Transfer jet tests with slurry discharge ...................................................................

Table C.8. Run 11 Pipe discharge tests using slurry discharge at high flow rate ....................................10

Table C.9. Run 12 Pipe transfer tests of slurry discharge at high flow rate...........................................11

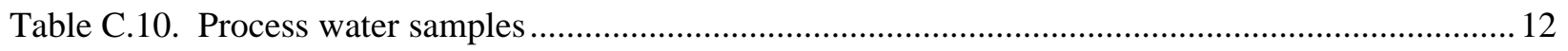

Table C.11. Run 8 Solids analysis from cutting jet impacting simulant at low pressure.......................... 13

Table C.12. Run 9 Solids analysis from cutting jet impacting simulant at high pressure......................... 13

Table C.13. Run 10 Solids analysis from transfer jet slurry discharge ................................................... 14 


\subsection{Introduction}

Waste mobilization and retrieval processes are implemented to remediate nuclear waste stored in 75 - $\mathrm{ft}$ (22.9-m) diameter million-gallon $\left(3785-\mathrm{m}^{3}\right.$ ) underground storage tanks at the Hanford Site in Washington state. These processes are developed based on the characteristics of the waste to be retrieved and other operational constraints. These processes have the potential to generate aerosols or suspend solids during operation. The purpose of this study was to evaluate the aerosol generation performance of several types of fluid transport processes that could be considered for future implementation. These processes included:

1. Discharging liquid or slurry from the mouth of a vertically oriented two-inch pipe. The discharging material was in free-fall from the mouth of the pipe near the top of the tank into a liquid or slurry pool at the bottom of the tank, a distance of $11.4 \mathrm{ft}(3.48 \mathrm{~m})$.

2. The jet from a nozzle transferring liquid or slurry waste from one side of the tank to the other. The discharging liquid was aimed at the opposite side of the tank from the nozzle and either impacted the tank wall or fell into a liquid or slurry pool in the bottom of the tank.

3. A high pressure fan jet of liquid striking a steel plate or simulated waste from a stand-off distance of a few inches.

To characterize the aerosol a water-soluble fluorescent dye was added to the liquid fraction as a tracer. Kaolin clay, added to the liquid fraction, was used to represent the solids. The tank was covered, and there was no forced ventilation in the tank during the tests. To calculate the release fraction, the quantity collected on each air sample was adjusted for the fraction of the tank volume sampled and divided by the quantity of material exposed in the simulation. These experiments build on research conducted at PNNL in the 1980 s to characterize aerosols generated by releases of powders and solutions (Ballinger et al 1986, 1987, 1988 and Sutter et al 1981). 


\subsection{Conclusions and Recommendations}

\subsection{Conclusions}

The release fraction results for this study are listed in Table 2.1. This summary focuses on the values obtained from measurements taken at the top of the tank which is the location from which ventilation air may be drawn. The liquid fraction results are presented because this method of measurement (dye tracer) was more sensitive than that used for the solids fraction (solids loading). These results range over nearly two orders of magnitude. It is noted that the height of the test tank is lower than that of the full scale tank by a factor of 4 , but the tests were not conducted to provide the release fraction as a function of height. ${ }^{\text {a) }}$ The release fractions calculated based on samples obtained near the point of the process or fluid stream ranged from the same to as much as an order of magnitude higher than the release fractions obtained from measurements taken near the tank top at an elevation of $11 \mathrm{ft}(3.35 \mathrm{~m})$.

Table 2.1. Release fraction summary

\begin{tabular}{|c|l|c|}
\hline Run & \multicolumn{1}{|c|}{ Process } & Release Fraction at Scaled Tank Top \\
\hline \multicolumn{2}{|c|}{ Pipe Transfer } & $0.9 \times 10^{-6}$ \\
\hline 2 & Liquid discharge at low flow rate & $2 \times 10^{-6}$ \\
\hline 11 & Slurry discharge at low flow rate & $4 \times 10^{-6}$ \\
\hline 12 & Slurry discharge at high flow rate & $3 \times 10^{-6}$ \\
\hline \multicolumn{2}{|c|}{ Transfer Jet } & $2 \times 10^{-6}$ \\
\hline 5 & Liquid discharge & $8 \times 10^{-5}$ \\
\hline 10 & Slurry discharge & $8 \times 10^{-5}$ \\
\hline & Cutting Jet
\end{tabular}

\subsection{Recommendations}

The release fraction measurements could be reported with all significant digits; however, there are simplifications made in simulating processes and significant spatial and orientation differences between the individual sampling locations. Release fractions are commonly used to make conservative estimates of emissions from processes. Usually, rather gross assumptions are made in such estimates, such as the

a) Height influences release fractions in two competing ways: 1) greater height of a spill is likely to increase aerosol generated, and 2) greater height from the source of aerosol of generation to the potential receptor decreases concentration due to particle depletion mechanisms. 
total failure of abatement equipment and the use of maximum inventory values. Consequently, it is common practice to report bounding release fraction values with single digit accuracy. 


\subsection{Aerosol Generation Processes}

Three processes were identified as potential sources of aerosol generation during their in-tank operation. These processes were investigated to determine their release fractions.

\subsection{Cutting Jet}

Cutting jets are mounted on an articulated arm or crawler and are used for cutting, dislodging, or cleaning solids or slurry from surfaces. The jet configuration to be used in waste retrieval equipment includes five jets mounted in a semicircle directed downward. The jets are commercially available wash jets (Spraying Systems Company ${ }^{\text {a) }} 1 / 4$ MEG 2505). Tests conducted at the Hanford cold test facility by others showed that the preferred pressure for cutting jet operation is 300 psig (2.07 MPag). The proposed jet system can operate at pressures up to 1200 psig (8.27 MPag). The effective stand-off distance for the cutting jets ranges from 1 to $5 \mathrm{in}$. based on the deployment configuration. The fan jet has a spray angle of 25 degrees. For this evaluation a single jet mounted in line with a pressure gage was used as shown in Figure 3.1.

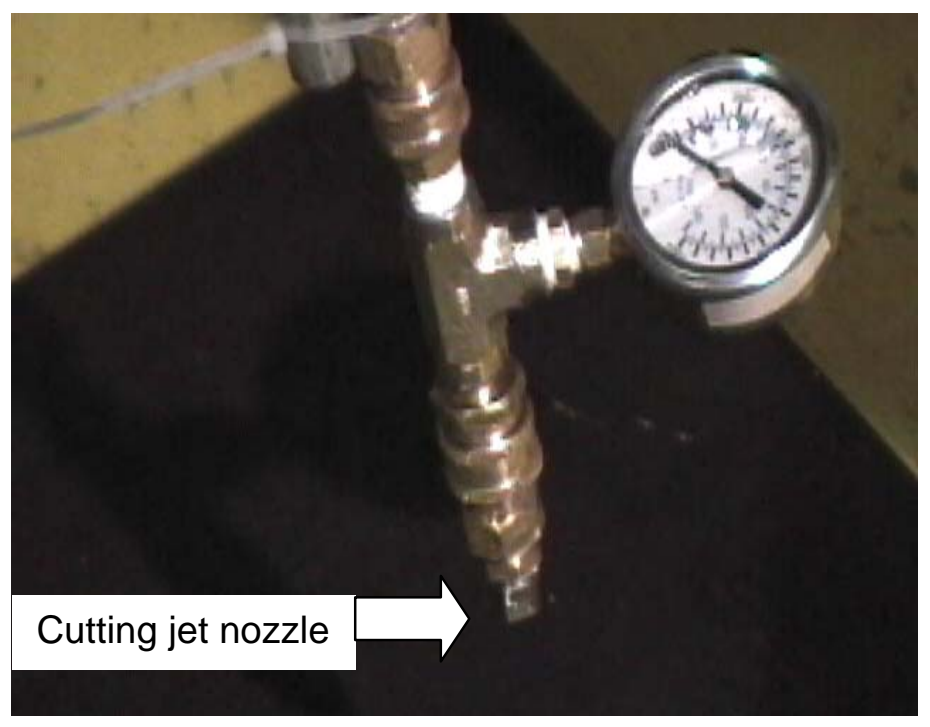

Figure 3.1. Cutting jet nozzle configuration

\subsection{Transfer Jet}

The transfer jet nozzle is mounted on the crawler as shown in Figure 3.2. The transfer nozzle configuration tested was mounted on the side of the tank and is shown in Figure 3.3. The nozzle operates at relatively low flow rates and pressures and is used to spray fluid from the crawler location to a collection location near a retrieval pump or other retrieval device.

a) Spraying Systems Company, Wheaton, Illinois. 


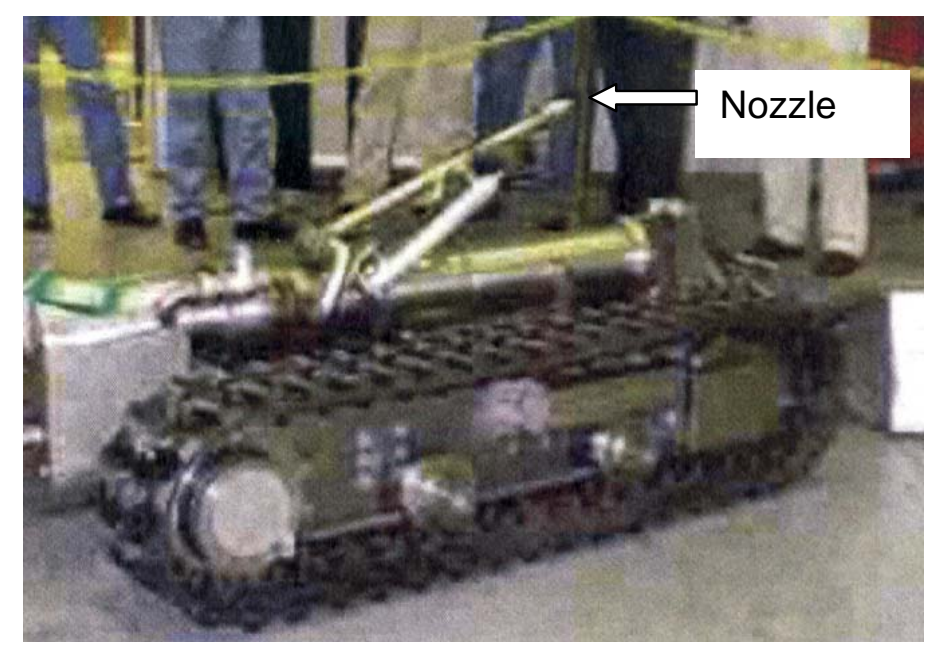

Figure 3.2. Crawler showing transfer nozzle

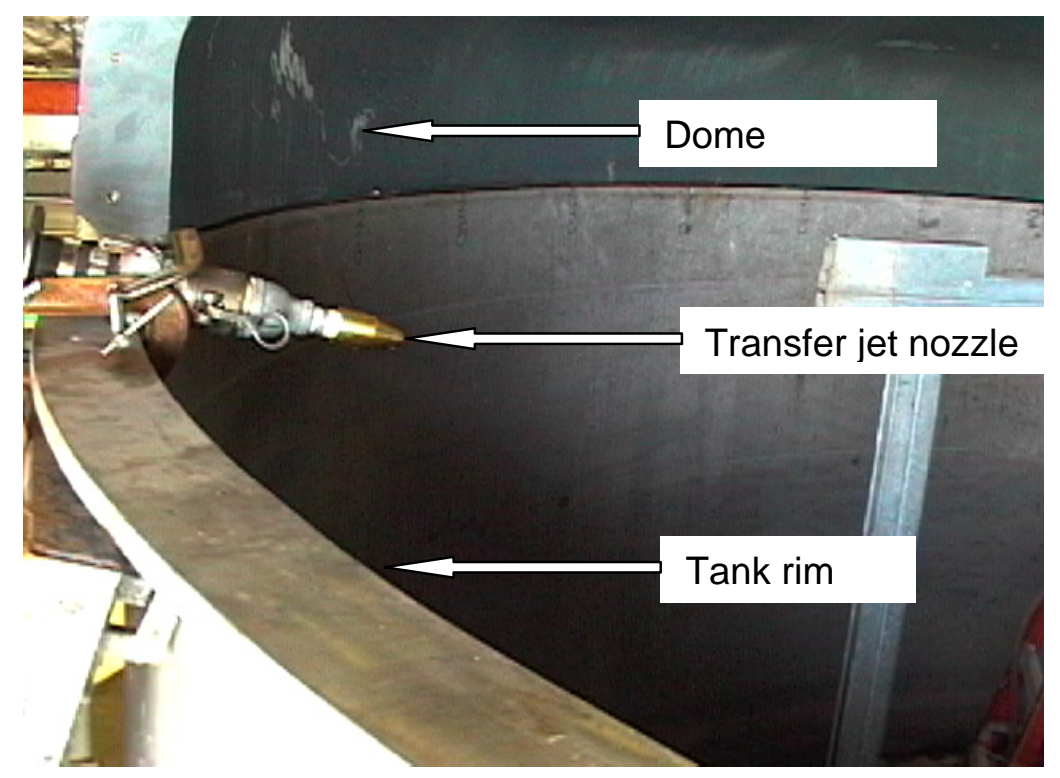

Figure 3.3. Transfer jet nozzle configuration

\subsection{Tank Transfer: Flow from an Open Pipe}

Transfers of fluid or slurry from tank to tank occur through nominal 2 in. $(5 \mathrm{~cm})$ diameter pipes or 2 in. (5 $\mathrm{cm})$ hose in hoses. Some transfers may be conducted using nominal 3 in. $(7.6 \mathrm{~cm})$ diameter pipe. The flow rate range is 50 to $60 \mathrm{gpm}\left(.0032\right.$ to $\left.0.0038 \mathrm{~m}^{3} / \mathrm{s}\right)$ for hose in hose transfers, 50 to $100 \mathrm{gpm}(0.0032$ to $0.0063 \mathrm{~m}^{3} / \mathrm{s}$ ) for 2 in. pipe transfers, and 50 to $160 \mathrm{gpm}$ ( 0.0032 to $0.0101 \mathrm{~m}^{3} / \mathrm{s}$ ) for 3 in. $(7.6 \mathrm{~cm})$ pipe transfers. The nozzle configuration evaluated is shown in Figure 3.3. 


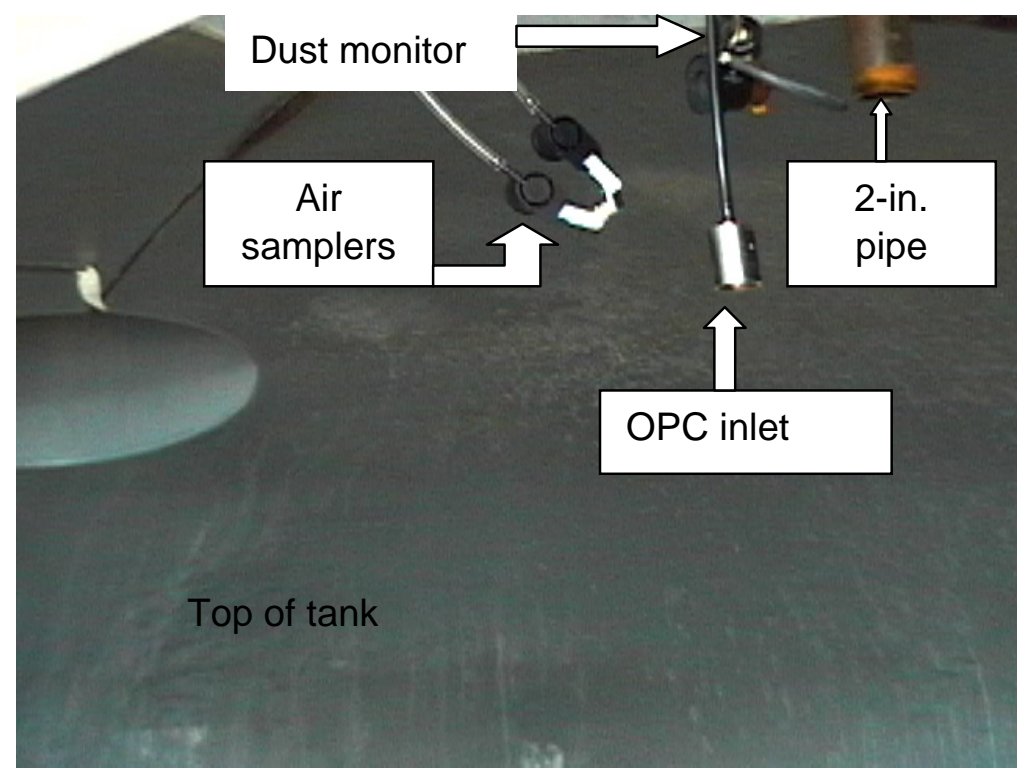

Figure 3.4. Pipe transfer nozzle configuration used to model flow from tank transfers

\subsection{Aerosol Generation Experiment Configuration}

All aerosol generation characterization tests were conducted in the 1/4-scale tank located in the 336 bldg. of Hanford's 300 Area to provide an enclosed structure (Bamberger et al 1993). The $1 / 4$-scale tank is a $1 / 4$ scale model of a $75-\mathrm{ft}(22.9 \mathrm{~m}) 1$ million gallon $\left(3785 \mathrm{~m}^{3}\right)$ Hanford double-shell tank. Three segments of the $1 / 4$-scale tank dome were installed; the remaining quadrant of the tank was closed with a plastic tarp. The enclosure prevented aerosol from entering or leaving the tank test chamber. Fluid or slurry was pumped from the mix tank through the nozzles into the $1 / 4$-scale tank. Figure 3.3 shows the arrangement of the $1 / 4$-scale tank with the top rim of the tank, part of the dome and one of the test nozzles. The air samplers clustered near the top of the tank are shown in Figure 3.4. The locations of the experiment components are summarized in Table 3.1.

The cutting jet was powered using a portable gasoline driven pressure washer. The unit provides pressure up to 3200 psig (22.1 MPag). The unit was instrumented with pressure gages to measure the pressure at the unit and at the nozzle. The pressure washer was located outside of the building away from the roll-up door so that no gasoline exhaust fumes from operation could blow into the building.

An Ingersol Rand Standard Pump Division centrifugal pump was used to circulate fluid between the mix tank and the nozzles being evaluated in the test tank. The pump has a capacity of $150 \mathrm{gpm}\left(0.0095 \mathrm{~m}^{3} / \mathrm{s}\right)$ and 275 psig (1.90 MPag). The mix tank supplies fluid to this pump. After the mix tank is emptied, the fluid or slurry is pumped back into the mix tank to provide the desired number of operating cycles. A 
compressed air driven transfer pump was used to move fluid from the $1 / 4$-scale tank to the mix tank. The transfer pump is powered by a rented $1650 \mathrm{scfm}\left(0.779 \mathrm{sm}^{3} / \mathrm{s}\right)$, diesel driven, portable air compressor located outside on the east side of the building.

A digital video camera mounted on the tank walkway around the perimeter of the tank was used to film the jet during the tests.

Table 3.1. Locations of hardware and sampling equipment

\begin{tabular}{|c|c|c|c|c|c|c|}
\hline \multirow{4}{*}{$\begin{array}{l}\text { Item } \\
\text { Sampler }\end{array}$} & \multirow{4}{*}{ Location } & \multicolumn{5}{|c|}{ Coordinate } \\
\hline & & \multicolumn{2}{|c|}{ Radial } & \multirow{2}{*}{$\begin{array}{l}\text { Angular } \\
\vartheta=0 \text { at North }\end{array}$} & \multicolumn{2}{|c|}{ Elevation } \\
\hline & & \multicolumn{2}{|c|}{$\mathbf{R}=\mathbf{0}$ at tank center } & & \multicolumn{2}{|c|}{$\mathrm{Z}=0$ at tank floor } \\
\hline & & ft & $\mathbf{m}$ & degrees & ft & $\mathbf{m}$ \\
\hline Sampler 1 & Top of tank & 1 & 0.31 & 188 & 11.5 & 3.51 \\
\hline Sampler 2 & Top of tank & 1 & 0.31 & 230 & 11 & 3.35 \\
\hline Sampler 3 & Top of tank & 1 & 0.31 & 230 & 11 & 3.35 \\
\hline Sampler 4 & Side of tank & 9.4 & 2.87 & 158 & 5 & 1.52 \\
\hline Sampler 5 & Side of tank & 9.4 & 2.87 & 186 & 5 & 1.52 \\
\hline Sampler 6 & In tank space & 4.6 & 1.40 & 155 & 4 & 1.22 \\
\hline Dust Monitor & Top of tank & 1 & 0.31 & 188 & 11.5 & 3.51 \\
\hline $\begin{array}{l}\text { Optical Particle } \\
\text { Counter (OPC) }\end{array}$ & Top of tank & 1 & 0.31 & 188 & 11 & 3.35 \\
\hline Process Hardware & Orientation & & & & & \\
\hline Discharge pipe & Vertical & 8.5 & 2.60 & 8 & 11.4 & 3.48 \\
\hline Transfer jet & Horizontal & 8 & 2.44 & 175 & 8 & 2.44 \\
\hline Cutting jet & Vertical & 4 & 1.22 & 153 & 1 & 3.35 \\
\hline Tank Dimensions & & & & & & \\
\hline Tank height & & & & & 8 & 2.44 \\
\hline Dome height & & & & & 3.5 & 1.07 \\
\hline Riser height & & & & & 0.5 & 0.15 \\
\hline Total height & & & & & 12 & 3.66 \\
\hline Tank radius & & 9.38 & 2.86 & & & \\
\hline Domed Area & & & & $\begin{array}{l}188.5 \text { to } 360 \text { to } \\
98.5\end{array}$ & & \\
\hline $\begin{array}{l}\text { Plastic Covered } \\
\text { Area }\end{array}$ & & & & 98.5 to 188.5 & & \\
\hline & & & & & & \\
\hline
\end{tabular}




\subsection{Measurement Methods}

Variables monitored during the tests included:

- Fluid initial and final level in the mix tank (used to calculate the volume of fluid used per cycle)

- Pump operating time used for calculating the average flow rate per run

- Real-time aerosol concentration

- Real-time aerosol concentration as a function of particle size

- Liquid and solid aerosol concentration measured with integrating air samplers.

Twelve test runs were conducted. The first run provided background measurements. The rest covered the range of operating parameters for the three simulated processes.

\subsection{Aerosol Measurement Methods}

Three methods were used for monitoring air concentration in the $1 / 4$-scale tank during the test runs. The first was to collect air samples on filters. The second method was to qualitatively monitor particle size and concentration in near real time with an optical particle counter (OPC). ${ }^{\text {a) }}$ A third method, using a realtime dust monitor, was unsuccessful and produced no meaningful data. The cluster of air monitors located at the top of the tank is shown in Figure 3.4, and Figure 4.1 shows the location of Air Sampler 6 inside the tank. Appendix A contains the detailed sampling and analysis procedure. The methods are further described below.

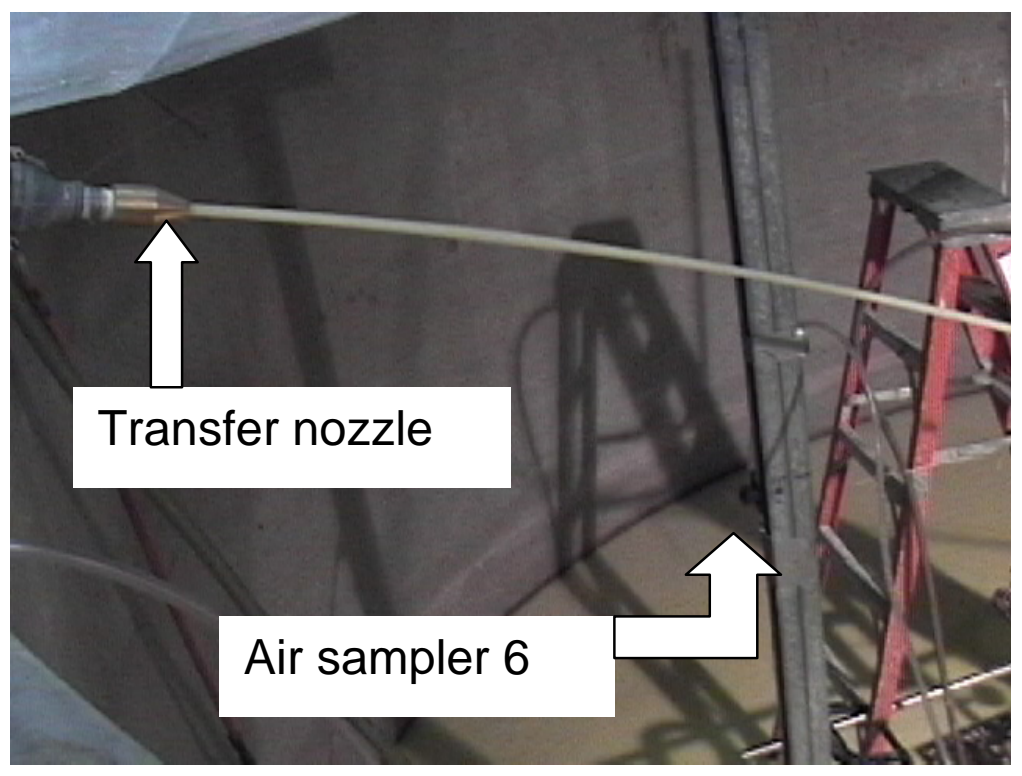

Figure 4.1. Location of air sampler 6 inside tank

a) Model 2408A, Pacific Scientific Instruments (formerly Met-One), Grants Pass, Oregon. 


\subsubsection{Air Sampling}

Samples of the airborne material were collected during the background run and eight of the process simulations. The samples were collected on 25-mm diameter mixed cellulose ester membrane filters. ${ }^{\text {a) }}$ The samples were contained in open-face filter holders ${ }^{\mathrm{b})}$ which were connected by flexible tubes to personal sampling pumps ${ }^{\mathrm{c}}$ located outside the tank.

The filter holders were placed to collect samples at four locations in the tank. Three (samplers 1, 2, and 3 ) were collocated at the center of the top of the tank. Two (samplers 4 and 5) were located along the tank wall $9.4 \mathrm{ft}(2.87 \mathrm{~m})$ from the tank center at elevations of $8(2.44 \mathrm{~m})$ and $5 \mathrm{ft}(1.52 \mathrm{~m})$ above the tank floor. The sixth air sampler was in the central area of the tank and in close proximity to the process stream and at an elevation of $5 \mathrm{ft}(1.52 \mathrm{~m})$ from the tank floor. The sampler positions were listed in Table 3.1. Only the three air samplers at the top of the tank were expected to measure aerosol at a location approximating that where exhaust air is drawn from the full scale tanks.

At the beginning of each test day, another filter holder was prepared and used to collect a background air sample. It was operated at sampling position 4. Sampling flow rates were $0.75 \mathrm{lpm}$ (liters per minute) for the sampler near the process stream and $1.5 \mathrm{lpm}$ for the others. A calibrator ${ }^{\mathrm{d})}$ was used to set the flow rates at the sampling pumps prior to and after the series of measurements.

The filter holder consisted of a filter cassette and the outer holder. Before a test run, these parts were thoroughly cleaned with water and sonicated in deionized water. The components were dried, and the cassettes were loaded with a filter disk. The cassettes were tare weighed, and the assembled filter holders were packaged for transport. Two cassettes were included with each run as field blanks.

Most test runs included several sequential operations of the simulated process. To provide the desired operating time, fluid in the mix tank was sprayed into the test tank. When the mix tank was empty, the spray process was stopped, and the fluid was pumped back into the mix tank. This process was completed up to four times to provide the desired operating time. The air samplers were always operated for the entire duration of the test run. At the end of a run, the air samplers were retrieved and packaged for transport. In the lab, the cassettes were removed from the filter holders and dried for thirty minutes in an oven at about $90^{\circ} \mathrm{F}\left(32^{\circ} \mathrm{C}\right)$. The cassettes were allowed to equilibrate to room temperature and were reweighed. For analysis, the filters were removed from the cassettes and placed in known quantities of deionized water to determine the fluorescent dye content. After several hours, the water was analyzed for the content of fluorescent dye as compared to prepared standards. Each run was analyzed as a batch. Standards, field blanks, and process blanks were analyzed with each batch of air samples.

Air sampler tare weight, final weight, flow rate, sampling duration, and analytical data were recorded on data sheets. The hand written data were then transferred to spreadsheets.

\footnotetext{
a) MF-Millipore, Model HAWP 02500, Millipore Inc., Billerica, Massachusetts.

b) SKC Incorporated, IOM Inhalable Particle Sampler, Eighty Four, Pennsylvania. This sampler was developed at the Institute of Occupational Medicine, Edinburgh, UK by Mark and Vincent (1986)

${ }^{c}$ SKC Incorporated, Model 224, Eighty Four, Pennsylvania.

${ }^{d)}$ DC-Lite 717-04, SKC Incorporated, Eighty Four, PA.
} 


\subsubsection{Analysis of Fluorometry Results}

Air samplers were operated during eight test runs and one background run. The estimated aerosol release fraction was calculated for each air sample according to Equation 4.1. The dye in the sample is obtained from the fluorometry results for each sample. The dye in the process is obtained from analyses of process water samples and measurements of the process water as listed in Section 5. The tank volume was calculated from tank geometry, and the sample volume was calculated from the flow rate and elapsed time. The fluorometry results and release fraction calculations are tabulated in Appendix C.

$$
\text { Release fraction of liquid }=\frac{\text { dye in sample }}{\text { dye in process }} \bullet \frac{\text { tank volume }}{\text { air sample volume }}
$$

\subsubsection{Analysis of Dry Weight Results}

The balance used was accurate to tenths of a milligram. When all of the background air samples and field blanks were considered, weight changes ranged from 0.1 to $-0.5 \mathrm{mg}$; and $53 \%$ of these samples showed $0.0 \mathrm{mg}$ weight change during a run. The mean weight change of these samples was $-0.09 \mathrm{mg}$. Only a sample weight gain of $0.2 \mathrm{mg}(200 \mu \mathrm{g})$ was considered as a valid measurement of deposited solids for this report.

After drying the samples, any sample weight gain should be attributed to the solids fraction of the waste simulant and the soluble fluorescent dye. However, the content of fluorescent dye measured by fluorometry on sample filters ranged from $7.3 \mu \mathrm{g}$ (Run 7, sample 7B4) to $3.2 \mathrm{ng}$ (Run 1, sample 1A4). Consequently, the contribution of the fluorescent dye was ignored in the weight gain measurements.

Solids were introduced into the process simulations during Runs 8 through 12 . For these runs, the air sample weight gain should represent the release of the solids portion of the process slurry. Solids were selected based on nonhazardous simulants developed to model performance of equipment planned for use in radioactive waste tanks (Powell, Golcar, Geeting 1997). The simulant used was selected for evaluation of the process equipment described in Section 3.

The equation to calculate the solids release fractions is given by Equation 4.2. The calculations of dry solids release fractions are located in Appendix C.

Release fraction of solids $=\frac{\text { solids in sample }}{\text { solids in process }} \bullet \frac{\text { tank volume }}{\text { air sample volume }}$

\subsection{Optical Particle Counter}

The OPC categorizes particulate into one of six size brackets based on the amount of laser light scattered by a particle that is equivalent to that of a spherical calibration particle made of polystyrene latex. To 
complicate analysis, the OPC has limited range, and there are inlet losses that are a function of particle size. However, there is value in using the particle size data from the OPC to observe trends.

Each OPC data record is the total particle count in each size range for a one-minute interval. There was a one second lag time between samples. The OPC aerosol inlet used was the manufacturer's inverted cone nozzle which was attached to the instrument with flexible conductive tubing to inhibit particle plate out in the tube. The inlet was collocated with air samplers 2 and 3 at the center of the top of the tank, and the OPC was $2 \mathrm{ft}$ ( $0.61 \mathrm{~m}$ ) above that and outside the enclosed air space. The sampling flow rate was 28.3 lpm. There was a single bend in the flexible tubing. The OPC was operated throughout each testing day and for all test runs. 


\subsection{Experiments}

The experimental test matrix evaluated three processes: cutting jet, transfer jet, and flow from an open pipe, and two fluids: water and slurry. In addition, the cutting jet impacted two surfaces: steel and simulant. The processes were operated at several flow rates.

\subsection{Water and Slurry Tests}

The water (Runs 2 through 7) and slurry (Runs 10 through 12) spray tests were conducted based on the following procedure. Run 1 was a background run. Fluorescent dye was added to the water in the mix tank to be used as a tracer for identifying the amount of water captured on the air samplers. To obtain slurry, water was sprayed through the cutting jet into a container of simulant during Runs 8 and 9. The slurry was used as the starting fluid during Runs 10 through 12. The solid captured on filters was measured to determine the solids in suspension. The procedure during the water and slurry tests included:

- Configure piping to include the process hardware that is to be tested.

- Set the valves to provide the desired flow rate.

- Record the liquid level in the mix tank.

- Turn on aerosol sampling equipment.

- Turn on video camera.

- $\quad$ Start the pump to route fluid from the mix tank through the process hardware.

- Observe the spray produced.

- Record the time the pump stopped and final level in mix tank.

Note: Based on the capacity of the mix tank, experiments to evaluate the transfer jet and the tank transfer were conducted as a series of sequential runs to provide an adequate sampling time. For these evaluations, the following additional steps were followed.

- Pump the liquid from the $1 / 4$-scale tank to the mix tank.

- Record the level in the mix tank and complete the steps listed above as many times as required to provide the desired operating time.

- Stop sampling pumps.

- Remove samplers and analyze the samples.

\subsection{Cutting Jet Tests}

The following procedure was used for the cutting jet tests for impacting steel or for erosion of simulant.

- Place the desired surface beneath the jet nozzle: either a steel plate or a container of simulant. The container will have $1 \mathrm{in}$. vertical slits on either side to permit water to run out of the container.

- Position the container so it can be moved beneath the wash jet.

- Configure piping for the cutting jet.

- Set the valves to provide the approximate flow rate.

- Record the liquid level in the mix tank.

- Turn on aerosol sampling equipment.

- Turn on video camera. 
- Start the pressure sprayer.

- If simulant is being used, incrementally move the simulant container beneath the wash jet during the test period.

- $\quad$ Observe the spray produced.

- $\quad$ Record time pump stopped and final level in mix tank.

- Use a new container of simulant for each cutting jet test.

\subsection{Cutting Jet Aerosol Generation Tests}

The tests with the cutting jet are described first, because the cutting jet was used to produce the slurry used during solids suspension tests conducted with the other processes. Each test run is described in the following subsections.

\subsubsection{Run 7: Cutting Jet Impacting Steel Plate at Low Pressure}

These tests were conducted by pumping water with fluorescent dye through the cutting jet which impacted a steel plate, mounted above the water level in the tank. Each test consisted of a single operating cycle. The fluid volume and flow rate data are summarized in Table 5.1. Photographs taken during the sequence are shown in Figure 5.1. The jet operating pressure was in the 340 to 380 psig (2.34 to $2.62 \mathrm{MPag}$ ) range. The monitored test conditions are fluid volume and time which provide data to calculate the average flow rate. The cutting jet may be used to scarify solid waste that is otherwise not sufficiently mobilized by other dislodging mechanisms. If the water-based cutting jet actually strikes bare steel, it is not striking waste, and waste is not being released at that particular time. Consequently, a measured release fraction from this run is not actually applicable to waste retrieval.

Table 5.1. Run 7 flow rate data through the cutting jet

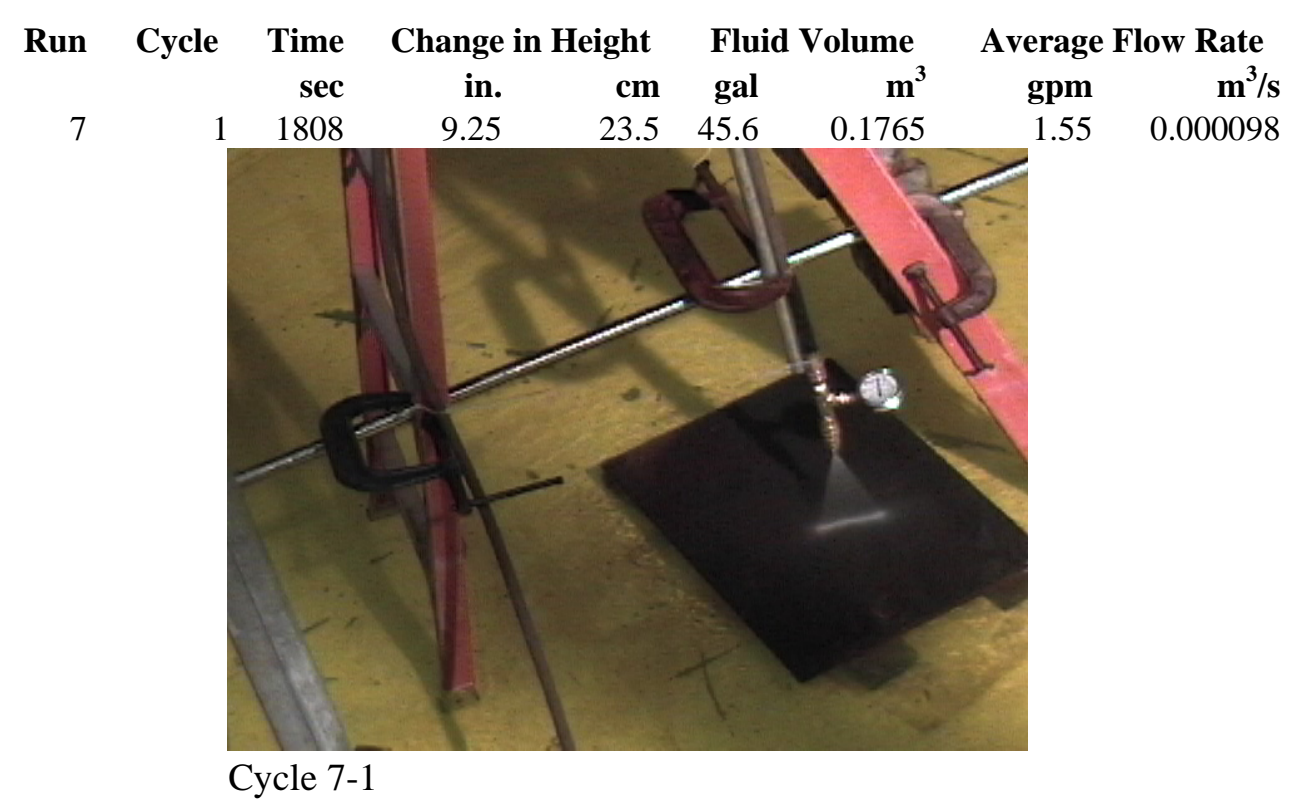

Figure 5.1. Photos from Run 7 showing the jet pattern on the steel plate 


\subsubsection{Run 8: Cutting Jet Impacting Simulant at Low Pressure}

These tests were conducted by pumping water with fluorescent dye through the cutting jet which impacted simulant contained in a box mounted above the water level in the tank. Each test consisted of one cycle. The fluid volume and flow rate data are summarized in Table 5.2. Photographs taken during the sequence are shown in Figure 5.2. Every 5 minutes during the 30 minute test, the simulant position was incremented to move new simulant beneath the jet. The jet operating pressure was in the $300 \mathrm{psig}$ (2.07 MPag) range. During the run the jet dislodged $9 \mathrm{~kg}$ of simulant out of $36.3 \mathrm{~kg}$ in the container. The monitored test conditions are fluid volume and time which provide data to calculate the average flow rate.

Table 5.2 Run 8 flow rate data through the cutting jet

\begin{tabular}{ccrcrcrrr} 
Run & Cycle & Time & \multicolumn{2}{c}{ Change in Height } & \multicolumn{2}{c}{ Fluid Volume } & \multicolumn{2}{c}{ Average Flow Rate } \\
& & $\begin{array}{r}\text { sec } \\
\text { in. }\end{array}$ & $\mathbf{c m}$ & gal & $\mathbf{m}^{3}$ & gpm & $\mathbf{m}^{3} / \mathbf{s}$ \\
8 & 1 & 1806 & 7.75 & 19.7 & 39.1 & 0.1478 & 1.30 & 0.000082
\end{tabular}
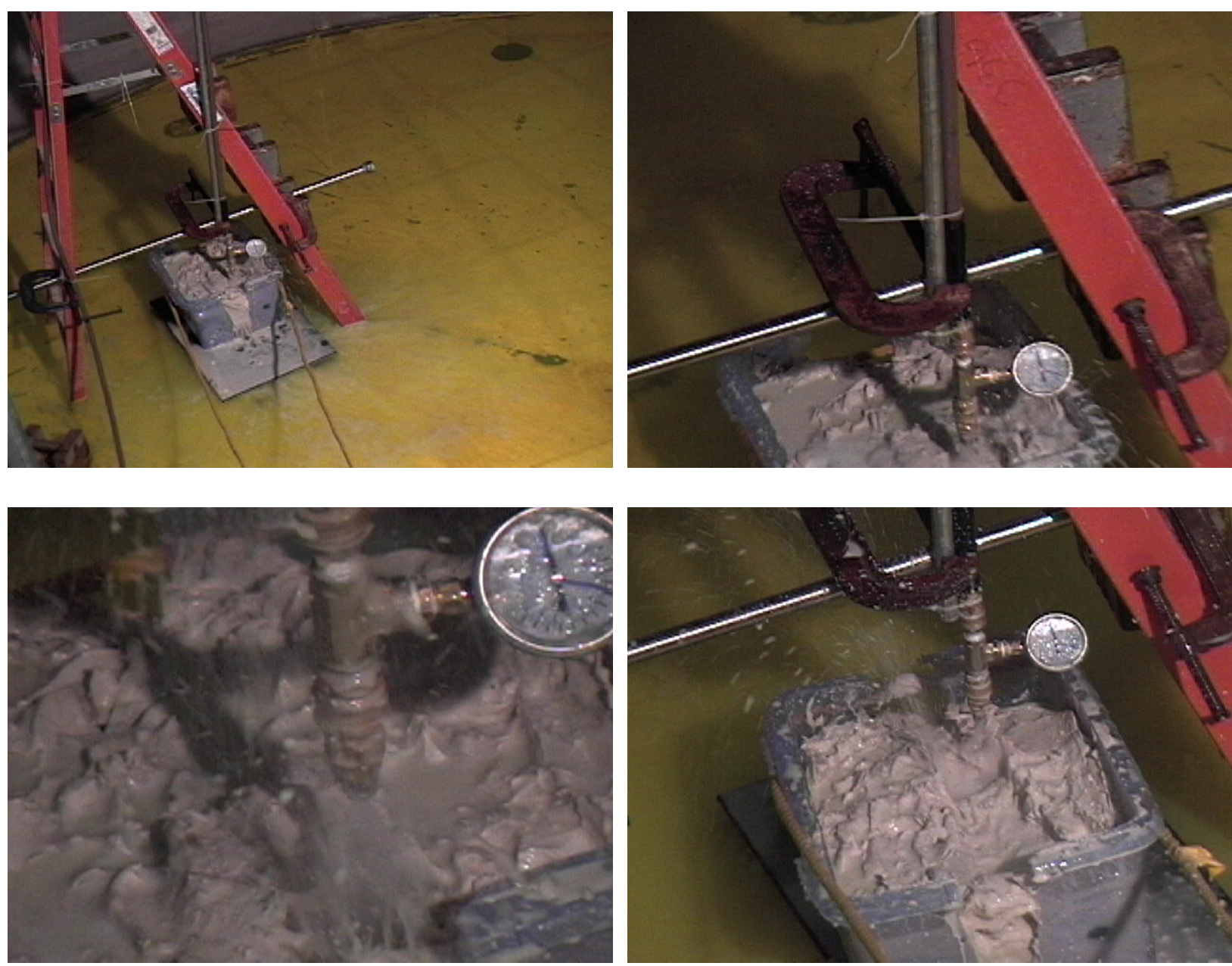

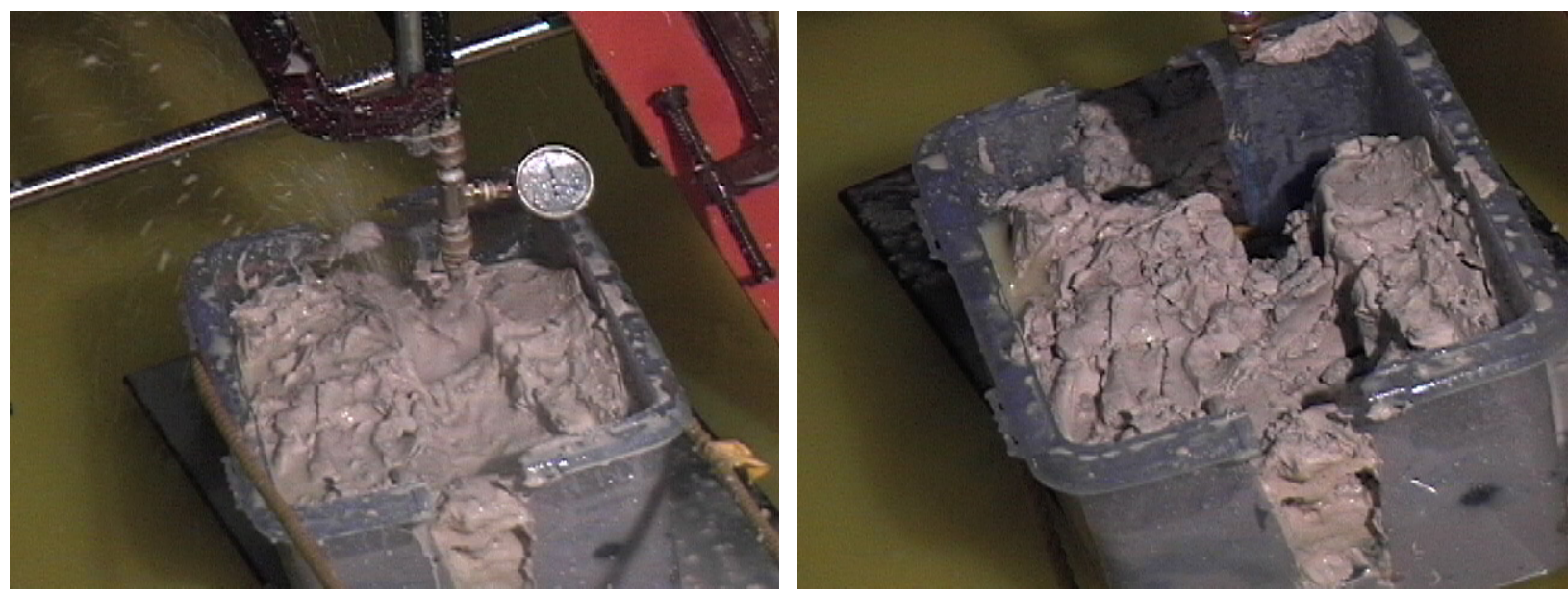

Cycle 8-1

Figure 5.2. Photos from Run 8 showing the cutting jet impacting the sludge simulant at low pressure

\subsubsection{Run 9: Cutting Jet Impacting Simulant at High Pressure}

These tests were conducted by pumping water with fluorescent dye through the cutting jet which impacted simulant contained in a box mounted above the water level in the tank. Each test consisted of one cycle. The fluid volume and flow rate data are summarized in Table 5.3. Photographs taken during the sequence are shown in Figure 5.3. Every 5 min during the 30 min test, the simulant position was incremented to move new simulant beneath the jet. The jet operating pressure was in the 1200 psig (8.27 MPag) range. During the run the jet dislodged $24 \mathrm{~kg}$ out of $34.1 \mathrm{~kg}$ of simulant in the container. The monitored test conditions are fluid volume and time which provide data to calculate the average flow rate.

Table 5.3. Run 9 flow rate data through the cutting jet

\begin{tabular}{|c|c|c|c|c|c|c|c|}
\hline \multirow[t]{2}{*}{ Run } & \multirow[t]{2}{*}{ Cycle } & \multirow{2}{*}{$\begin{array}{r}\text { Time } \\
\text { sec }\end{array}$} & \multicolumn{2}{|c|}{ Change in Height } & \multicolumn{2}{|c|}{ Fluid Volume } & Average Flow Rate \\
\hline & & & in. & cm & gal & $\mathbf{m}^{3}$ & gpm $\quad \mathbf{m}^{3} / \mathbf{s}$ \\
\hline 9 & 1 & 1804 & 16.25 & 41.3 & 81.9 & 0.3100 & 0.000172 \\
\hline
\end{tabular}

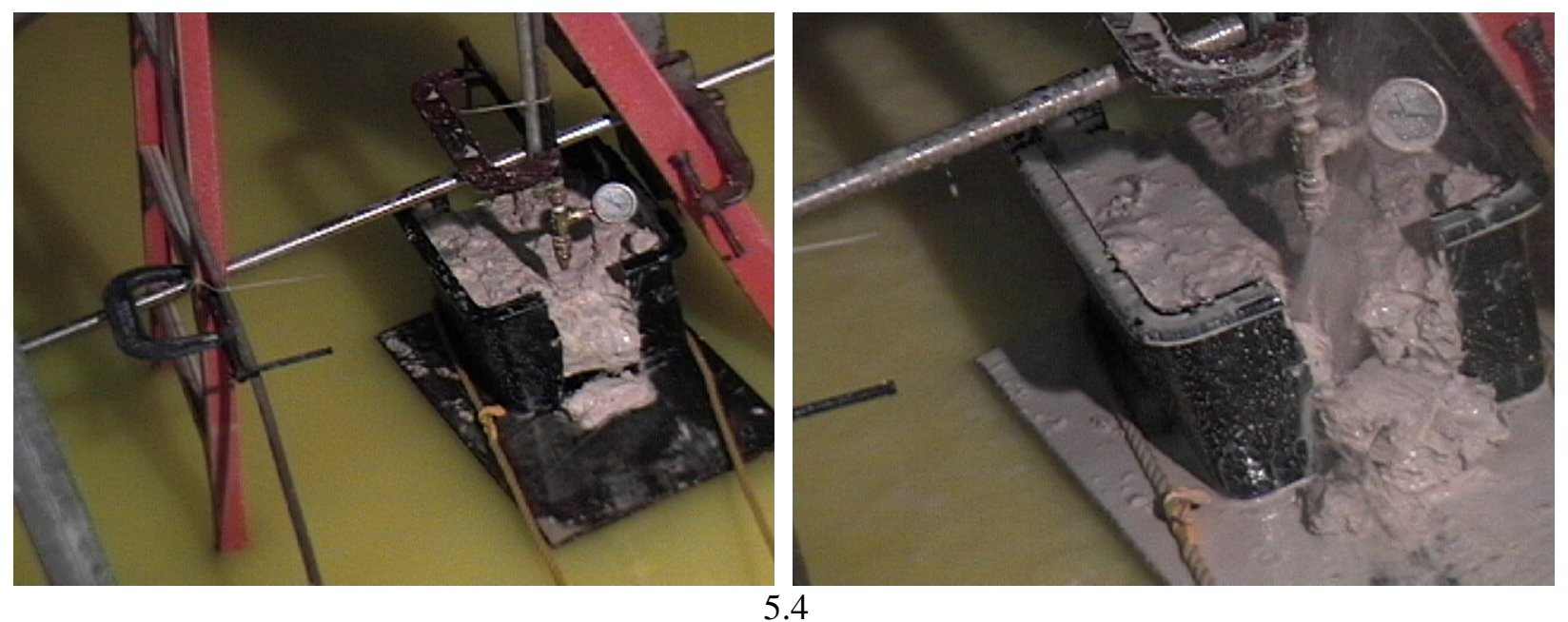



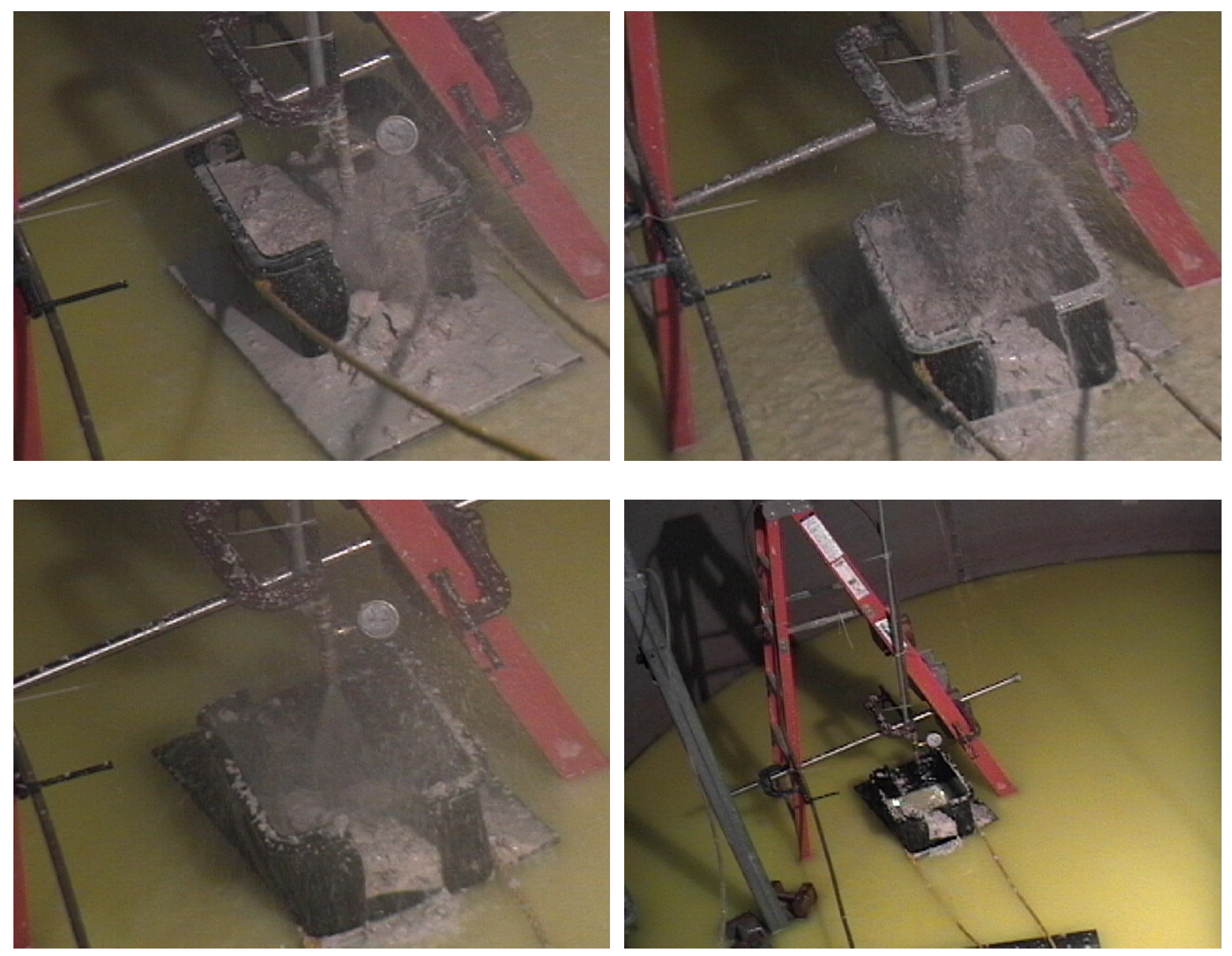

Cycle 9-1

Figure 5.3. Photos from Run 9 showing the cutting jet impacting the sludge simulant at high pressure

\subsection{Tank Transfer Aerosol and Solids Generation Tests}

Aerosol generation tests were conducted with water for Runs 2, 3, and 4 and slurry for Runs 11 and 12. The slurry was generated by adding simulant to the water in the mix tank. The mixer was operated to keep the solids in suspension. Descriptions and a series of pictures taken during each of the runs follows.

\subsubsection{Run 2: Water at Low Flow Rate}

These tests were conducted by pumping water with fluorescent dye through the $2 \mathrm{in}$. diameter nozzle. Each test consisted of four cycles. The operating time, fluid volume and calculated average flow rates are summarized in Table 5.4. Photographs taken during the sequence are shown in Figure 5.4. 
Table 5.4. Run 2 flow rate data through a discharge pipe at low flow rate

\begin{tabular}{|c|c|c|c|c|c|c|c|c|}
\hline \multirow[t]{2}{*}{ Run } & \multirow[t]{2}{*}{ Cycle } & \multirow{2}{*}{$\begin{array}{r}\text { Time } \\
\text { sec }\end{array}$} & \multicolumn{2}{|c|}{ Change in Height } & \multicolumn{2}{|c|}{ Fluid Volume } & \multicolumn{2}{|c|}{ Average Flow Rate } \\
\hline & & & in. & cm & gal & $\mathbf{m}^{3}$ & gpm & $\mathrm{m}^{3} / \mathrm{s}$ \\
\hline 2 & 1 & 374 & 37.5 & 95.3 & 189.0 & 0.7154 & 30.3 & 0.001913 \\
\hline & 2 & 312 & 37.5 & 95.3 & 189.0 & 0.7154 & 36.3 & 0.002293 \\
\hline & 3 & 401 & 37.5 & 95.3 & 189.0 & 0.7154 & 28.3 & 0.001784 \\
\hline & 4 & 257 & 37.5 & 95.3 & 189.0 & 0.7154 & 44.1 & 0.002784 \\
\hline & $\begin{array}{l}\text { Mean } \\
\text { Std. }\end{array}$ & 336 & 37.5 & 95.3 & 189.0 & 0.7154 & 34.8 & 0.002193 \\
\hline & Dev. & 64.5 & $\mathbf{0}$ & 0.0 & 0.0 & 0.0 & 7.1 & 0.000449 \\
\hline & & & & & $\begin{array}{r}\text { Total } \\
\text { gal }\end{array}$ & $\begin{array}{r}\text { luid Sp } \\
\mathbf{m}^{3}\end{array}$ & & \\
\hline
\end{tabular}
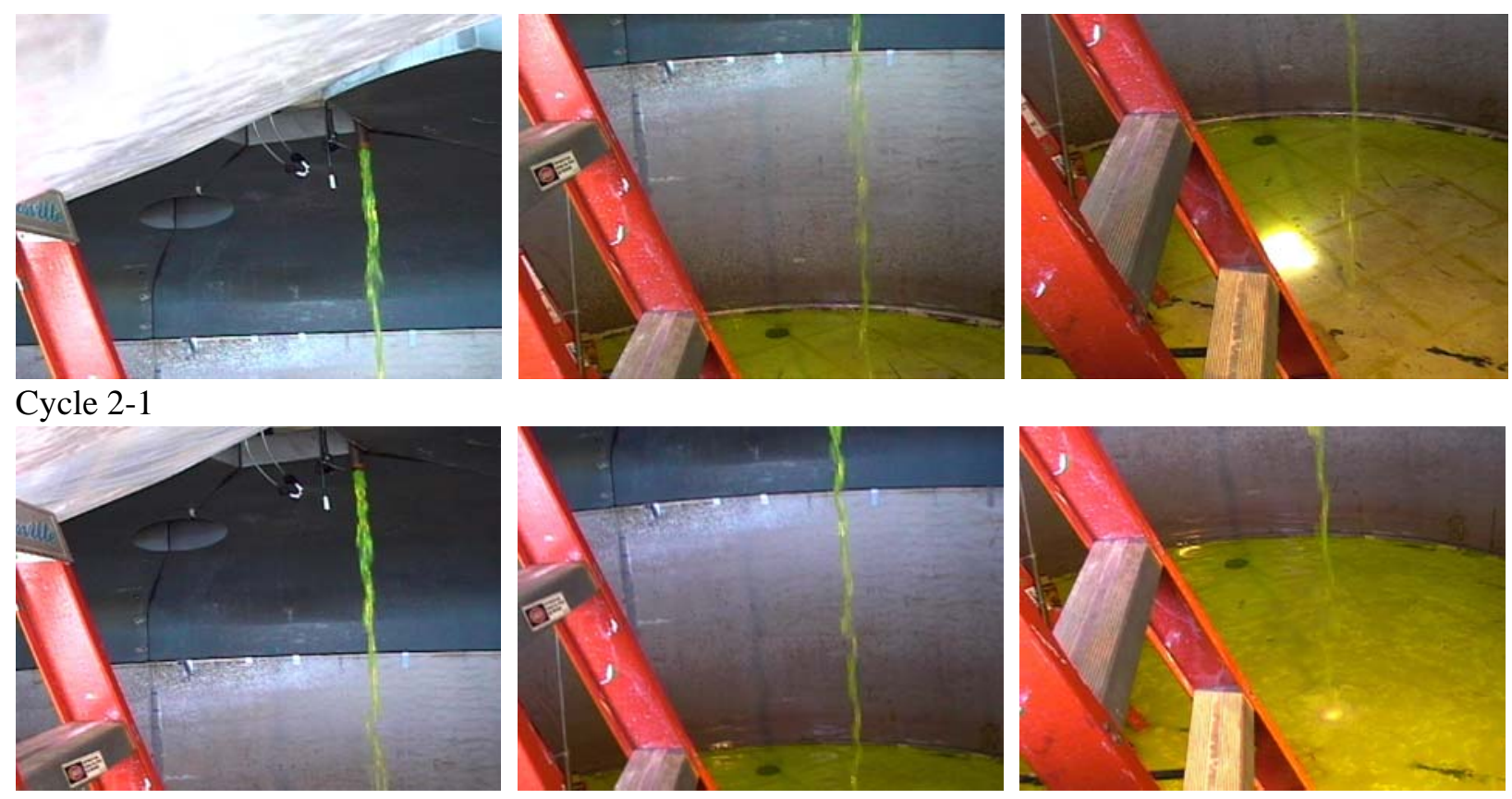

Cycle 2-2
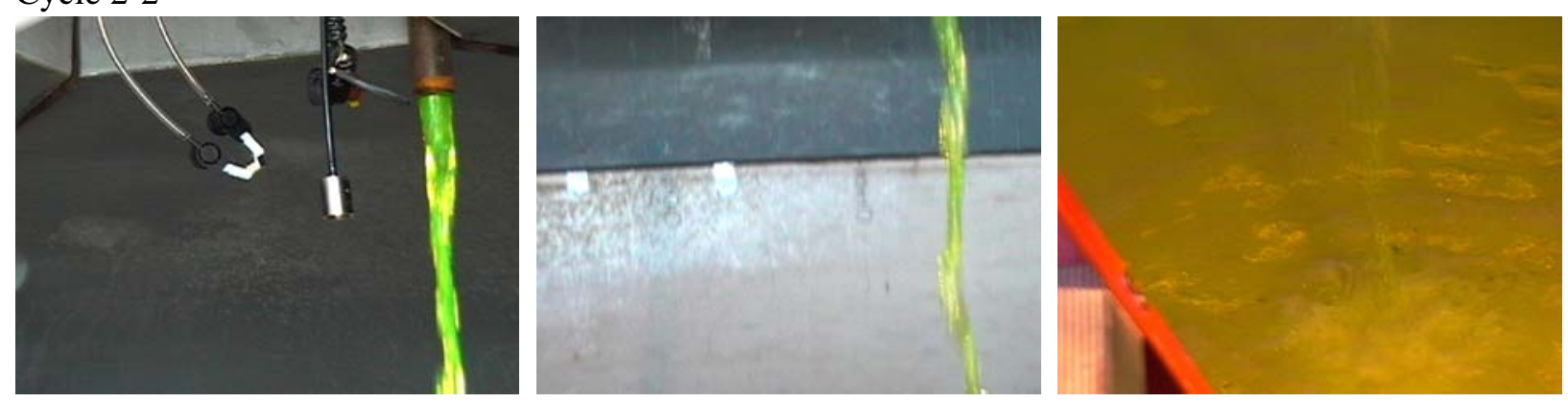

Cycle 2-3 

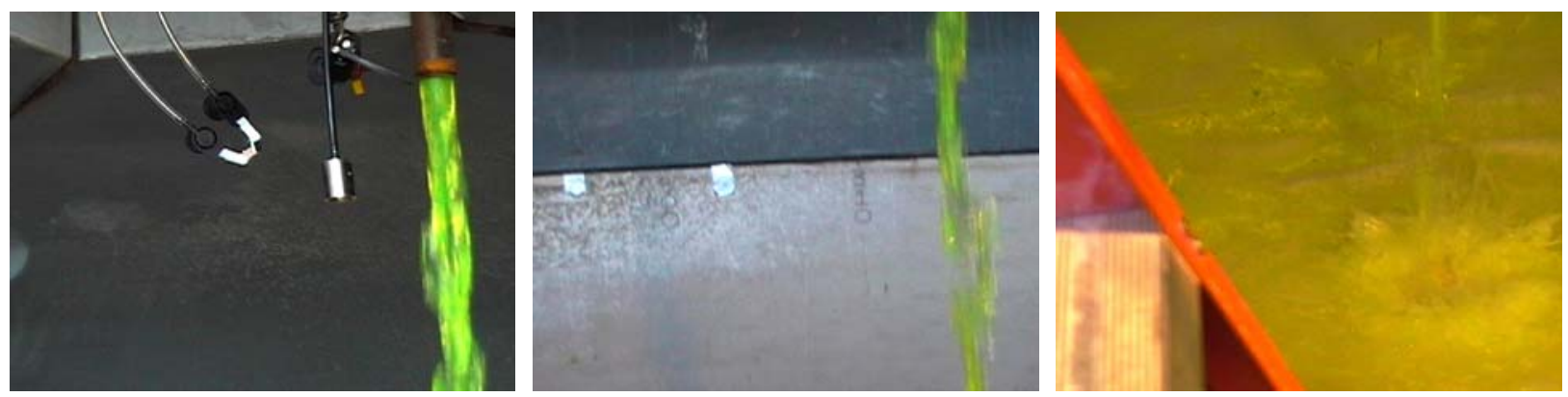

Cycle 2-4

Figure 5.4. Photos from Run 2 showing water transfer from a discharge pipe at low flow rate

\subsubsection{Run 3: Water at High Flow Rate}

These tests were conducted by pumping water through the 2 in. diameter nozzle. Each test consisted of four cycles. The operating time, fluid volume and calculated average flow rates are summarized in Table 5.5. Photographs taken during the sequence are shown in Figure 5.5.

Table 5.5. Run 3 flow rate data through a discharge pipe at high flow rate

\begin{tabular}{|c|c|c|c|c|c|c|c|c|}
\hline \multirow[t]{2}{*}{ Run } & \multirow[t]{2}{*}{ Cycle } & \multirow{2}{*}{$\begin{array}{r}\text { Time } \\
\text { sec }\end{array}$} & \multicolumn{2}{|c|}{ Change in Height } & \multicolumn{2}{|c|}{ Fluid Volume } & \multicolumn{2}{|c|}{ Average Flow Rate } \\
\hline & & & in. & $\mathbf{c m}$ & gal & $\mathbf{m}^{3}$ & gpm & $\mathrm{m}^{3} / \mathrm{s}$ \\
\hline \multirow[t]{7}{*}{3} & 1 & 110 & 38.5 & 97.8 & 194.0 & 0.7345 & 105.8 & 0.006677 \\
\hline & 2 & 109 & 38.5 & 97.8 & 194.0 & 0.7345 & 106.8 & 0.006738 \\
\hline & 3 & 111 & 37.5 & 95.3 & 189.0 & 0.7154 & 102.2 & 0.006445 \\
\hline & 4 & 110 & 37.5 & 95.3 & 189.0 & 0.7154 & 103.1 & 0.006504 \\
\hline & $\begin{array}{l}\text { Mean } \\
\text { Std. }\end{array}$ & 110 & 38.0 & 96.5 & 191.5 & 0.7249 & 104.5 & 0.006591 \\
\hline & Dev. & 0.82 & 0.6 & 1.5 & 2.9 & 0.0 & 2.2 & 0.000139 \\
\hline & & & & & $\begin{array}{r}\text { Total } \\
\text { gal } \\
766.0\end{array}$ & $\begin{array}{r}\text { luid Sp } \\
\mathbf{m}^{3} \\
2.900\end{array}$ & & \\
\hline
\end{tabular}
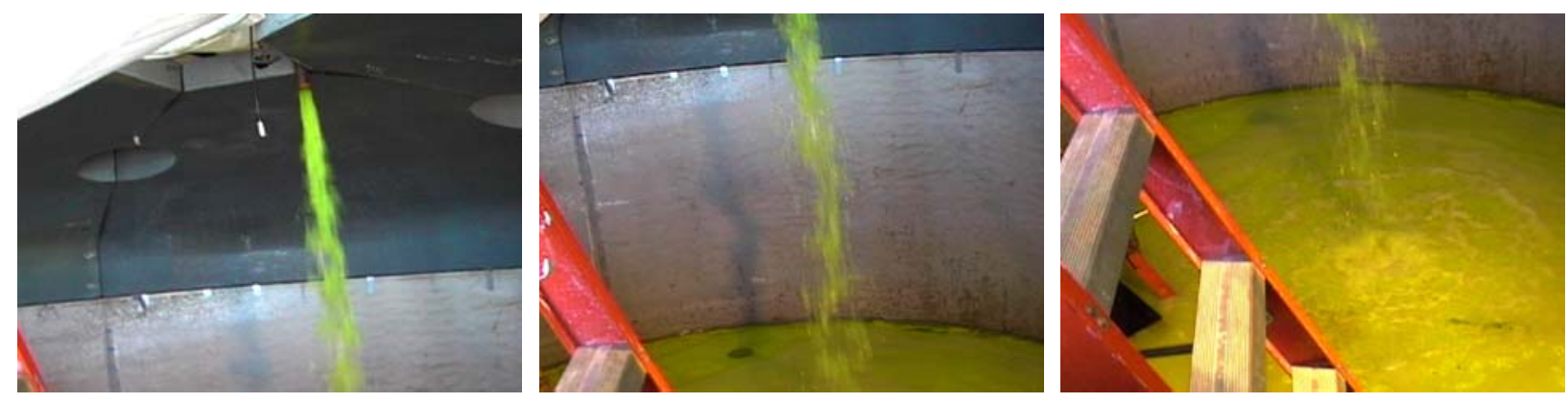

Cycle 3-2

Figure 5.5. Photos from Run 3 showing water transfer from a discharge pipe at high flow rate 


\subsubsection{Run 4: Water at Highest Flow Rate}

These tests were conducted by pumping water through the 2 in. diameter nozzle. Each test consisted of four cycles. The operating time, fluid volume and calculated average flow rates are summarized in Table 5.6. Photographs taken during the sequence are shown in Figure 5.6.

Table 5.6. Run 4 flow rate data through a discharge pipe at highest flow rate

\begin{tabular}{|c|c|c|c|c|c|c|c|c|}
\hline \multirow[t]{2}{*}{ Run } & \multirow[t]{2}{*}{ Cycle } & \multirow{2}{*}{$\begin{array}{r}\text { Time } \\
\text { sec }\end{array}$} & \multicolumn{2}{|c|}{ Change in Height } & \multicolumn{2}{|c|}{ Fluid Volume } & \multicolumn{2}{|c|}{ Average Flow Rate } \\
\hline & & & in. & $\mathbf{c m}$ & gal & $\mathbf{m}^{3}$ & gpm & $\mathrm{m}^{3} / \mathrm{s}$ \\
\hline \multirow[t]{7}{*}{4} & 1 & 64 & 37.5 & 95.3 & 189.0 & 0.7154 & 177.2 & 0.011178 \\
\hline & 2 & 64 & 37.5 & 95.3 & 189.0 & 0.7154 & 177.2 & 0.011178 \\
\hline & 3 & 61 & 37.5 & 95.3 & 189.0 & 0.7154 & 185.9 & 0.011728 \\
\hline & 4 & 65 & 37.5 & 95.3 & 189.0 & 0.7154 & 174.4 & 0.011006 \\
\hline & $\begin{array}{l}\text { Mean } \\
\text { Std. }\end{array}$ & 63.5 & 37.5 & 95.3 & 189.0 & 0.7154 & 178.7 & 0.011272 \\
\hline & Dev. & 1.73 & 0.0 & 0.0 & 0.0 & 0.0 & 5.0 & 0.000314 \\
\hline & & & & & \multicolumn{4}{|c|}{$\begin{array}{l}\text { Total Fluid Sprayed } \\
\text { gal } \mathbf{m}^{3}\end{array}$} \\
\hline
\end{tabular}
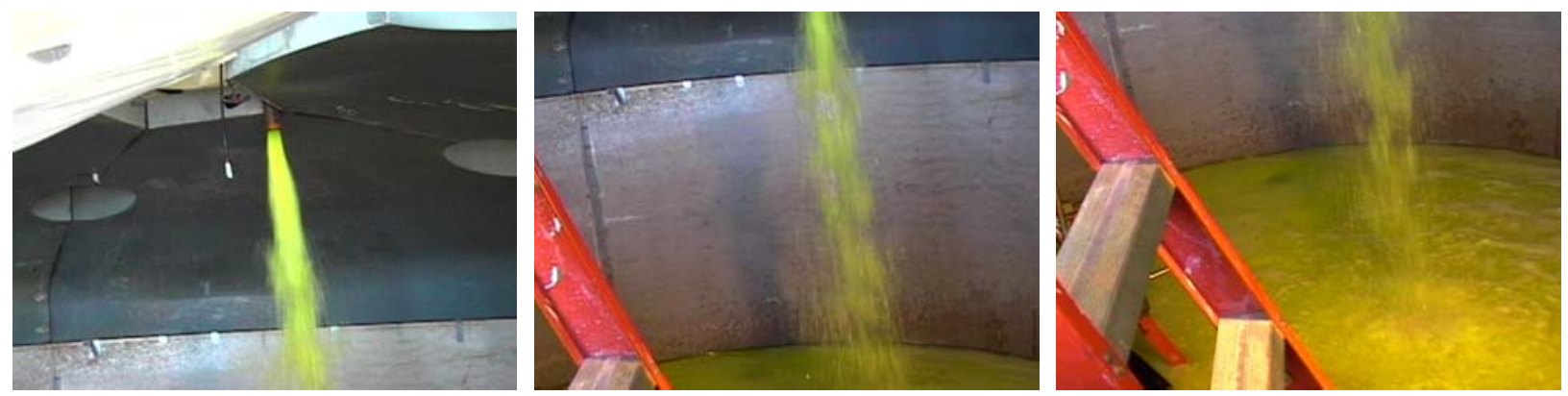

Cycle 4-1
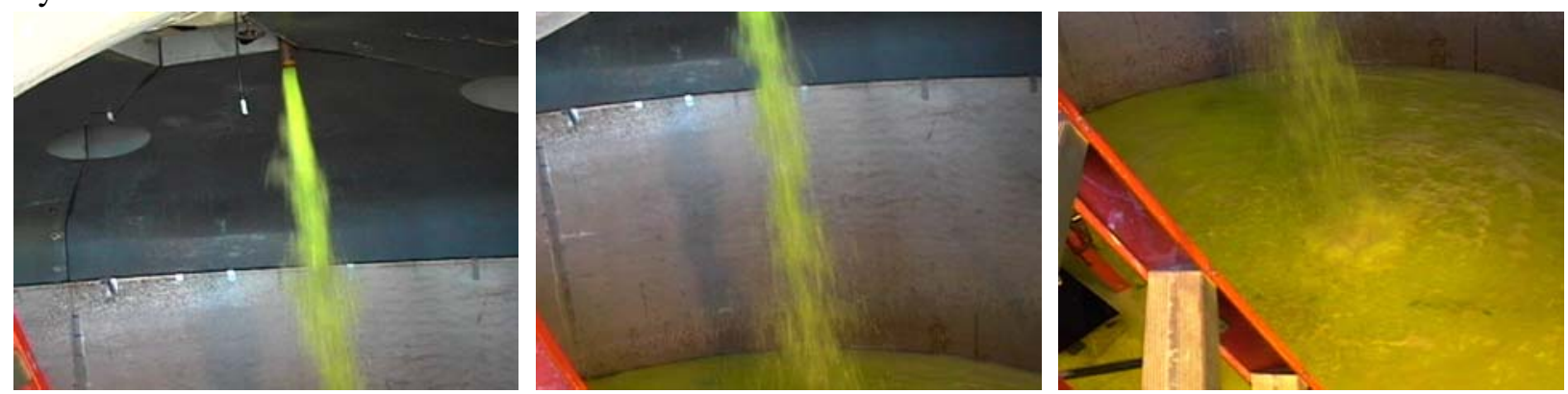

Cycle 4-2 


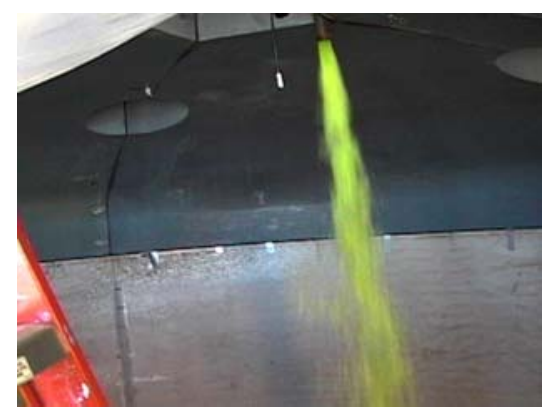

Cycle 4-3
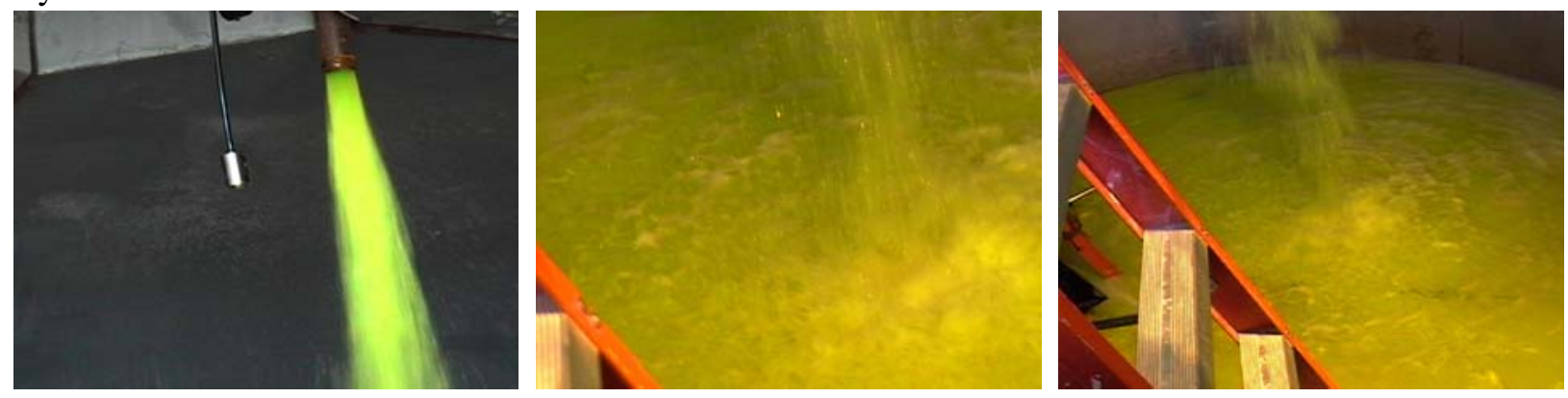

Cycle 4-4 Close up of jet

Figure 5.6. Photos from Run 4 showing water transfer from a discharge pipe at highest flow rate

\subsubsection{Run 11: Slurry Transfer at Low Flow Rate}

These tests were conducted by pumping slurry through the 2 in. diameter nozzle. Each test consisted of four cycles. The operating time, fluid volume and calculated average flow rates are summarized in Table 5.7. Photographs taken during the sequence are shown in Figure 5.7.

Table 5.7. Run 11 slurry flow rate data through discharge pipe at low flow rate

\begin{tabular}{|c|c|c|c|c|c|c|c|c|}
\hline \multirow[t]{2}{*}{ Run } & \multirow[t]{2}{*}{ Cycle } & \multirow{2}{*}{$\begin{array}{r}\text { Time } \\
\text { sec }\end{array}$} & \multicolumn{2}{|c|}{ Change in Height } & \multicolumn{2}{|c|}{ Fluid Volume } & \multicolumn{2}{|c|}{ Average Flow Rate } \\
\hline & & & in. & cm & gal & $\mathbf{m}^{3}$ & gpm & $\mathbf{m}^{3} / \mathbf{s}$ \\
\hline \multirow[t]{7}{*}{11} & 1 & 399 & 37.5 & 95.3 & 189.0 & 0.7154 & 28.4 & 0.001793 \\
\hline & 2 & 449 & 37.5 & 95.3 & 189.0 & 0.7154 & 25.3 & 0.001593 \\
\hline & 3 & 211 & 37.5 & 95.3 & 189.0 & 0.7154 & 53.7 & 0.003390 \\
\hline & 4 & 174 & 37.5 & 95.3 & 189.0 & 0.7154 & 65.2 & 0.004111 \\
\hline & $\begin{array}{l}\text { Mean } \\
\text { Std. }\end{array}$ & 308.3 & 37.5 & 95.3 & 189.0 & 0.7154 & 43.1 & 0.002722 \\
\hline & Dev. & 136 & $\mathbf{0 . 0}$ & $\mathbf{0 . 0}$ & 0.0 & 0.0 & 19.4 & 0.001227 \\
\hline & & & & & $\begin{array}{r}\text { Total } \\
\text { gal } \\
755.9\end{array}$ & $\begin{array}{c}\text { luid Spr } \\
\mathbf{m}^{3} \\
2.862\end{array}$ & & \\
\hline
\end{tabular}



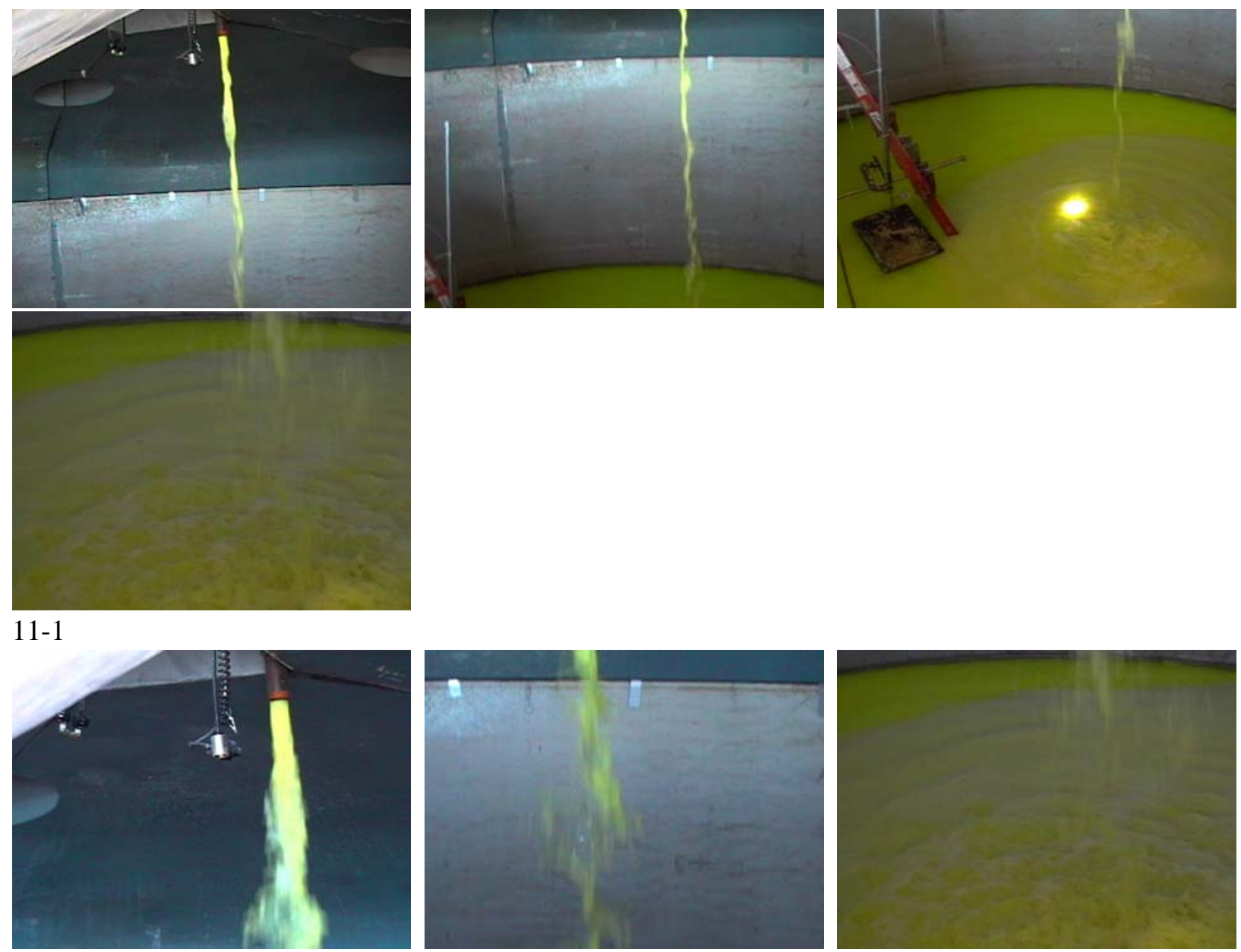

Close up of jet during cycle 11-4

Figure 5.7. Photos from Run 11 showing slurry transfer through a discharge pipe at low flow rate

\subsubsection{Run 12: Slurry Transfer at High Flow Rate}

These tests were conducted by pumping slurry through the discharge pipe. Each test consisted of four cycles. The fluid volume and flow rates are summarized in Table 5.8. Photographs taken during the sequence are shown in Figure 5.8. 
Table 5.8. Run 12 slurry flow rate data through a discharge pipe at high flow rate

\begin{tabular}{|c|c|c|c|c|c|c|c|c|}
\hline \multirow[t]{2}{*}{ Run } & \multirow[t]{2}{*}{ Cycle } & \multirow{2}{*}{$\begin{array}{r}\text { Time } \\
\text { sec }\end{array}$} & \multicolumn{2}{|c|}{ Change in Height } & \multicolumn{2}{|c|}{ Fluid Volume } & \multicolumn{2}{|c|}{ Average Flow Rate } \\
\hline & & & in. & $\mathbf{c m}$ & ga & $\mathbf{m}^{3}$ & gpm & $\mathrm{m}^{3} / \mathrm{s}$ \\
\hline 12 & 1 & 93 & 37.5 & 95.3 & 189.0 & 0.7154 & 121.9 & 0.007692 \\
\hline & 2 & 92 & 37.5 & 95.3 & 189.0 & 0.7154 & 123.3 & 0.007776 \\
\hline & 3 & 90 & 37.5 & 95.3 & 189.0 & 0.7154 & 126.0 & 0.007949 \\
\hline & 4 & 89 & 37.5 & 95.3 & 189.0 & 0.7154 & 127.4 & 0.008038 \\
\hline & $\begin{array}{l}\text { Mean } \\
\text { Std. }\end{array}$ & 91 & 37.5 & 95.3 & 189.0 & 0.7154 & 124.6 & 0.007864 \\
\hline & Dev. & 1.8 & 0.0 & 0.0 & 0.0 & 0.0 & 2.5 & 0.000158 \\
\hline & & & & & $\begin{array}{r}\text { Tota } \\
\text { ga } \\
755.9\end{array}$ & $\begin{array}{r}\text { luid Sp } \\
\mathbf{m}^{3} \\
2862\end{array}$ & & \\
\hline
\end{tabular}
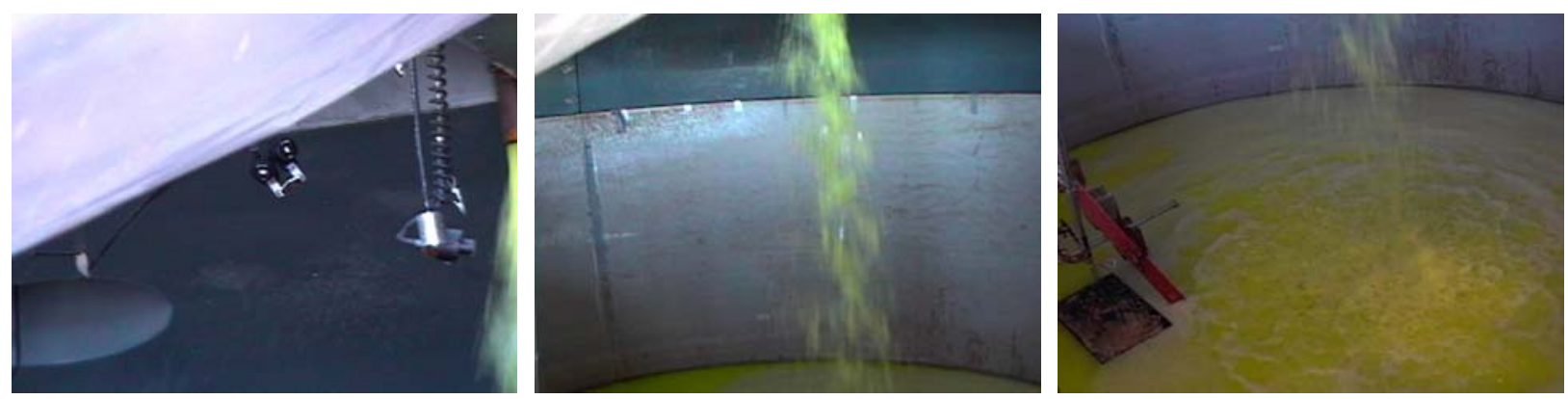

Cycle 12-1

Figure 5.8. Photos from Run 12 showing slurry transfer through a discharge pipe at high flow rate

\subsection{Transfer Jet Aerosol Generation Tests}

\subsubsection{Run 5: Water at Low Flow Rate}

These tests were conducted by pumping water with fluorescent dye through the 9/16 in. $(1.43 \mathrm{~cm})$ diameter transfer jet. Each test consisted of four cycles. The operating time, fluid volume and calculate average flow rates are summarized in Table 5.9. Photographs taken during the sequence are shown in Figure 5.9. 
Table 5.9. Run 5 flow rate data through a transfer jet at low flow rate

\begin{tabular}{|c|c|c|c|c|c|c|c|c|}
\hline \multirow[t]{2}{*}{ Run } & \multirow[t]{2}{*}{ Cycle } & \multirow{2}{*}{$\begin{array}{r}\text { Time } \\
\text { sec }\end{array}$} & \multicolumn{2}{|c|}{ Change in Height } & \multicolumn{2}{|c|}{ Fluid Volume } & \multicolumn{2}{|c|}{ Average Flow Rate } \\
\hline & & & in. & $\mathbf{c m}$ & gal & $\mathbf{m}^{3}$ & gpm & $\mathbf{m}^{3} / \mathbf{s}$ \\
\hline \multirow[t]{7}{*}{5} & 1 & 414 & 37.5 & 95.3 & 189.0 & 0.7154 & 27.4 & 0.001728 \\
\hline & 2 & 311 & 37.5 & 95.3 & 189.0 & 0.7154 & 36.5 & 0.002300 \\
\hline & 3 & 300 & 37.5 & 95.3 & 189.0 & 0.7154 & 37.8 & 0.002385 \\
\hline & 4 & 417 & 37.5 & 95.3 & 189.0 & 0.7154 & 27.2 & 0.001716 \\
\hline & $\begin{array}{l}\text { Mean } \\
\text { Std. }\end{array}$ & 360.5 & 37.5 & 95.3 & 189.0 & 0.7154 & 32.2 & 0.002032 \\
\hline & Dev. & 63.7 & 0.0 & 0.0 & 0.0 & 0.0 & 5.7 & 0.000360 \\
\hline & & & & & $\begin{array}{r}\text { Total } \\
\text { gal }\end{array}$ & $\begin{array}{r}\text { luid Sp1 } \\
\mathbf{m}^{3}\end{array}$ & & \\
\hline
\end{tabular}
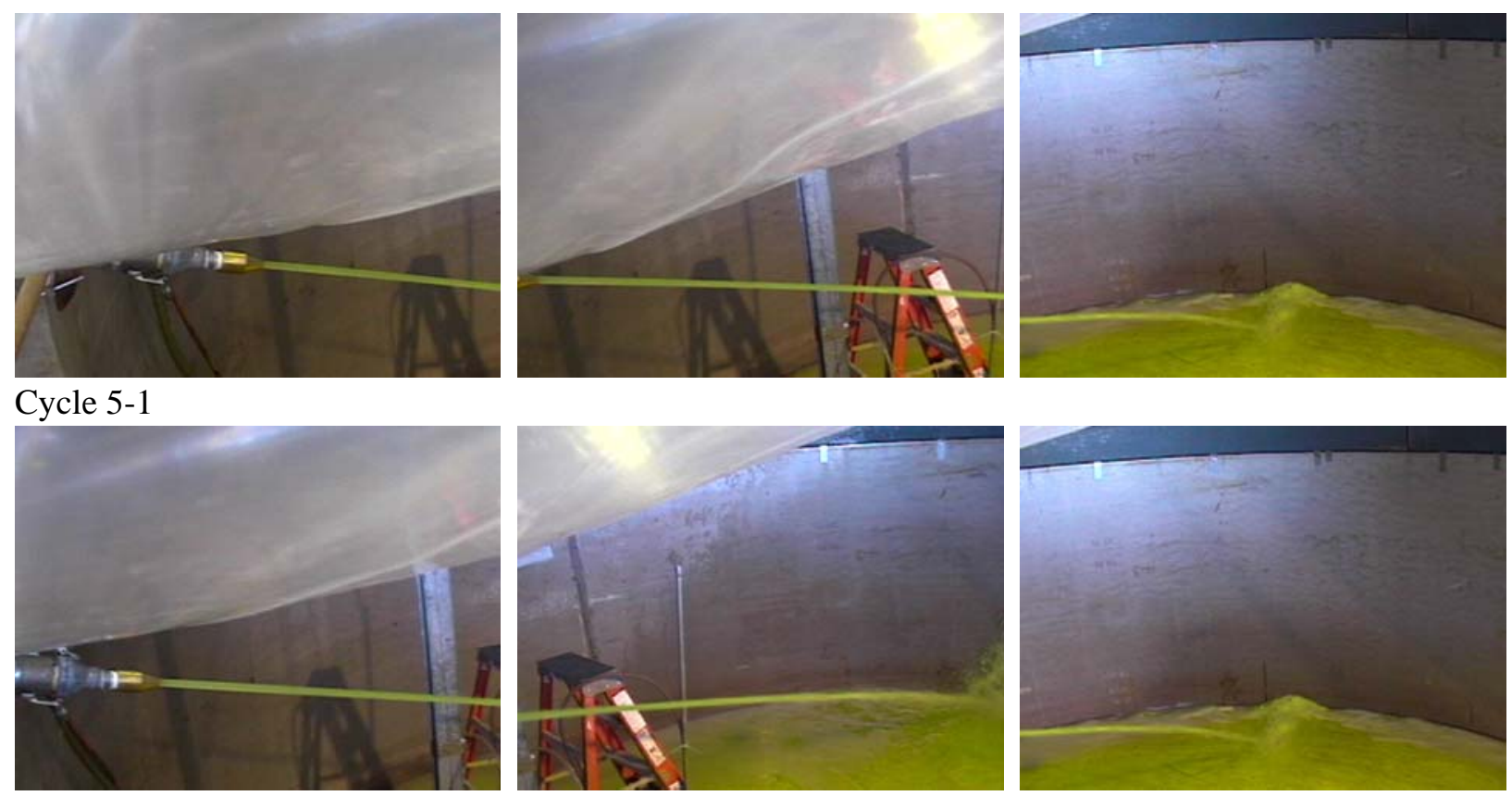

Cycle 5-2
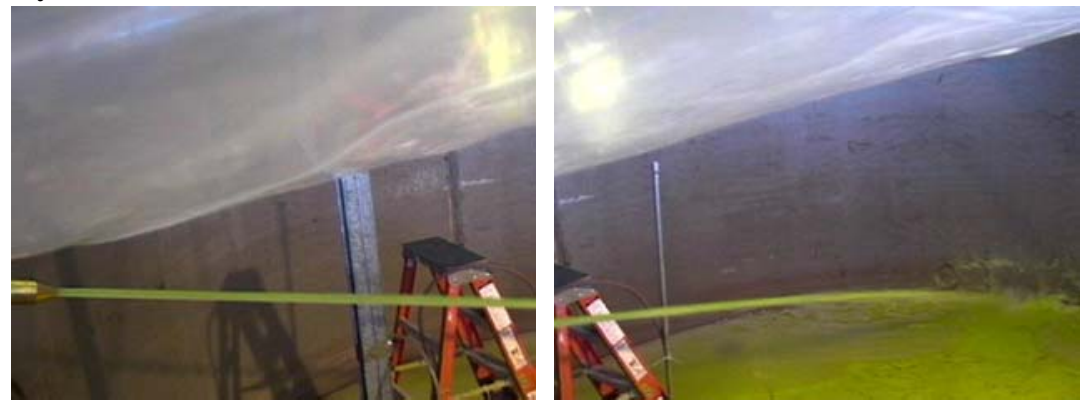

Cycle 5-3 

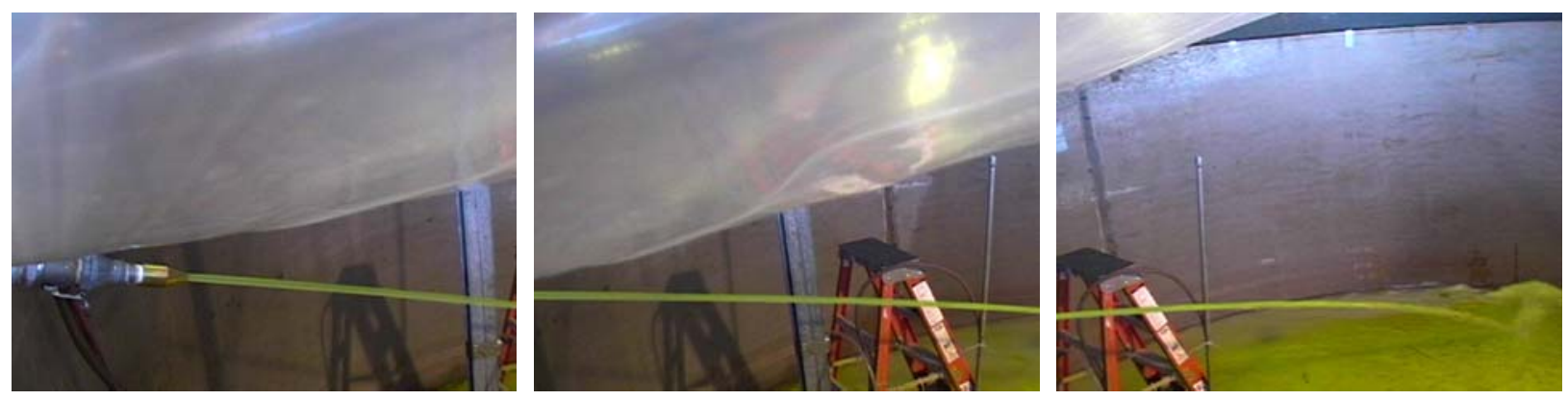

Cycle 5-4

Figure 5.9. Photos from Run 5 showing water transfer jet test sequence at low flow rate

\subsubsection{Run 6: Water at High Flow Rate}

These tests were conducted by pumping water with fluorescent dye through the $9 / 16$ in. $(1.43 \mathrm{~cm})$ diameter transfer jet. Each test consisted of four cycles. The operating time, fluid volume and calculated average flow rates are summarized in Table 5.10. Photographs taken during the sequence are shown in Figure 5.10.

Table 5.10. Run 6 flow rate data through a transfer jet at high flow rate

\begin{tabular}{|c|c|c|c|c|c|c|c|c|}
\hline \multirow[t]{2}{*}{ Run } & \multirow[t]{2}{*}{ Cycle } & \multirow{2}{*}{$\begin{array}{r}\text { Time } \\
\text { sec }\end{array}$} & \multicolumn{2}{|c|}{ Change in Height } & \multicolumn{2}{|c|}{ Fluid Volume } & \multicolumn{2}{|c|}{ Average Flow Rate } \\
\hline & & & in. & $\mathbf{c m}$ & gal & $\mathbf{m}^{3}$ & gpm & $\mathbf{m}^{3} / \mathbf{s}$ \\
\hline \multirow[t]{7}{*}{6} & 1 & 201 & 37.5 & 95.3 & 189.0 & 0.7154 & 56.4 & 0.003559 \\
\hline & 2 & 199 & 37.5 & 95.3 & 189.0 & 0.7154 & 57.0 & 0.003595 \\
\hline & 3 & 200 & 37.5 & 95.3 & 189.0 & 0.7154 & 56.7 & 0.003577 \\
\hline & 4 & 199 & 37.5 & 95.3 & 189.0 & 0.7154 & 57.0 & 0.003595 \\
\hline & $\begin{array}{l}\text { Mean } \\
\text { Std. }\end{array}$ & 199.8 & 37.5 & 95.3 & 189.0 & 0.7154 & 56.8 & 0.003581 \\
\hline & Dev. & 0.96 & 0.0 & 0.0 & 0.0 & 0.0 & 0.3 & 0.000017 \\
\hline & & & & & $\begin{array}{r}\text { Total } \\
\text { gal }\end{array}$ & $\begin{array}{l}\text { luid Spr } \\
\mathbf{m}^{3}\end{array}$ & & \\
\hline
\end{tabular}
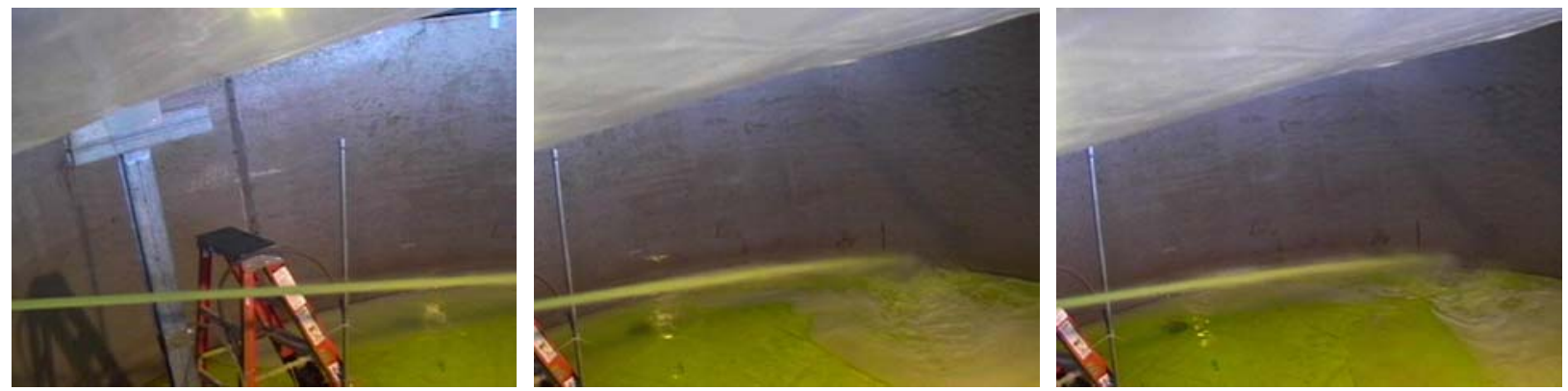

Cycle 6-1 

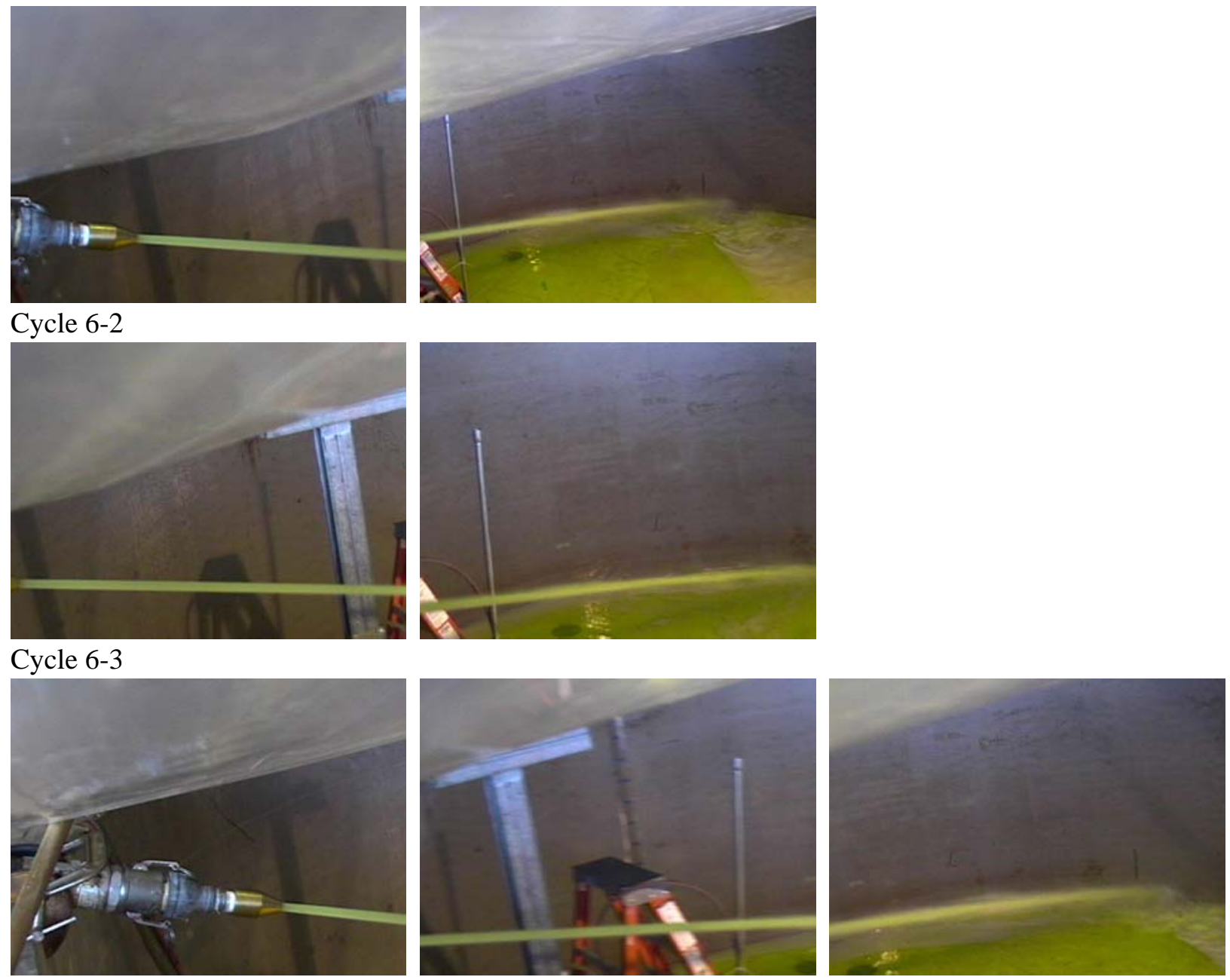

Cycle 6-4

Figure 5.10. Photos from Run 6 showing water transfer jet test sequence at high flow rate

\subsubsection{Run 10: Slurry at Low Flow Rate}

These tests were conducted by pumping slurry with fluorescent dye through the $9 / 16 \mathrm{in}$. $(1.43 \mathrm{~cm})$ diameter transfer jet. Each test consisted of four cycles. The operating time, fluid volume and calculated average flow rates are summarized in Table 5.11. This test was stopped after the nozzle became plugged during cycle 4. Photographs taken during the sequence are shown in Figure 5.11. 
Table 5.11. Run 10 slurry flow rate data through a transfer jet at low flow rate

\begin{tabular}{|c|c|c|c|c|c|c|c|c|}
\hline \multirow[t]{2}{*}{ Run } & \multirow[t]{2}{*}{ Cycle } & \multirow{2}{*}{$\begin{array}{r}\text { Time } \\
\text { sec }\end{array}$} & \multicolumn{2}{|c|}{ Change in Height } & \multicolumn{2}{|c|}{ Fluid Volume } & \multicolumn{2}{|c|}{ Average Flow Rate } \\
\hline & & & in. & $\mathbf{c m}$ & gal & $\mathbf{m}^{3}$ & gpm & $\mathbf{m}^{3} / \mathbf{s}$ \\
\hline \multirow[t]{7}{*}{10} & 1 & 525 & 37.5 & 95.3 & 189.0 & 0.7154 & 21.6 & 0.001363 \\
\hline & 2 & 456 & 37.5 & 95.3 & 189.0 & 0.7154 & 24.9 & 0.001569 \\
\hline & 3 & 440 & 37.5 & 95.3 & 189.0 & 0.7154 & 25.8 & 0.001626 \\
\hline & 4 & 537 & 37.5 & 95.3 & 189.0 & 0.7154 & 21.1 & 0.001332 \\
\hline & $\begin{array}{l}\text { Mean } \\
\text { Std. }\end{array}$ & 489.5 & 37.5 & 95.3 & 189.0 & 0.7154 & 23.3 & 0.001472 \\
\hline & Dev. & 48.6 & 0.0 & 0.0 & 0.0 & 0.0 & 2.3 & 0.000147 \\
\hline & & & & & $\begin{array}{r}\text { Total } \\
\text { gal }\end{array}$ & $\begin{array}{r}\text { luid } \mathbf{S p} \\
\mathbf{m}^{3}\end{array}$ & & \\
\hline
\end{tabular}
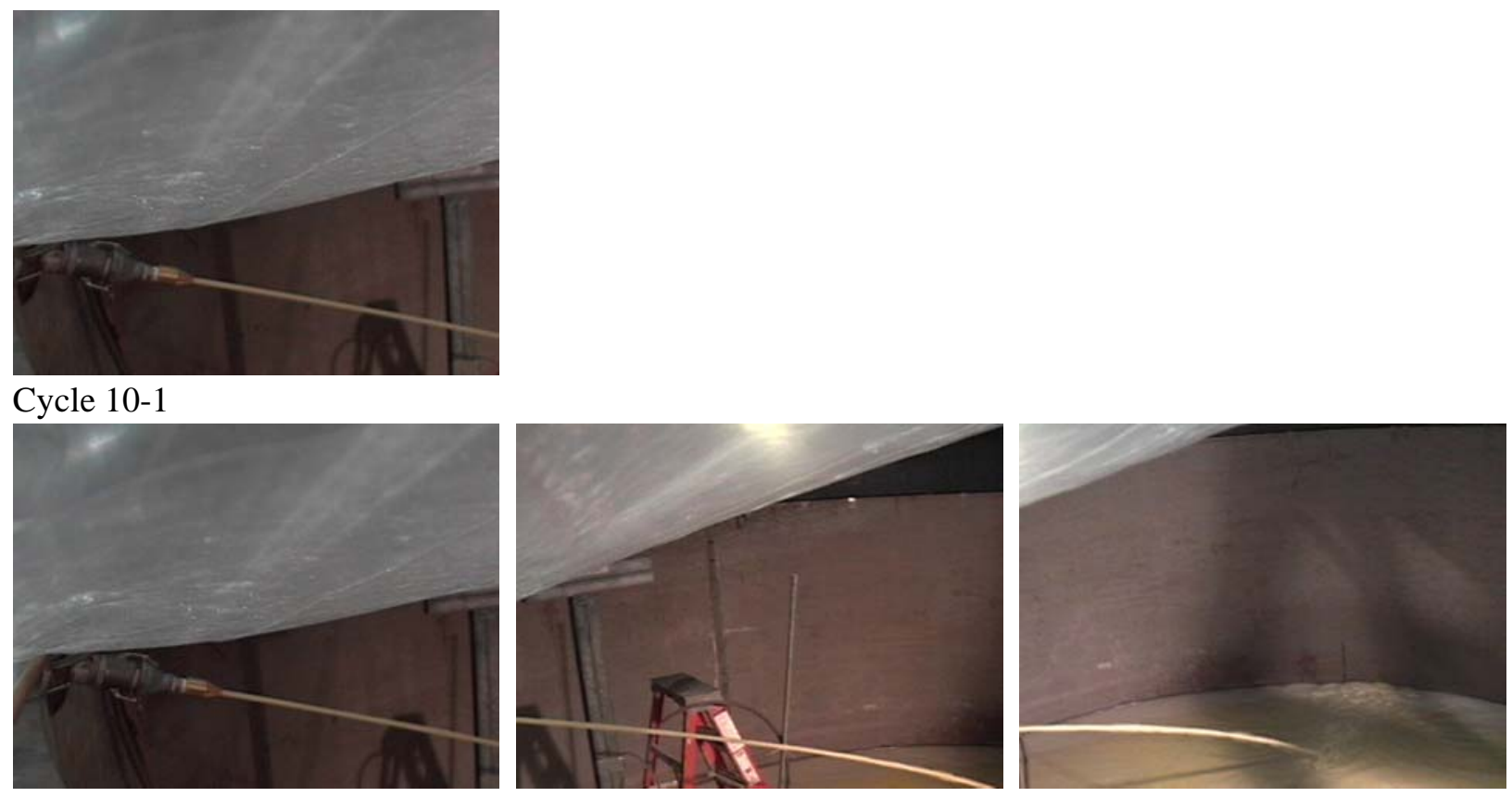

Cycle 10-2
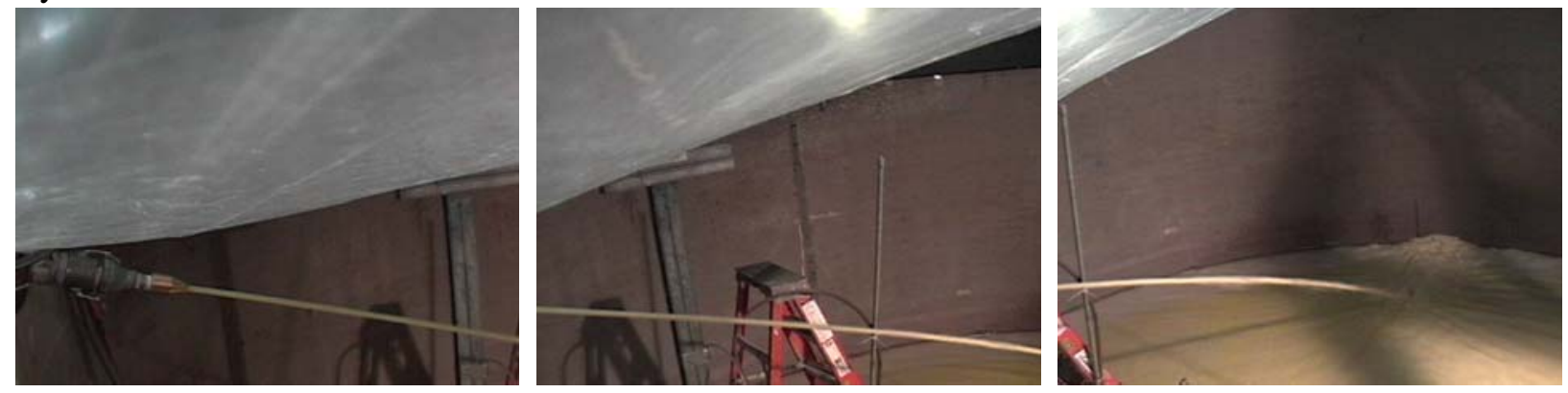

Cycle 10-3 

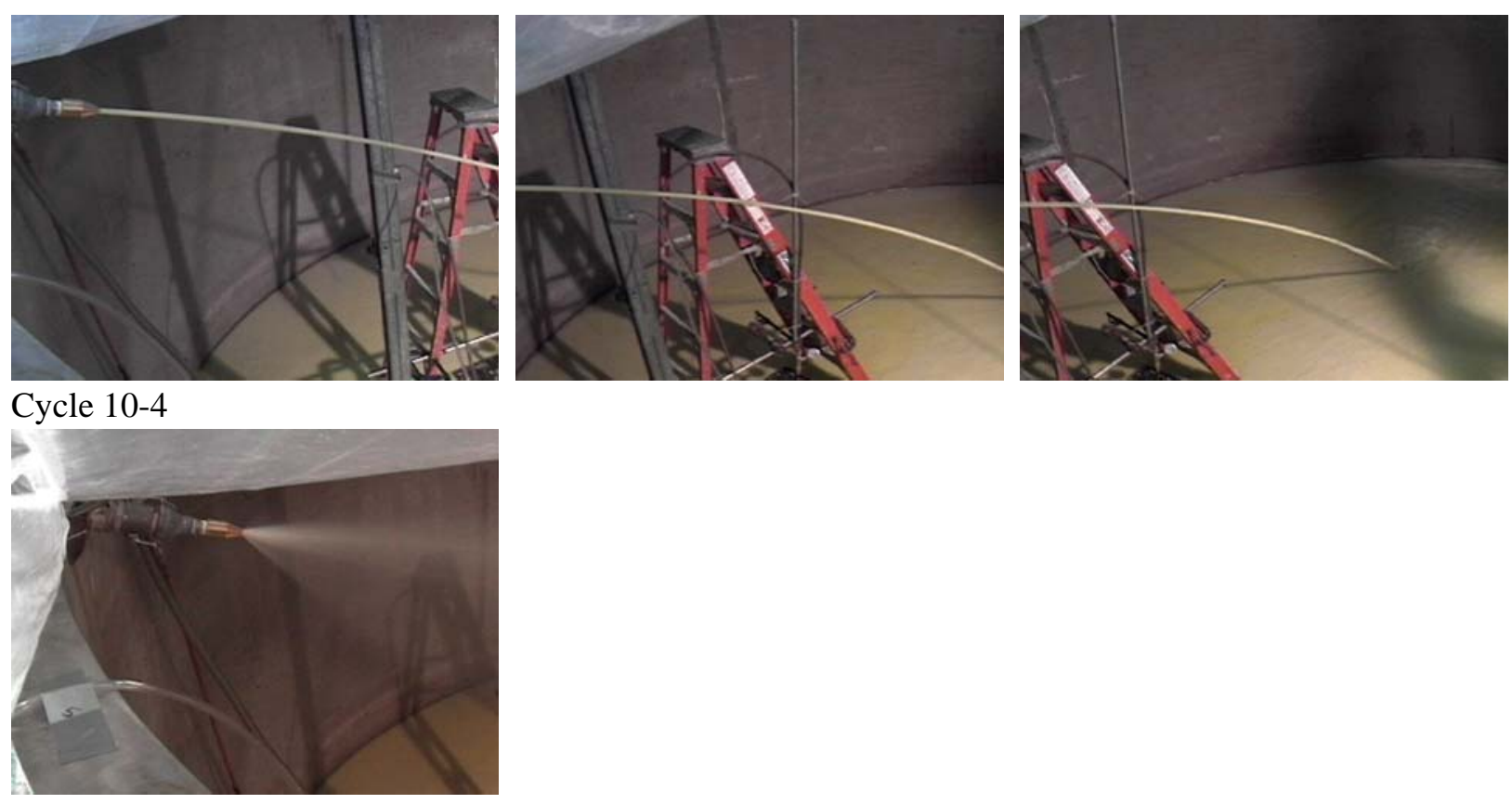

Plugged nozzle at end of cycle 4

Figure 5.11. Photos from Run 10 showing slurry transfer jet test sequence at low flow rate 


\subsection{Results}

This section describes the characteristics of the aerosol created by the processes simulated in the $1 / 4$-scale tank. The results presented and discussed include the real-time aerosol concentration, particle size distribution, and the release fractions.

\subsection{Aerosol Concentration Results}

With each test run, the optical particle counter (OPC) data showed a sharp increase in aerosol concentration from the background level and a gradual decline in aerosol concentration at the conclusion of the process simulation. The particle count data were converted to the volume (or mass) of aerosol in each particle size interval. Plots of these converted OPC data for all of the runs are included in Appendix B.

Run 3-4 OPC Particle Volume 9/16 Nozzle w/Liquid

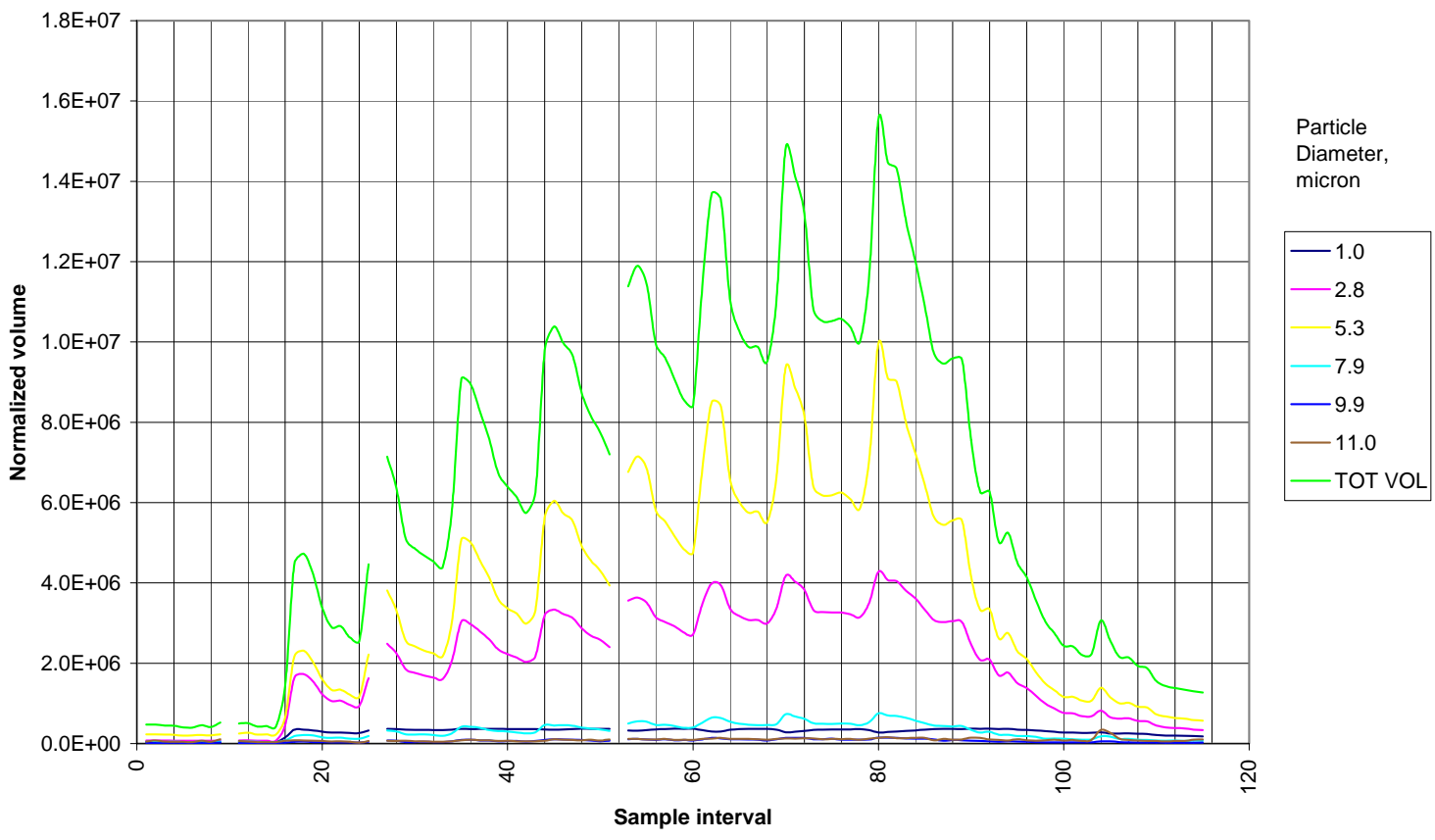

Figure 6.1. Example plot of real-time aerosol concentration data

Figure 6.1 shows the OPC particle concentration data for Runs 3 and 4 combined. In these runs, the 2-in. nozzle was used to transfer liquid into the tank from the top and the liquid impacted floor or liquid at the bottom of the tank. The operation was repeated eight times, and the airborne concentration peaked each time. The peaks and the baselines in between operations gradually increased. These data show that when a process is repeated rapidly enough the concentration of airborne material continues to ratchet upward, and the concentration does not decrease back to background during the cycles, either because the tank was not ventilated or because sufficient time had not elapsed in between operations. 
The total volume concentration peaked at sample interval 80 during the last repetition of the operation. The concentration had not returned to background in this unventilated tank even after 35 sample intervals (about 36 minutes). In Table 6.1, the number of sample intervals (each about 61 seconds) that elapsed from the peak of each runs' final operation to the return to background levels are tabulated. The shortest concentration decay to background observed was 51 samples (about 52 minutes). The table also lists the ratio of peak material volume concentration to the background level. These peak/background ratios were inconsistent; no trends were observed.

Table 6.1. Sampling cycles for OPC data to return to background and maximum/background concentration ratios

\begin{tabular}{|c|l|c|c|}
\hline Run & \multicolumn{1}{|c|}{ Process } & Max/Background & $\begin{array}{c}\text { Number of Samples to } \\
\text { Return to Background }\end{array}$ \\
\hline & Pipe Discharge & & $>64$ \\
\hline 2 & Liquid discharge $35 \mathrm{gpm}\left(0.0022 \mathrm{~m}^{3} / \mathrm{s}\right)$ & 11.5 & $>35$ \\
\hline $3-4$ & $\begin{array}{l}\text { Liquid discharge } 105 \mathrm{and} 179 \mathrm{gpm} \\
\left(0.00662 \text { and } 0.0 .0113 \mathrm{~m}^{3} / \mathrm{s}\right)\end{array}$ & 34 & $>28$ \\
\hline 11 & Slurry discharge $43 \mathrm{gpm}\left(0.00271 \mathrm{~m}^{3} / \mathrm{s}\right)$ & 40 & 68 \\
\hline 12 & Slurry discharge $125 \mathrm{gpm}\left(0.00789 \mathrm{~m}^{3} / \mathrm{s}\right)$ & 4.6 & $>12$ \\
\hline & Transfer Jet & & 51 \\
\hline 5 & Liquid discharge $32 \mathrm{gpm}\left(0.00202 \mathrm{~m}^{3} / \mathrm{s}\right)$ & 14 & 99 \\
\hline 6 & Liquid discharge $57 \mathrm{gpm}\left(0.00360 \mathrm{~m}^{3} / \mathrm{s}\right)$ & 2.5 & $>78$ \\
\hline 10 & Slurry discharge 23 gpm $\left(0.00145 \mathrm{~m}^{3} / \mathrm{s}\right)$ & 8.6 & 62 \\
\hline & Cutting Jet & & \\
\hline 7 & Jet on steel at low pressure & 4.3 & \\
\hline 8 & Jet on simulant at low pressure & 97 & \\
\hline 9 & Jet on simulant at high pressure & 10 & \\
\hline
\end{tabular}

\subsection{Particle Size Results}

The particle count data from the OPC was converted to a volume (equivalent to mass for homogenous particles) within each size bracket. As shown in Figure 6.2, the data were reasonably well represented by a unimodal (single peak) distribution; so they were fitted to log-normal distributions. In most cases, the secondary fine particle mode had only a minor contribution to the particle volume distribution. The distribution parameters are the geometric mean diameter ${ }^{\mathrm{a})}$ (GMD) and the geometric standard deviation ${ }^{\mathrm{b})}$ (GSD). The results are tabulated in Table 6.2 for each run and for the time intervals that represented the background and peak concentrations during the operation. Even thou,gh data in Table 6.1 showed that the aerosol concentration was markedly elevated during the operations most of the time, the GMD

\footnotetext{
a) Half of the total aerosol volume is associated with particles larger than the GMD, and the other half with smaller particles. The units are micrometers $(\mu \mathrm{m})$.

b) The GSD represents the spread of the data. A GSD of one means that all particles are of the same size.
} 
remained about the same for the 2-in. and 9/16-in. $(1.43 \mathrm{~cm})$ nozzles. When the high pressure spray was used, the GMD decreased.

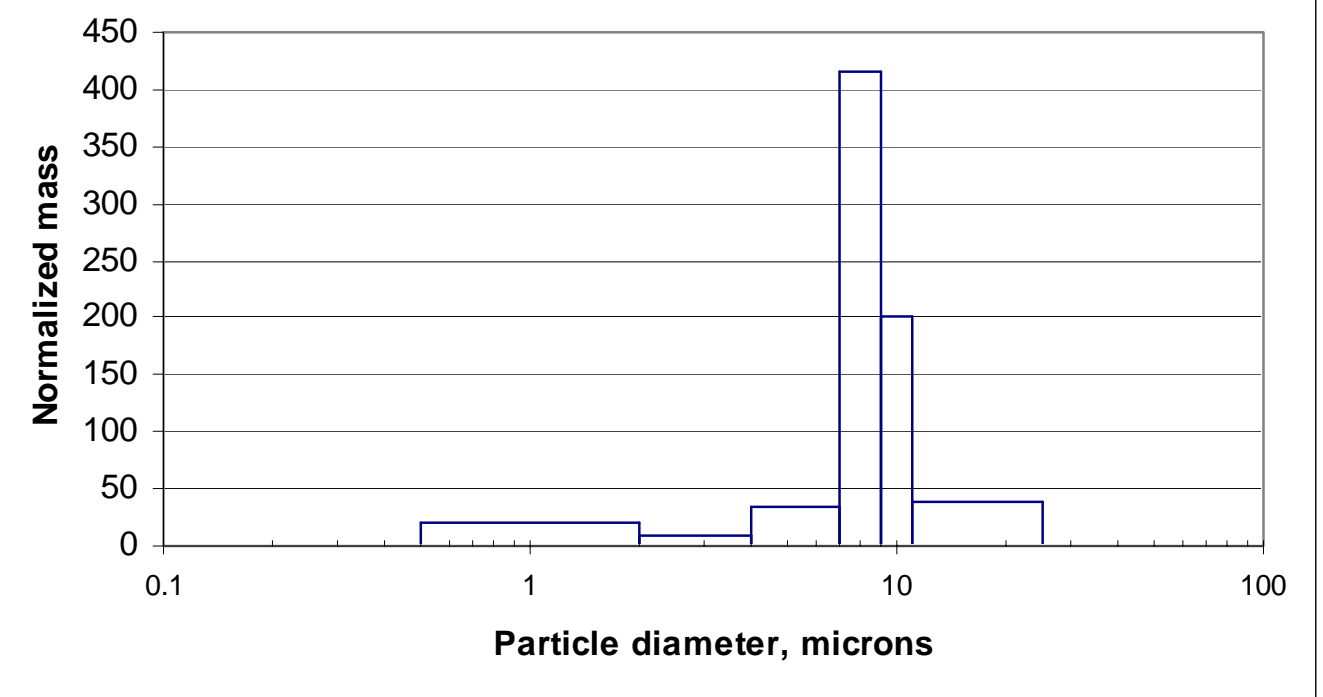

Figure 6.2. Run 2 particle size plot during the background measurement ${ }^{\mathrm{a})}$

Table 6.2. Particle size data from the OPC

\begin{tabular}{|c|c|c|c|c|c|}
\hline \multirow{2}{*}{ Run } & \multirow{2}{*}{ Process } & \multicolumn{2}{|c|}{ Background } & \multicolumn{2}{|c|}{ Peak } \\
\hline & & GMD $\mu \mathrm{m}$ & GSD $\mu \mathrm{m}$ & GMD $\mu \mathrm{m}$ & GSD $\mu \mathrm{m}$ \\
\hline \multirow[t]{2}{*}{1} & Background & 6.0 & 1.7 & N.A. & N.A. \\
\hline & Pipe Discharge & & & & \\
\hline 2 & Liquid discharge $35 \mathrm{gpm}\left(0.0022 \mathrm{~m}^{3} / \mathrm{s}\right)$ & 6.6 & 1.8 & 7.5 & 1.4 \\
\hline $3-4$ & $\begin{array}{l}\text { Liquid discharge } 105 \text { and } 179 \text { gpm } \\
\left(0.00662 \text { and } 0.0 .0113 \mathrm{~m}^{3} / \mathrm{s}\right)\end{array}$ & 6.2 & 1.7 & 6.8 & 1.4 \\
\hline 11 & Slurry discharge $43 \mathrm{gpm}\left(0.00271 \mathrm{~m}^{3} / \mathrm{s}\right)$ & 4.0 & 2.3 & 6.7 & 1.4 \\
\hline \multirow[t]{2}{*}{12} & Slurry discharge 125 gpm $\left(0.00789 \mathrm{~m}^{3} / \mathrm{s}\right)$ & 6.9 & 1.6 & 6.4 & 1.4 \\
\hline & Transfer Jet & & & & \\
\hline 5 & Liquid discharge 32 gpm $\left(0.00202 \mathrm{~m}^{3} / \mathrm{s}\right)$ & 7.4 & 1.7 & 7.0 & 1.4 \\
\hline 6 & Liquid discharge 57 gpm $\left(0.00360 \mathrm{~m}^{3} / \mathrm{s}\right)$ & 8.0 & 1.4 & 7.2 & 1.3 \\
\hline \multirow[t]{2}{*}{10} & Slurry discharge 23 gpm $\left(0.00145 \mathrm{~m}^{3} / \mathrm{s}\right)$ & 6.5 & 1.6 & 5.0 & 1.6 \\
\hline & Cutting Jet & & & & \\
\hline 7 & Jet on steel at low pressure & 8.1 & 1.4 & 7.1 & 1.3 \\
\hline 8 & Jet on simulant at low pressure & 5.4 & 1.6 & 4.0 & 1.5 \\
\hline 9 & Jet on simulant at high pressure & 6.4 & 1.4 & 3.2 & 1.5 \\
\hline \multicolumn{2}{|r|}{ Average } & 6.5 & 1.7 & 6.1 & 1.4 \\
\hline
\end{tabular}

a) On the y-axis, the arbitrary mass units are divided by the difference in logarithms of the boundaries of each particle size range to remove the bias in the histogram from the logarithmically irregular size brackets. 


\subsection{Release Fractions}

Appendix C shows the detailed calculations of release fractions. In instances where samples were damaged or flow was lost, the results for those samples were disregarded. Observations and notations are provided with the calculations.

The release fraction results are tabulated in Table 6.3 by location in the $1 / 4$-scale tank and for each process simulated. The fluorometry based release fractions represent the release of the liquid fraction of the process slurry. There is an entry in the table for each air sampler unless the sampler pump malfunctioned and no data was obtained for that sampler.

Table 6.3. Release fraction results

\begin{tabular}{|c|c|c|c|c|}
\hline \multirow[b]{2}{*}{ Run } & \multirow[b]{2}{*}{ Process } & \multicolumn{3}{|c|}{$\begin{array}{c}\text { Release Fraction Data from Fluorescent Tracer in Process } \\
\text { Water and from the Dry Solids (in parentheses) }\end{array}$} \\
\hline & & Tank top & Tank Wall & $\begin{array}{c}\text { Near } \\
\text { process } \\
\text { stream } \\
\end{array}$ \\
\hline & Pipe Discharge & & & \\
\hline 2 & $\begin{array}{l}\text { Liquid discharge } 35 \mathrm{gpm} \\
\left(0.0022 \mathrm{~m}^{3} / \mathrm{s}\right)\end{array}$ & $0.69,0.80$, and $0.93 \times 10^{-6}$ & 0.55 and $1.2 \times 10^{-6}$ & $2.2 \times 10^{-6}$ \\
\hline 11 & $\begin{array}{l}\text { Slurry discharge } 43 \text { gpm } \\
\left(0.00271 \mathrm{~m}^{3} / \mathrm{s}\right)\end{array}$ & $0.43,1.5$ and $1.7 \times 10^{-6}$ & 2.1 and $2.4 \times 10^{-6}$ & $2.1 \times 10^{-6}$ \\
\hline \multirow[t]{2}{*}{12} & $\begin{array}{l}\text { Slurry discharge } 125 \text { gpm } \\
\left(0.00789 \mathrm{~m}^{3} / \mathrm{s}\right)\end{array}$ & $3.1,3.7$ and $4.1 \times 10^{-6}$ & $5.0 \times 10^{-6}$ & $4.5 \times 10^{-6}$ \\
\hline & Transfer Jet & & & \\
\hline 5 & $\begin{array}{l}\text { Liquid discharge } 32 \mathrm{gpm} \\
\left(0.00202 \mathrm{~m}^{3} / \mathrm{s}\right)\end{array}$ & 0.48 and $3.2 \times 10^{-6}$ & 3.6 and $5.0 \times 10^{-6}$ & $4.1 \times 10^{-6}$ \\
\hline \multirow[t]{2}{*}{10} & $\begin{array}{l}\text { Slurry discharge } 23 \text { gpm } \\
\left(0.00145 \mathrm{~m}^{3} / \mathrm{s}\right)\end{array}$ & $1.8,2.1$ and $2.1 \times 10^{-6}$ & $\begin{array}{r}2.5 \text { and } 2.7 \times 10^{-6} \\
\left(3.5 \text { and } 6.8 \times 10^{-6}\right) \\
\end{array}$ & $\begin{array}{r}1.6 \times 10^{-5} \\
\left(4.4 \times 10^{-5}\right) \\
\end{array}$ \\
\hline & Cutting Jet & & & \\
\hline 7 & Jet on steel at low pressure & 1.0 and $5.6 \times 10^{-4}$ & 0.12 and $6.3 \times 10^{-4}$ & $4.0 \times 10^{-4}$ \\
\hline 8 & Jet on simulant at low pressure & 5.5 and $7.7 \times 10^{-5}$ & N.A. & $\begin{array}{r}1.4 \times 10^{-4} \\
\left(1.3 \times 10^{-4}\right) \\
\end{array}$ \\
\hline 9 & Jet on simulant at high pressure & $\begin{array}{c}6.0,6.0 \text { and } 8.1 \times 10^{-5} \\
\left(6.6,6.6 \text {, and } 7.9 \times 10^{-5}\right)\end{array}$ & $\begin{array}{r}8.8 \text { and } 9.1 \times 10^{-5} \\
\left(3.9 \text { and } 3.9 \times 10^{-5}\right)\end{array}$ & $8.0 \times 10^{-5}$ \\
\hline
\end{tabular}

As noted in section 5.3.1, the results for Run 7 are for the cutting jet on bare steel. The cutting jet may be used to scarify solid waste that is otherwise not sufficiently mobilized by other dislodging mechanisms. If the water-based cutting jet actually strikes bare steel, it is not striking waste, and waste is not being released at that particular time. Consequently, a measured release fraction from this run is not actually applicable to waste retrieval. The results from Runs 8 and 9 are the appropriate release fractions to use for this purpose. The process simulation only contained a solids component for Runs 8 through 12 . 
Solids release fractions were obtained for only a third of the possible instances (runs X positions), because the measurement method was not as sensitive as it was for the liquid fraction. Agreement between the liquid and solid release fractions was variable but always within a factor of 3 . However, in the one case (Run 9) where both release fractions were measurable at the top of the tank, the results showed excellent agreement among the three samplers. 


\subsection{References}

Ballinger, MY, and WH Hodgson. 1986. Aerosols Generated by Spills of Viscous Solutions and Slurries. NUREG/CR-4658, Pacific Northwest Laboratory, Richland, Washington.

Ballinger, MY, JW Buck, PC Owczarski, and JE Ayer. 1988. Methods for Describing Airborne Fractions of Free Fall Spills of Powders and Liquids, NUREG/CR-4997, Pacific Northwest Laboratory, Richland, Washington.

Ballinger, MY, SL Sutter, and WH Hodgson. 1987. New Data for Aerosols Generated by Releases of Pressurized Powders and Solutions in Static Air NUREG/CR-4779, Pacific Northwest Laboratory, Richland, Washington.

Bamberger, JA, JM Bates, ED Waters, and DT Heimberger. 1993. System Design Specification for the 1/4-Scale Tank and Ancillary Equipment, PNL-8120, Pacific Northwest Laboratory, Richland, Washington.

Mark, D and JH Vincent. 1986. A New Personal Sampler for Airborne Total Dust in Workplaces. Annals of Occupational Hygiene, Vol. 30, pp. 89-102.

Powell, ML., GR Golcar, and JGH Gheeting. 1997. Retrieval Process Development and Enhancements Waste Simulant Compositions and Defensbility, PNNL-11685, Pacific Northwest National Laboratory, Richland, Washington.

Sutter, SL, JW Johnston, and J Mishima. 1981. Aerosols Generated by Free Fall Spills of Powders and Solutions in Static Air, NUREG/CR-2139, Pacific Northwest Laboratory, Richland, Washington. 


\section{Appendix A}

\section{Air Sampling Procedure for Suspension Experiment}




\section{Test Preparation}

1. Obtain and characterize simulants

2. Obtain waste process simulators

3. Obtain $0.01 \mathrm{mg}$ capable balance and verify that it is in calibration

4. Obtain fluorometer and its calibration data

5. Obtain fluorometer procedure

6. $\quad$ Obtain sample filter leaching solutions (distilled water) and containers

7. Obtain air sample filter holders, filters, cassettes, caps

8. Obtain air sampler calibrator

9. Obtain optical particle counter interfaced with laptop and data logging software. Record particle data in differential mode.

10. Obtain dust monitor(s), interface with laptop and data logging software

11. Calculate quantity of dye (fluorescein) needed for makeup water

12 Obtain determined quantity of dye (dry or solution) sufficient for each batch of makeup water

13. Determine process simulator operating parameters
a. Pressure
b. Run time
c. Configuration
d. Sampler run strategy or test instructions

14. Prepare data sheets

15. Calibrate fluorometer

16. Calibrate air sampling pumps and record on data sheets.

a. Calibrate the sampling pump using a representative loaded IOM Sampler ${ }^{\mathrm{a})}$ in-line.

b. Using flexible tubing, connect the outlet of the IOM Calibration Adapter (Figure A.1) to a flow meter.

c. Load a representative filter into an IOM cassette. Insert the cassette into a clean IOM Sampler body. Attach the Calibration Adapter to the IOM by raising the adapter's flat plate (held by springs on both ends) sufficiently to place the IOM front cover face down onto the foam pad.

d. Ensure that the IOM front cover is positioned centrally.

e. $\quad$ Connect the IOM Sampler outlet to the inlet of a sampling pump.

f. Adjust the flow rate to $2 \mathrm{~L} / \mathrm{min}$. See calibrator and sampling pump operating instructions for additional information.

g. Disconnect the representative sampler from the pump and calibrator and set aside for flow verification after sampling.

a) SKC Incorporated, IOM Inhalable Particle Sampler, Eighty Four, Pennsylvania. This sampler was developed at the Institute of Occupational Medicine, Edinburgh, UK by Mark and Vincent (1986). 


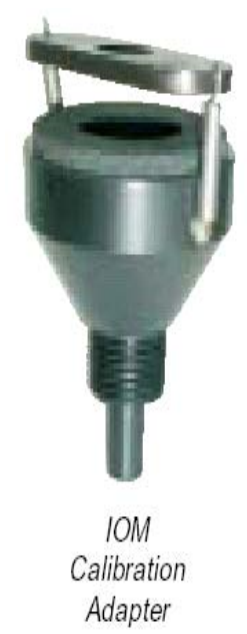

Figure A.1. Calibration adaptor

\section{Instructions for Each Test}

1. Prepare air sampling cassettes and record tare weights on data sheet for the test. Use $25 \mathrm{~mm}$ membrane filters. Place in Ziploc bag. Prepare enough units for sampling plus two for field blanks.

a. Handling: wear gloves when handling cassettes and use tweezers when working with filters or foams to prevent the transfer of moisture, dust, or other contaminants onto the sampling media.

b. Cleaning sampler

i. $\quad$ Disassemble the IOM Sampler (Figure A.2). The foam disc will not be used.

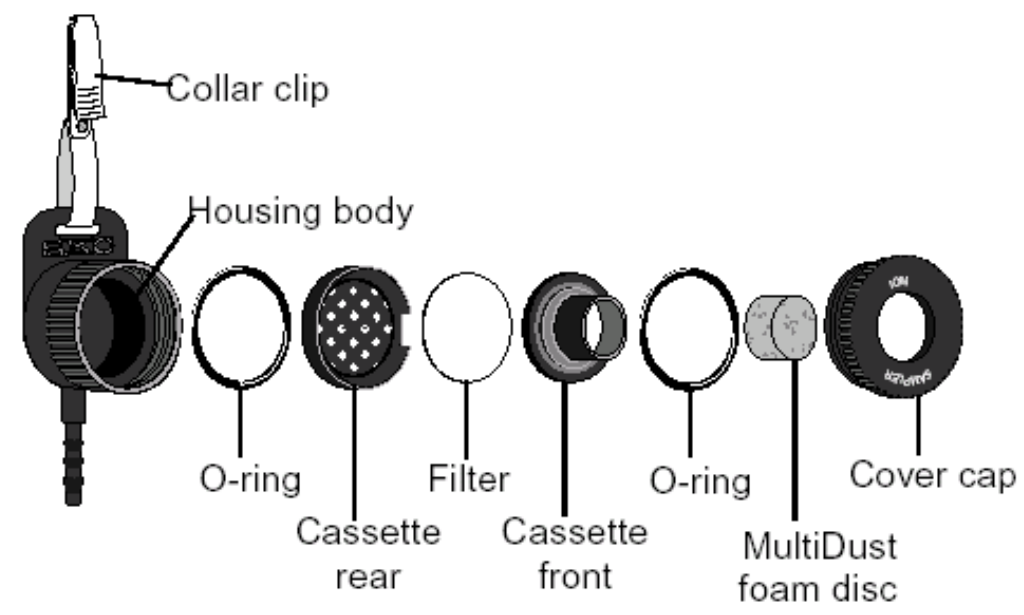

Figure A.2. IOM sampler 
ii. $\quad$ Place parts in an ultrasonic cleaner with water and a wetting agent such as soap. IOM components may also be cleaned with a solvent such as isopropyl alcohol. O-rings should be cleaned separately using water only.

iii. Clean the components using a lint-free paper or cloth, or a soft lint-free brush. Allow components to dry completely

c. Loading a filter into the IOM cassette

i. $\quad$ Use gentle pressure to separate the two halves of the cassette (Figure A.3)

ii. Place a filter into the cassette rear (on the support grid). Snap the cassette front into the cassette rear, ensuring a tight fit.

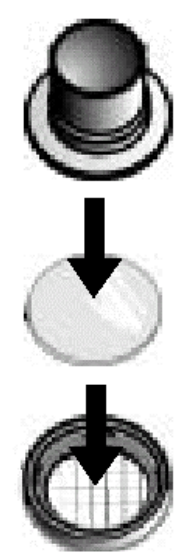

Figure A.3. Cassette assembly

d. General weighing guidelines

i. $\quad$ Pre- and post-weigh filter and cassette as a single unit. Before pre- and postweighing, wipe the external surface with a clean lint-free paper or cloth, or a soft lint-free brush.

ii. Field blanks can be used to correct weights when using plastic cassettes at low filter loadings

iii. The IOM cassette assembled with filter or the filter alone should be weighed on a five-figure forced balance. Allow the cassette three-and-half minutes to stabilize before taking a reading. The same balance should be used for both pre- and postweighing procedures.

e. $\quad$ Pre-weighing

i. $\quad$ Equilibrate cassette and filter at room temperature and humidity for 30 minutes.

ii. Wipe the external surface of a loaded IOM cassette with a clean lint-free paper, cloth, or soft brush.

iii. $\quad$ Pre-weigh the loaded IOM cassette as a single unit (Figure A.4).

iv. Note the result and reference it to the cassette or complete IOM sampler with a number or letter. 
v. $\quad$ Note: The cassette cover (Figure A.4) can be included in pre- and post weighing as part of the complete cassette if required, but must be referenced to the cassette used.

f. $\quad$ Assemble the cassette in the IOM sampler as shown in Figure A.5. Place in Ziploc ${ }^{\circledR}$ bag for transport to the test site. The large black cap can also be installed over the assembly for transport and run setup.

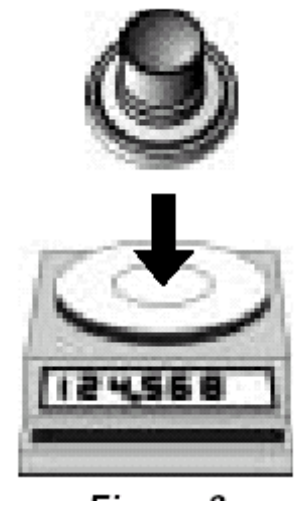

Figure A.4. Weighing cassette

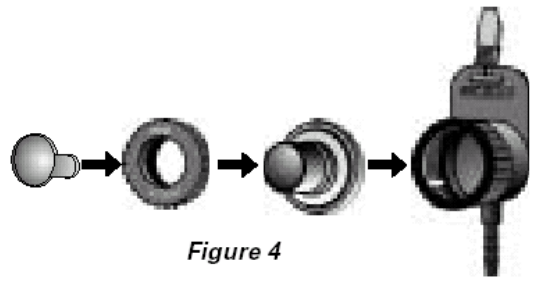

Figure A.5. Cassette assembly

2. Add predetermined fluorescent dye to simulant or process makeup water

3. Mix process makeup water.

4. Position process simulator and waste simulant in tank.

5. Position air monitoring instrumentation and data logging computers.

6. $\quad$ Enter new logging file names if needed.

7. Collect background data for dust monitor and the particle counter for 30 minutes. Run one filter sample for 30 min as a background. Retrieve air sample cassette. Place in Ziploc® bag for transport to lab.

8. Replace background air filter cassette with newly loaded and tared cassette or sampler. Remove large black (if used) and red caps from other samplers.

9. Collect a sample of the process water $(20-50 \mathrm{ml})$.

10. Note height of process water in tank.

11. Restart dust monitor, particle counter, air filters

12. Start process simulation per predetermined parameters and record actual operating parameters

13. Observe logging of dust monitor and particle counter data, air sampler flow rates.

14. Terminate process simulation.

15. Close data log files and record file names. 
16. Record height of process water in tank.

17. Cap and retrieve air sample cassettes or complete IOM samplers. Place in individual Ziploc® bags for transport to lab.

\section{Analysis of Air Samples}

1. Remove sample cassettes from IOM samplers.

2. Treat field blanks the same as the actual samples.

3. Dry cassettes in oven at $90{ }^{\circ} \mathrm{F}\left(32^{\circ} \mathrm{C}\right)$ for $30-60 \mathrm{~min}$. Note if cassettes were capped or not.

4. Allow cassettes to equilibrate at room temperature and humidity for 30 minutes.

5. $\quad$ Reweigh air sample cassettes and record results on the data sheets.

6. Include three process blank solution samples with each analysis batch for the remainder of the steps.

7. Remove sample filters and place in $50 \mathrm{ml}$ beakers or other containers, collection side up.

8. Tare weigh the containers with the filters.

9. Put about $20 \mathrm{ml}$ of distilled water into the container with the filters

10. Agitate containers occasionally for one hour

11. Reweigh the containers to determine amount of water added.

12. Filter and transfer solution into fluorometer cuvette, about $3 / 4$ full

13. Analyze each cuvette in Turner fluorometer. ${ }^{\text {a) }}$ Repeat three times, rotating cuvette between readings. Record gain setting and readings. Convert readings to mass using calibration data.

14. Clean and dry non-disposable containers, IOM samplers, and air filter cassettes

a) Turner Model 450 Digital Fluorometer, currently available from Barnstead International, Dubuque, Iowa. 


\section{Appendix B}

Optical Particle Counter Measured Concentration as a Function of Time

B.1 


\section{Optical Particle Counter Measured Concentration as a Function of Time}

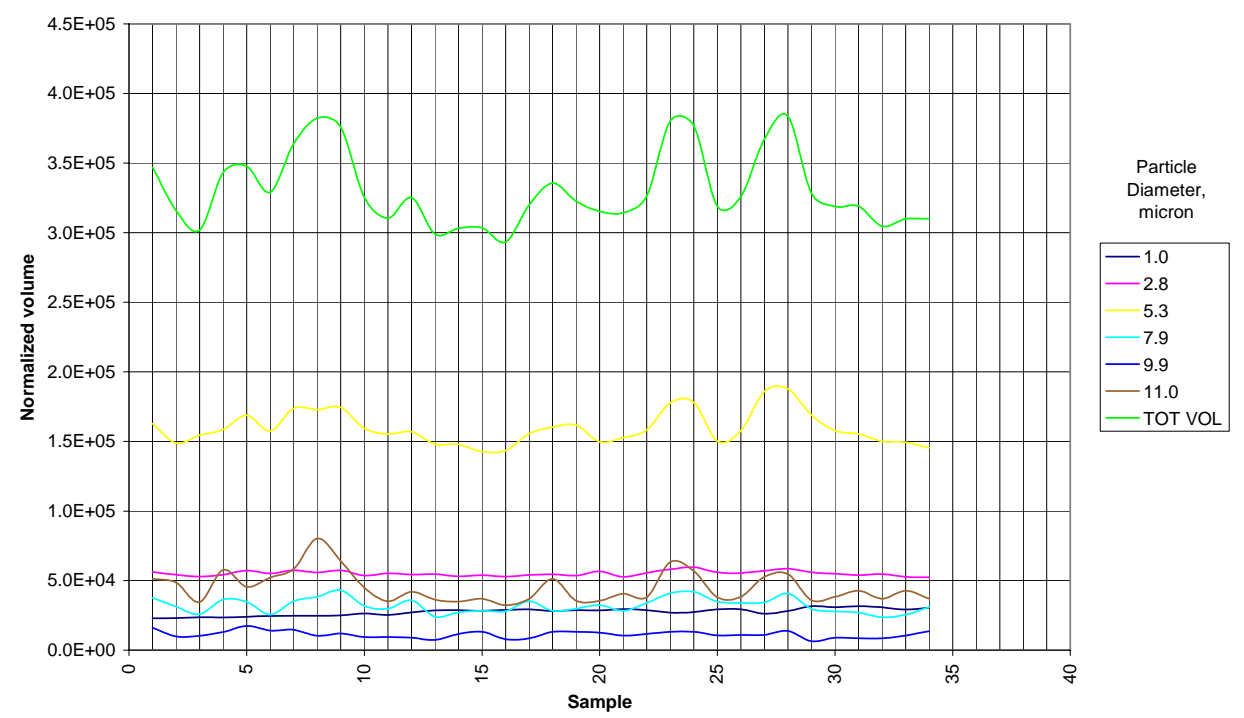

Figure B.1. Run 1 Optical Particle Counter Background Concentration

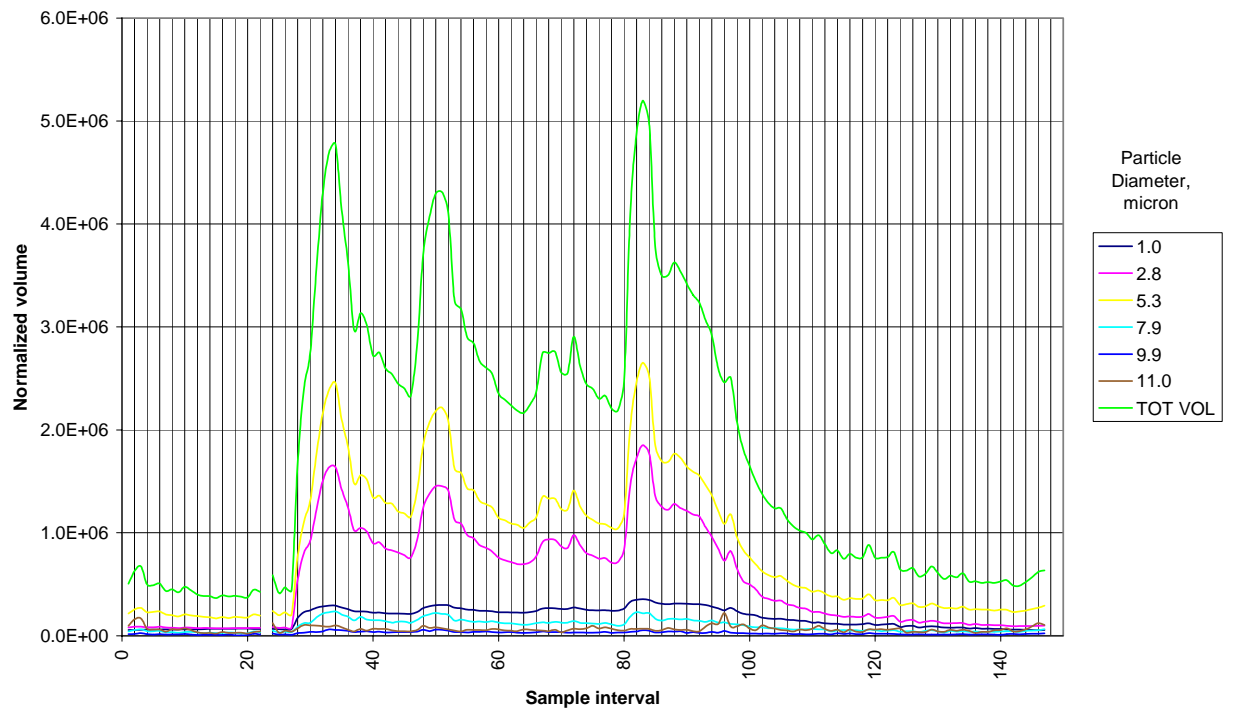

Figure B.2. Run 2 Optical Particle Counter concentration pipe discharge with water 


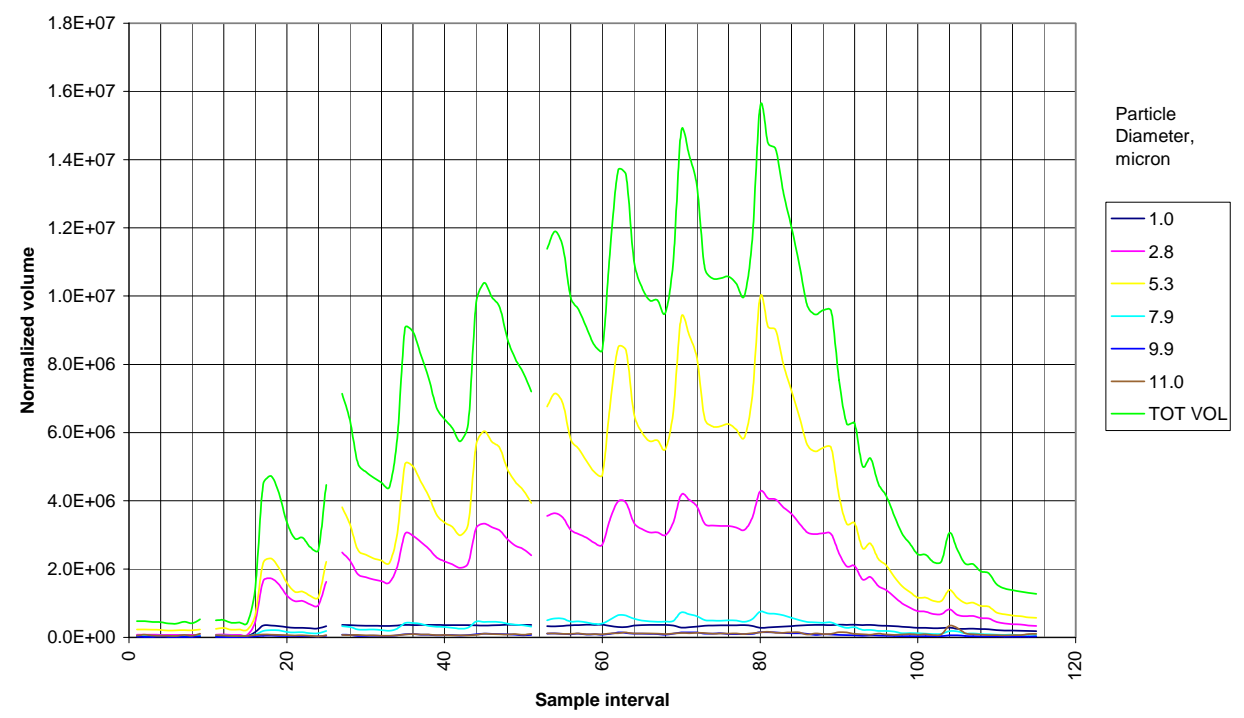

Figure B.3. Run 3-4 Optical Particle Counter concentration for pipe discharge with water at high flow rate

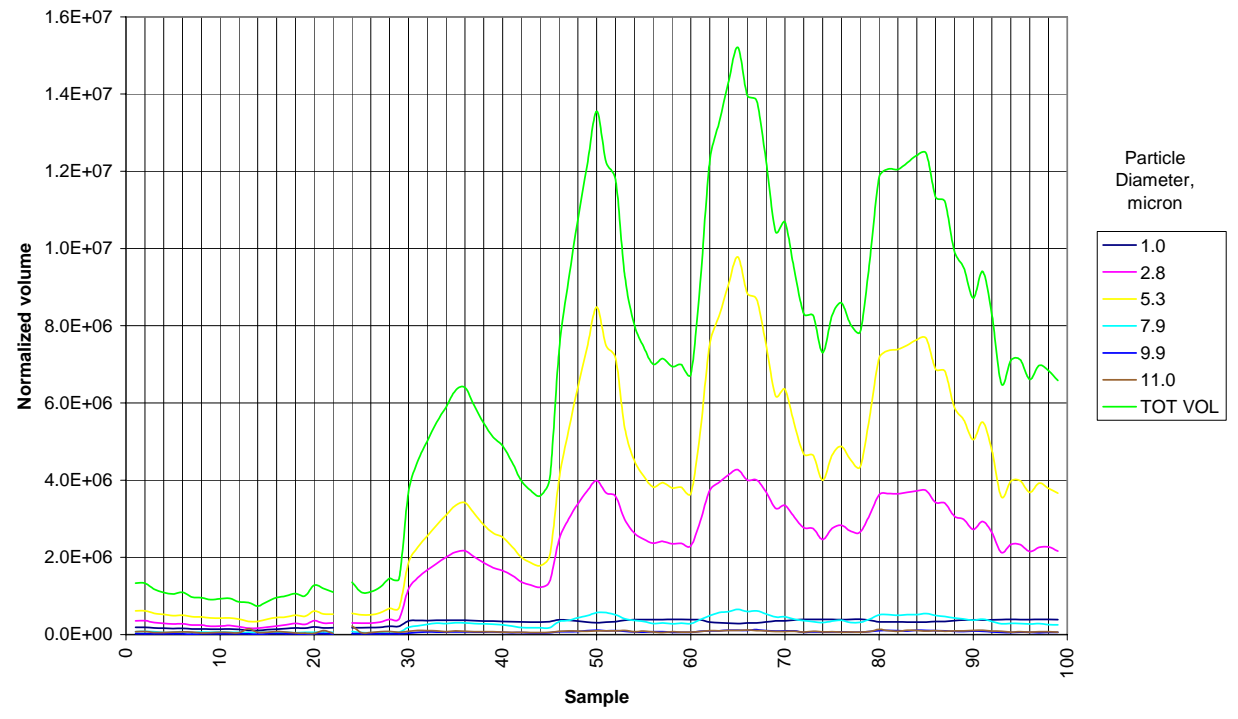

Figure B.4. Run 5 Optical Particle Counter concentration for transfer jet with water 


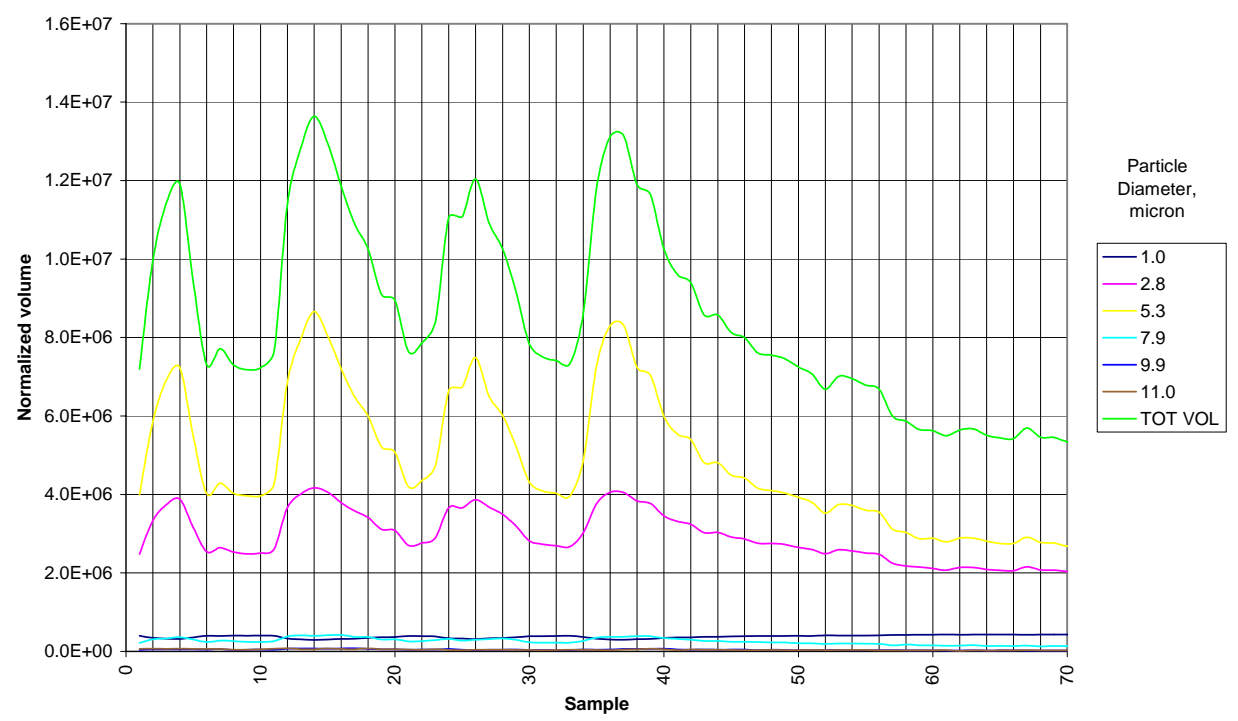

Figure B.5. Run 6 Optical Particle Counter concentration for transfer jet with Water

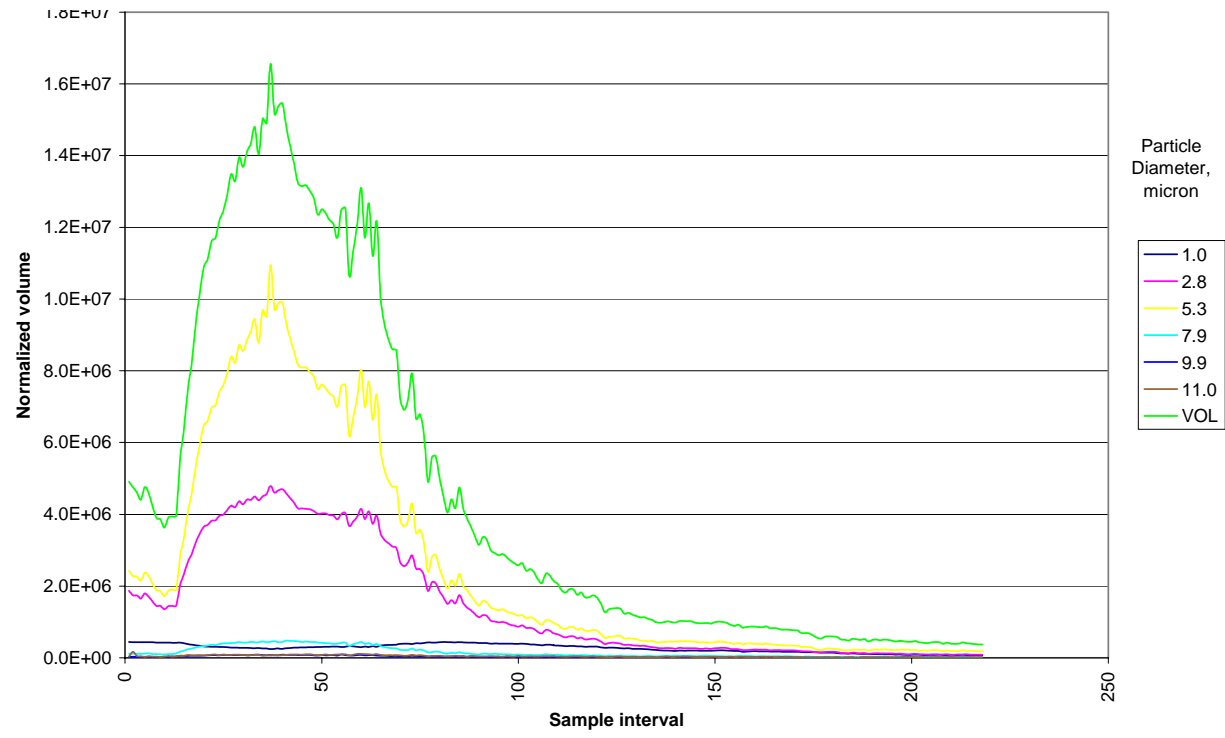

Figure B.6. Run 7 Optical Particle Counter concentration for cutting jet impacting steel plate at low pressure

B.5 


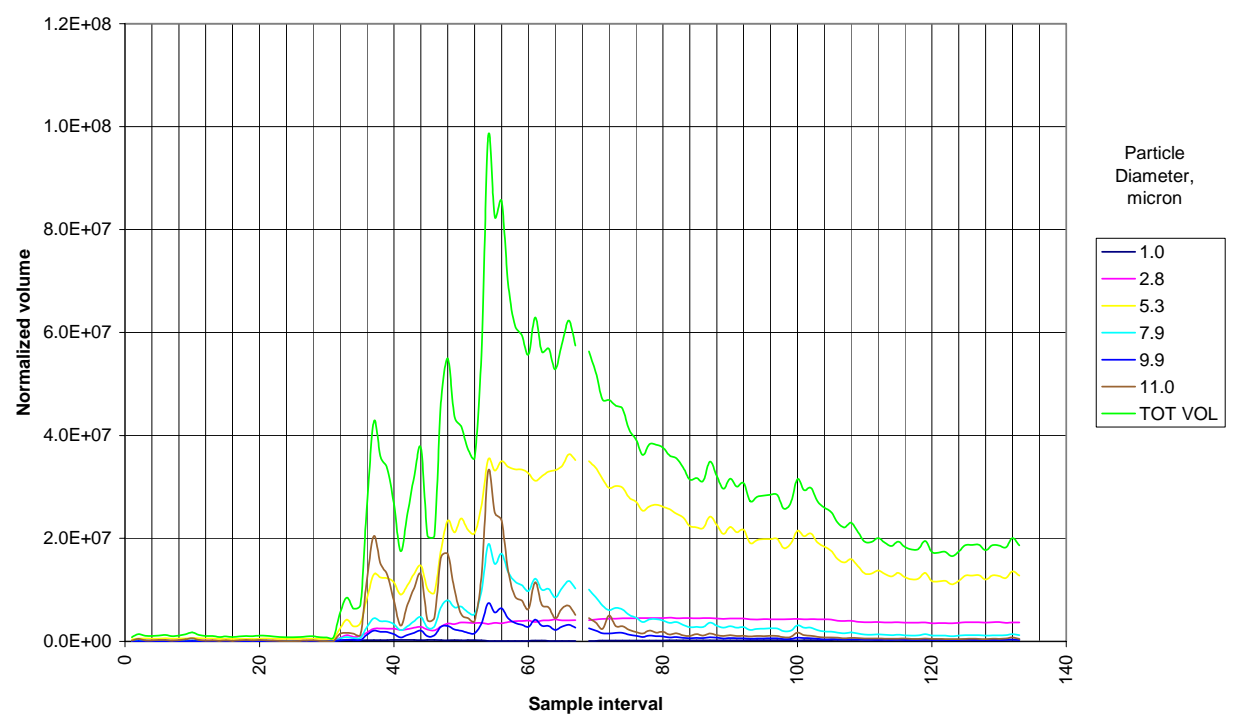

Figure B.7. Run 8 Optical Particle Counter concentration for cutting jet impacting simulant at low pressure

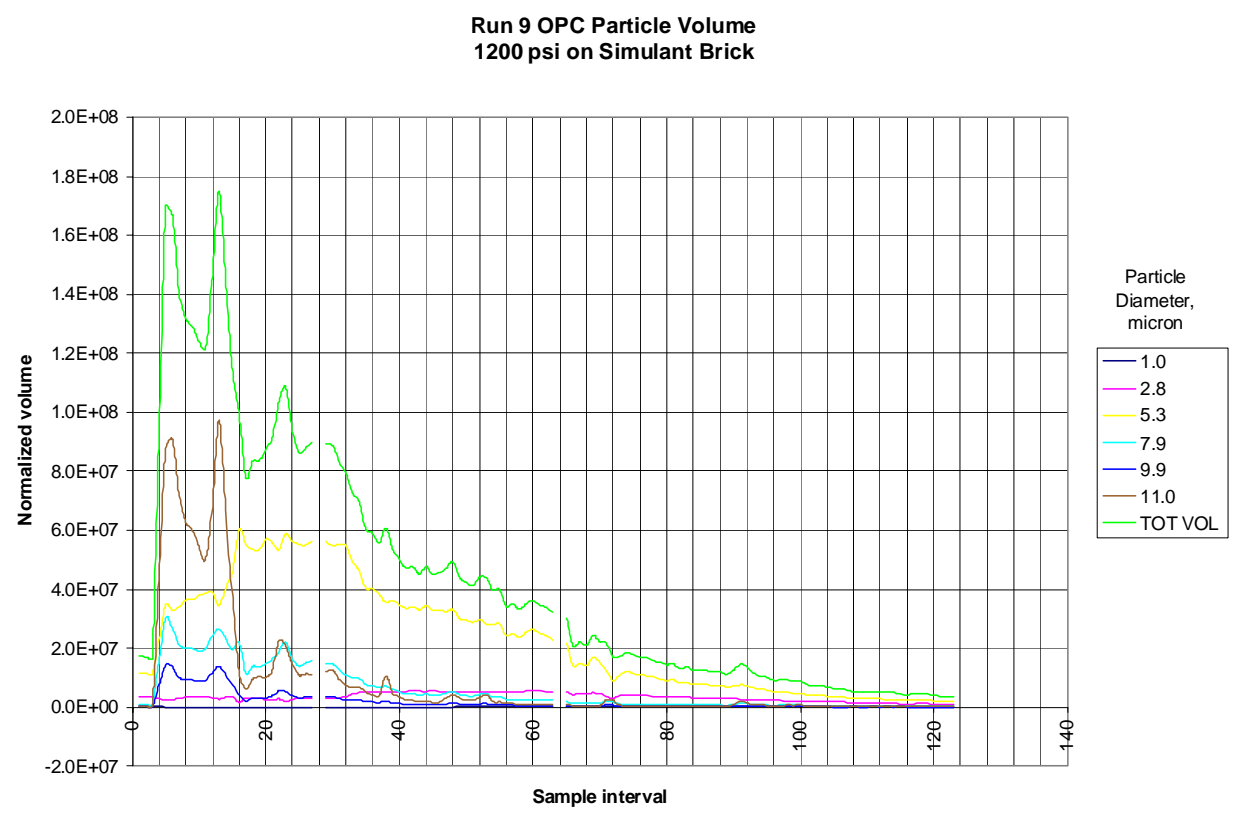

Figure B.8. Run 9 Optical Particle Counter concentration for cutting jet impacting simulant at high pressure 


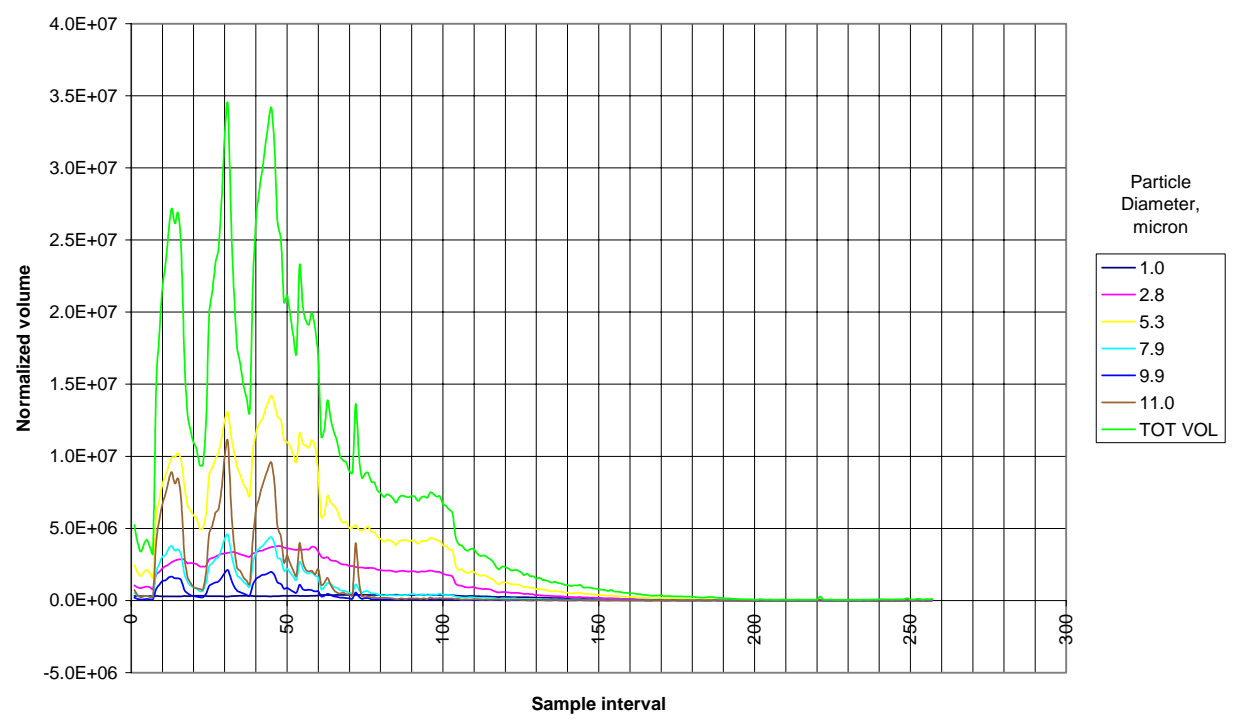

Figure B.9. Run 10 Optical Particle Counter Concentration for transfer jet slurry discharge

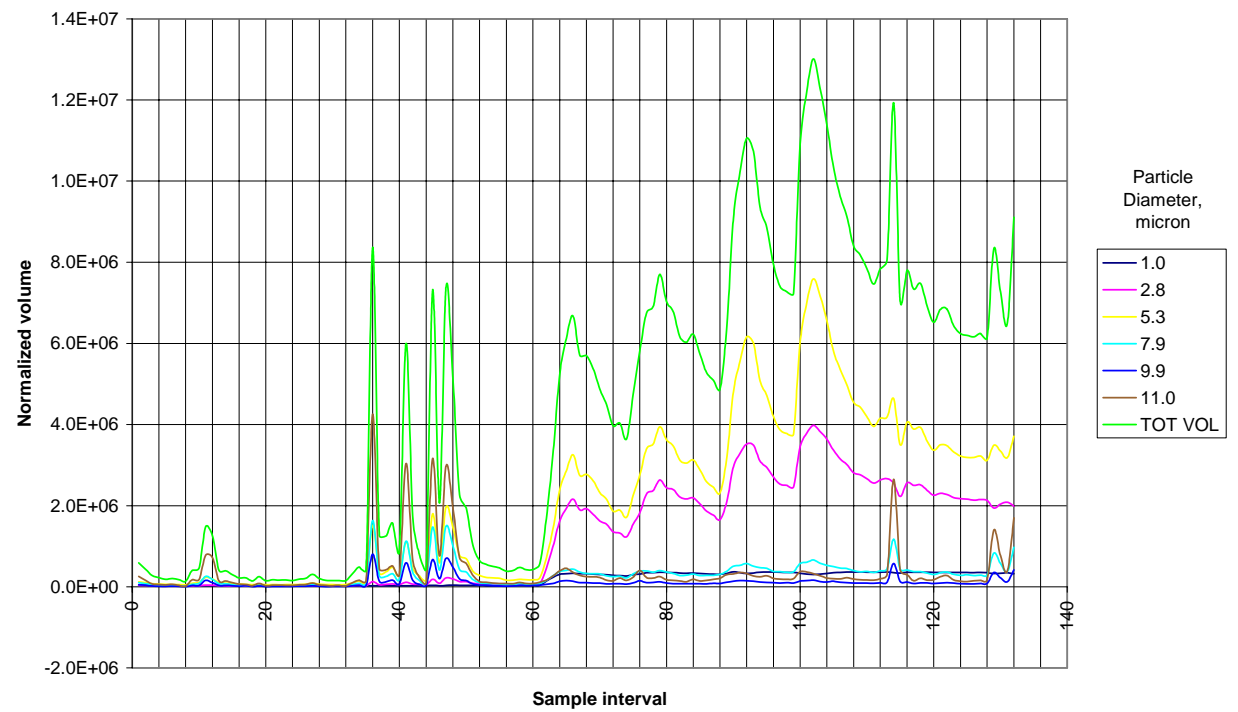

Figure B.10. Run 11 Optical Particle Counter concentration for slurry discharge from a pipe at low flow rate

Note the elevated concentration caused by setup activities prior to the simulated operations. 


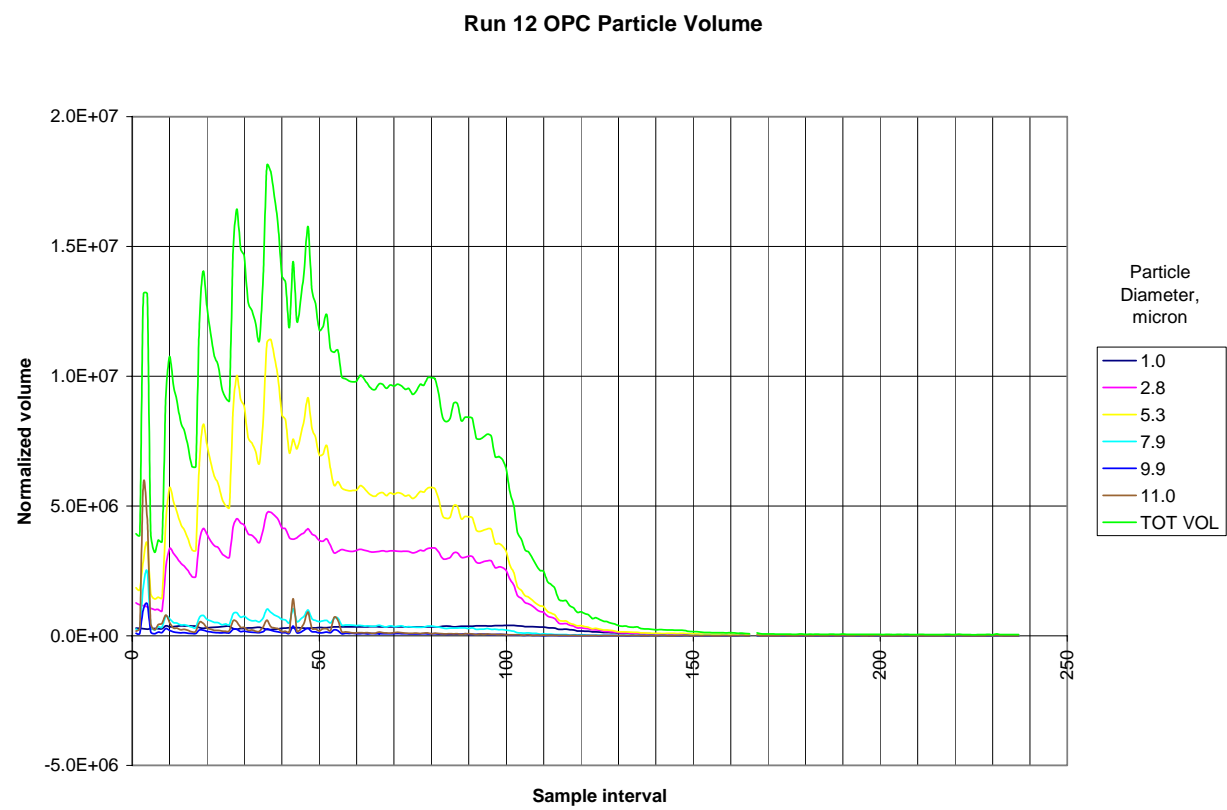

Figure B.11. Run 12 Optical Particle Counter concentration for slurry transfer at high flow rate Note the elevated concentration caused by setup activities prior to the simulated operations. 


\section{Appendix C}

\section{Release Fraction Calculations}

C.1 


\title{
Release Fraction Calculations
}

\author{
Table C.1. Run 1 Background
}

\section{Background, No Process}

Let blank value float to view variability and drift

Concluded that it would be good practice to monitor blank in between samples or often.

Solution Gain FL 1 FL2 FL3 Average Concentrat Mass $\quad \begin{aligned} & \text { Sample } \\ & \text { Volume }\end{aligned}$

Sample

$\mathrm{g}$

$$
\mathrm{g} / \mathrm{g}
$$

$\mathrm{L}$
621.7 2.18E-08 4.39E-07

-28.3 1.70E-10 3.41E-09

-28.3 1.70E-10 3.41E-09

-28.7 1.59E-10 3.18E-09

-28.3 1.70E-10 3.40E-09

$-25.3 \quad 2.70 \mathrm{E}-10$ 5.40E-09

$-10.0 \quad 7.81 \mathrm{E}-10$ 1.58E-08

-15.7 5.92E-10 1.18E-08

-20.7 4.26E-10 8.51E-09

-24.7 2.92E-10 5.85E-09

-1.3 1.07E-09 2.14E-08

-14.0 6.48E-10 1.29E-08

Comments picked up some fluorescent 45 contamination 45 45 45 45 22.5

$1 \mathrm{~A} 8$

9 BG

PB1

PB2

PB3

blk 2

blk 3

blk 4

$\begin{array}{rrrrr}20.00 & 50 & -24 & -25 & -25 \\ 19.98 & 50 & -4 & -23 & 23\end{array}$

$\begin{array}{lllll}19.94 & 50 & -15 & -15 & -12\end{array}$

$\begin{array}{llll}50 & -24 & -26 & -24\end{array}$

$\begin{array}{llll}50 & -42 & -46 & -42\end{array}$

$\begin{array}{llll}50 & -33 & -32 & -32\end{array}$

Run 1 Standards

Avg blk

Soln 4
50

$\begin{array}{llll}50 & 130 & 120 & 137\end{array}$
$-24.7 \quad 2.92 \mathrm{E}-10$

$-43.3-3.29 \mathrm{E}-10$

$-32.3 \quad 3.70 \mathrm{E}-11$

Std. g/g

$$
\begin{array}{rr}
-33.4 & 0 \\
129.0 & 5.41 \mathrm{E}-09
\end{array}
$$

slope 3.33E-11

intercept 1.11E-09

\begin{abstract}
Additional readings

$\begin{array}{lrrrrr}\text { blk } 5 & 10 & 0 & 0 & -1 & -0.3 \\ \text { Soln } 6 & 10 & 168 & 169 & 170 & 169.0\end{array}$

$\begin{array}{llllll}\text { Soln } 6 & 10 & 168 & 169 & 170 & 169.0\end{array}$
\end{abstract}


Table C.2. Run 2 Pipe transfer tests with water at low flow rate

\section{2 inch tank transfer}

35 gpm

Tank Volume 81530 liters

Dye $\quad 275.4 \mathrm{~g}$

\begin{tabular}{|c|c|c|c|c|c|c|c|c|c|c|}
\hline Sample & $\begin{array}{r}\text { Solution } \\
\mathrm{g}\end{array}$ & Gain & FL 1 & FL2 & FL3 & Average & $\begin{array}{l}\text { Concentration } \\
\text { g/g }\end{array}$ & $\begin{array}{l}\text { Mass } \\
\mathrm{g}\end{array}$ & $\begin{array}{ll}\text { Sample } & \text { Release } \\
\text { Volume } & \text { Fraction } \\
\text { L } & \end{array}$ & Comments \\
\hline 2B1 & 20.06 & 10 & 41 & 42 & 42 & 41.7 & 1.13E-08 & $2.26 \mathrm{E}-07$ & 97.5 6.86E-07 & \\
\hline 2B2 & 20.05 & 10 & 49 & 49 & 50 & 49.3 & $1.31 \mathrm{E}-08$ & 2.62E-07 & 97.5 7.95E-07 & \\
\hline 2B3 & 19.99 & 10 & 59 & 60 & 59 & 59.3 & $1.54 \mathrm{E}-08$ & 3.07E-07 & 97.5 9.34E-07 & \\
\hline 2B4 & 19.99 & 10 & 77 & 79 & 77 & 77.7 & 1.97E-08 & 3.93E-07 & $97.51 .19 \mathrm{E}-06$ & \\
\hline 2B5 & 20.00 & 10 & 32 & 32 & 32 & 32.0 & $9.01 \mathrm{E}-09$ & $1.80 \mathrm{E}-07$ & 97.5 5.47E-07 & \\
\hline 2B6 & 20.01 & 10 & 71 & 71 & 72 & 71.3 & $1.82 \mathrm{E}-08$ & $3.64 \mathrm{E}-07$ & 48.75 2.21E-06 & \\
\hline 2B7 & 20.02 & 10 & 0 & 0 & 0 & 0.0 & & & & \\
\hline 2B8 & 20.24 & 10 & 0 & -1 & 0 & -0.3 & & & & \\
\hline 2B9 BG & 20.04 & 10 & 0 & 0 & 0 & 0.0 & $1.56 \mathrm{E}-09$ & $3.13 \mathrm{E}-08$ & 49.5 1.87E-07 & \\
\hline 2PB1 & 20.03 & 10 & 0 & 0 & 0 & 0.0 & & & & \\
\hline 2PB2 & 20.02 & 10 & 0 & 0 & -1 & -0.3 & & & & \\
\hline 2PB3 & 20.03 & 10 & 0 & 0 & 0 & 0.0 & & & & \\
\hline & & & & & & & & & Mean 1.06E-06 & \\
\hline blk 2 & & 10 & 0 & 0 & 0 & 0.0 & & & S.D. 6.04E-07 & \\
\hline blk 3 & & 10 & 0 & 3 & 0 & 1.0 & & & Rel S.D. $\quad 57 \%$ & \\
\hline blk 4 & & 10 & -2 & 0 & 0 & -0.7 & & & & \\
\hline \multicolumn{6}{|c|}{ Run 2 Standards } & & Std. $\mathrm{g} / \mathrm{g}$ & & & \\
\hline & Avg. Blank & & & & & 0.1 & $\begin{array}{r}0 \\
0\end{array}$ & & & \\
\hline & Soln 4 & 10 & 19 & 19 & 22 & 20.0 & 5.41E-09 & & & \\
\hline & Soln 6 & 10 & 149 & 152 & 150 & 150.3 & $3.92 \mathrm{E}-08$ & & & \\
\hline & Soln 7 & 101 & 1669 & 1666 & 1671 & 1668.7 & $3.90 \mathrm{E}-07$ & & & \\
\hline & & & & & & $\begin{array}{r}\text { slope } \\
\text { intercept }\end{array}$ & $\begin{array}{l}2.3292 \mathrm{E}-10 \\
1.5612 \mathrm{E}-09\end{array}$ & & & \\
\hline
\end{tabular}


Table C.3. Run 5 Transfer jet tests with water

\section{9/16 nozzle}

Use results from GAIN 10, except Gain 50 for sampl $\quad$ Tank Volume 81530 liters Gain 50 regression from Run $8 \quad$ Dye $308.27 \mathrm{~g}$

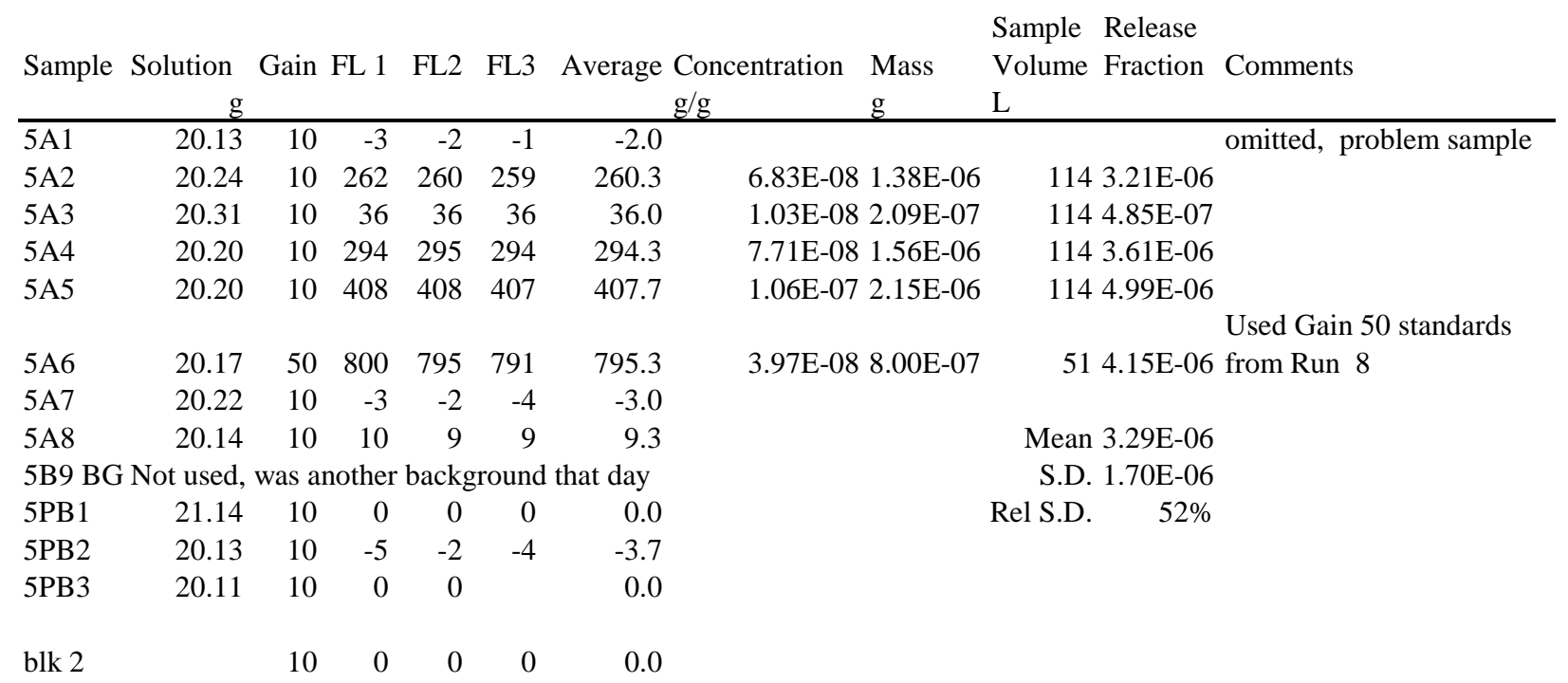

Run 5 Standards

\begin{tabular}{|c|c|c|c|c|c|}
\hline \multicolumn{5}{|l|}{ andards } & \multirow{2}{*}{$\begin{array}{r}\text { sta. g/g } \\
0\end{array}$} \\
\hline Avg BI & - Process $\mathrm{E}$ & Blanks & & -0.9 & \\
\hline Soln 4 & 10 & 17 & 17 & 17.0 & 5.41E-09 \\
\hline Soln 6 & $10 \quad 145$ & 144 & 145 & 144.7 & 3.92E-08 \\
\hline Soln 7 & 101508 & 1506 & 1502 & 1505.3 & 3.90E-07 \\
\hline & & & & slope & $2.58 \mathrm{E}-1$ \\
\hline & & & & intercept & 9.94H \\
\hline
\end{tabular}

Extra readings

$\begin{array}{llllll}\text { blk } 3 & 50 & 0 & 2 & 0 & 0.7\end{array}$

blk $4 \quad 50 \quad 1 \quad-2 \quad-1 \quad 0.7$

5A6 $20.17 \quad 10 \quad 158 \quad 158.0$ incomplete readings, use Gain 50 readings 
Table C.4. Run 7 Cutting jet tests with water on steel at low pressure

\section{High pressure jet on steel -- 300 psig}

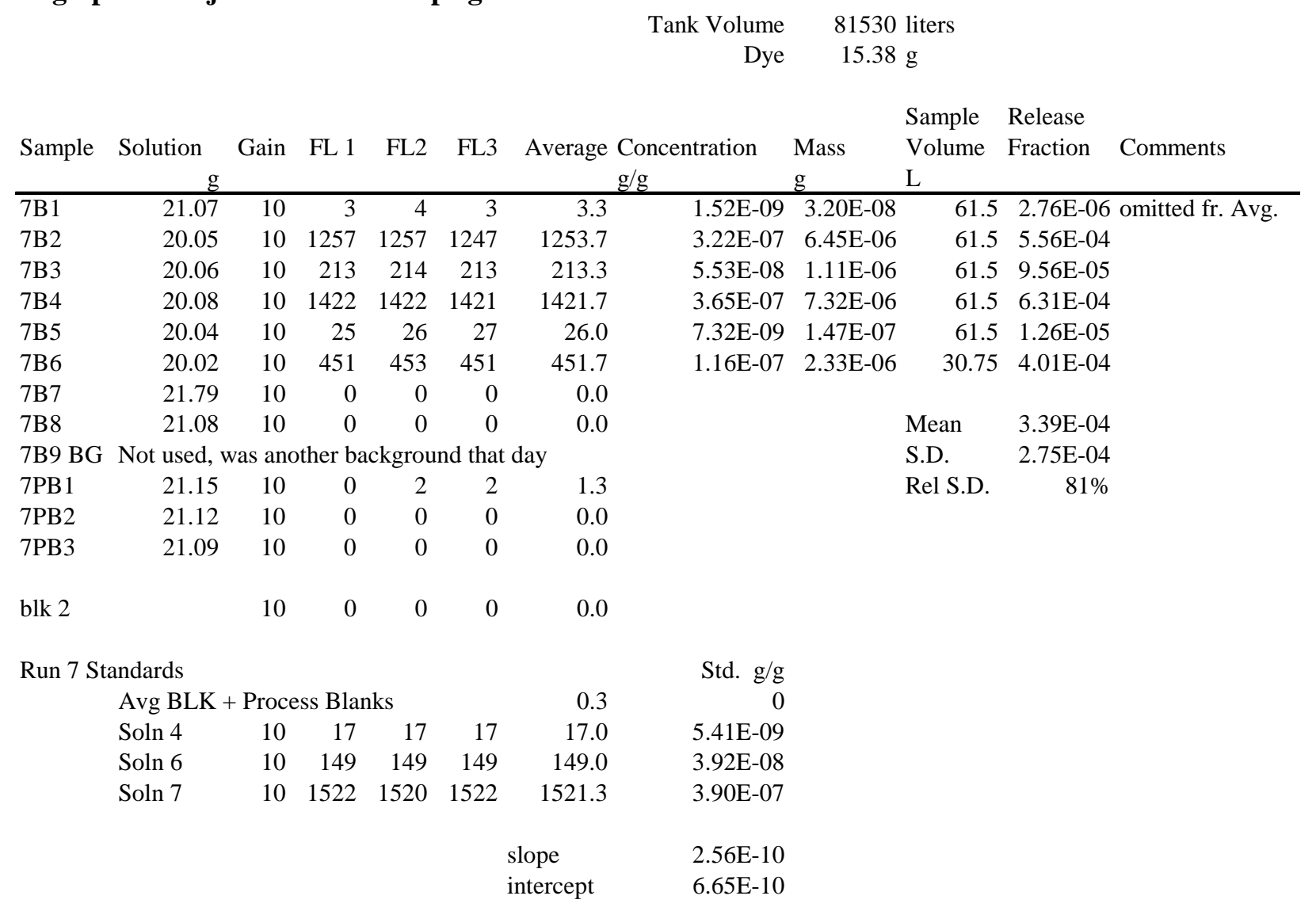


Table C.5. Run 8 Cutting jet tests on simulant at low pressure

\section{High pressure jet on simulant -- 300 psig}

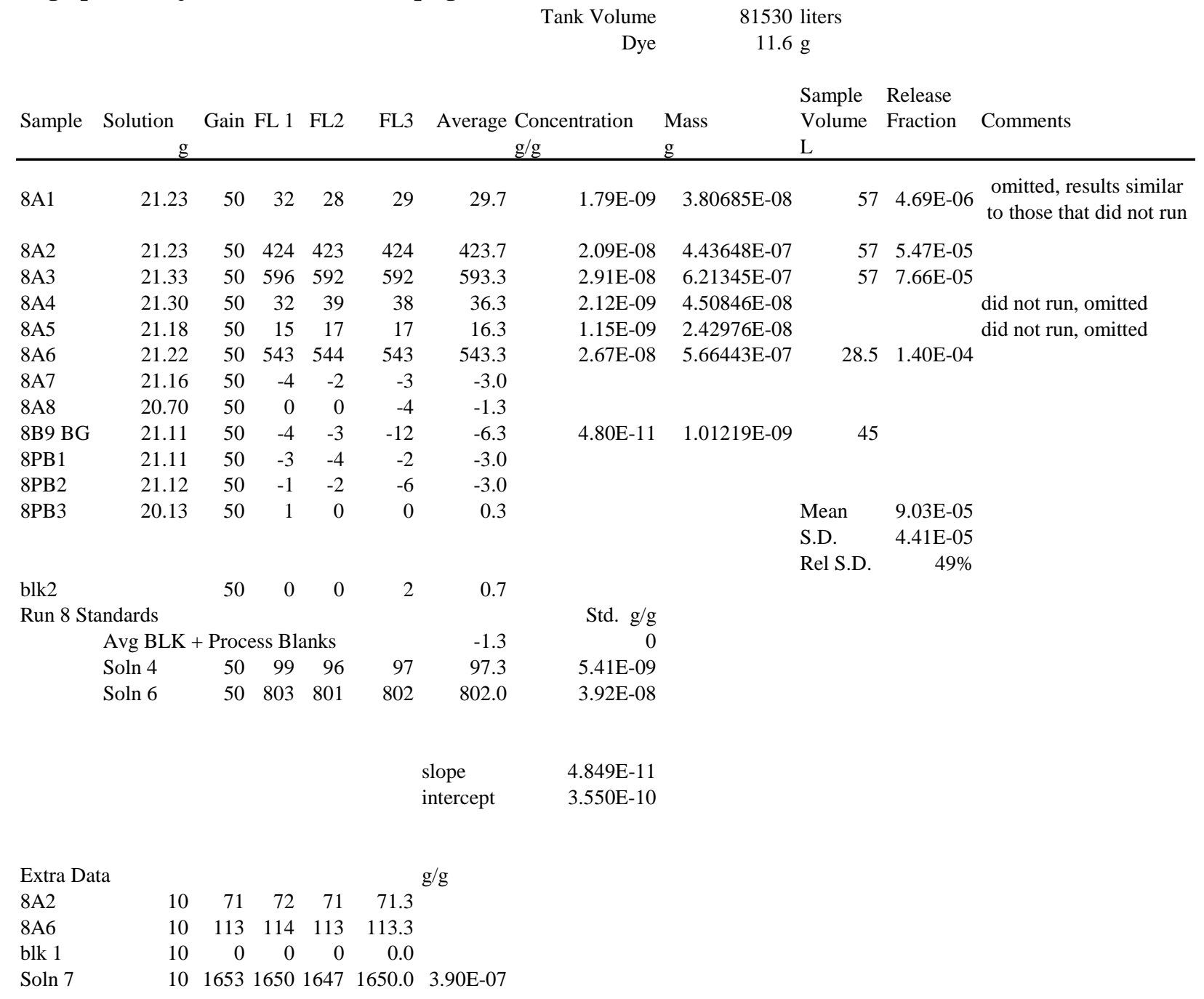

\section{C.7}


Table C.6. Run 9 Cutting jet tests on simulant at high pressure

\section{High pressure jet ON clay -- 1200 psig}

Tank Volume 81530 liters Dye $\quad 22.25 \mathrm{~g}$

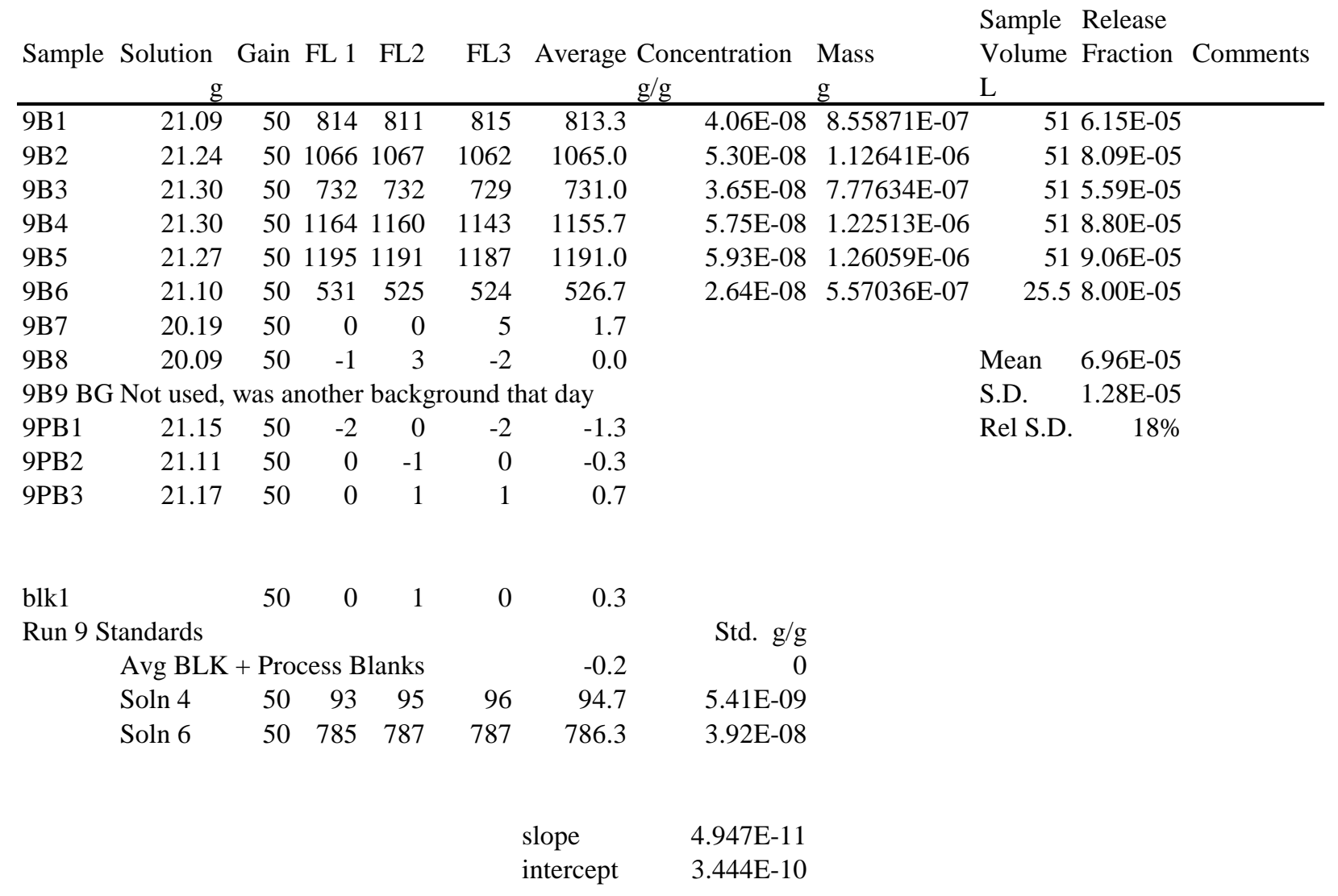

\begin{tabular}{lrrrrrr} 
Extra Data & & & & \multicolumn{3}{l}{ g/g } \\
8A2 & 10 & 71 & 72 & 71 & 71.3 & \\
8A6 & 10 & 113 & 114 & 113 & 113.3 & \\
blk 2 & 10 & 0 & 0 & 0 & 0.0 & \\
Soln 7 & 10 & 1653 & 1650 & 1647 & 1650.0 & $3.90 \mathrm{E}-07$
\end{tabular}


Table C.7. Run 10 Transfer jet tests with slurry discharge

\section{9/16 nozzle with clay}

Tank Volume 81530 liters

Dye $295.97 \mathrm{~g}$

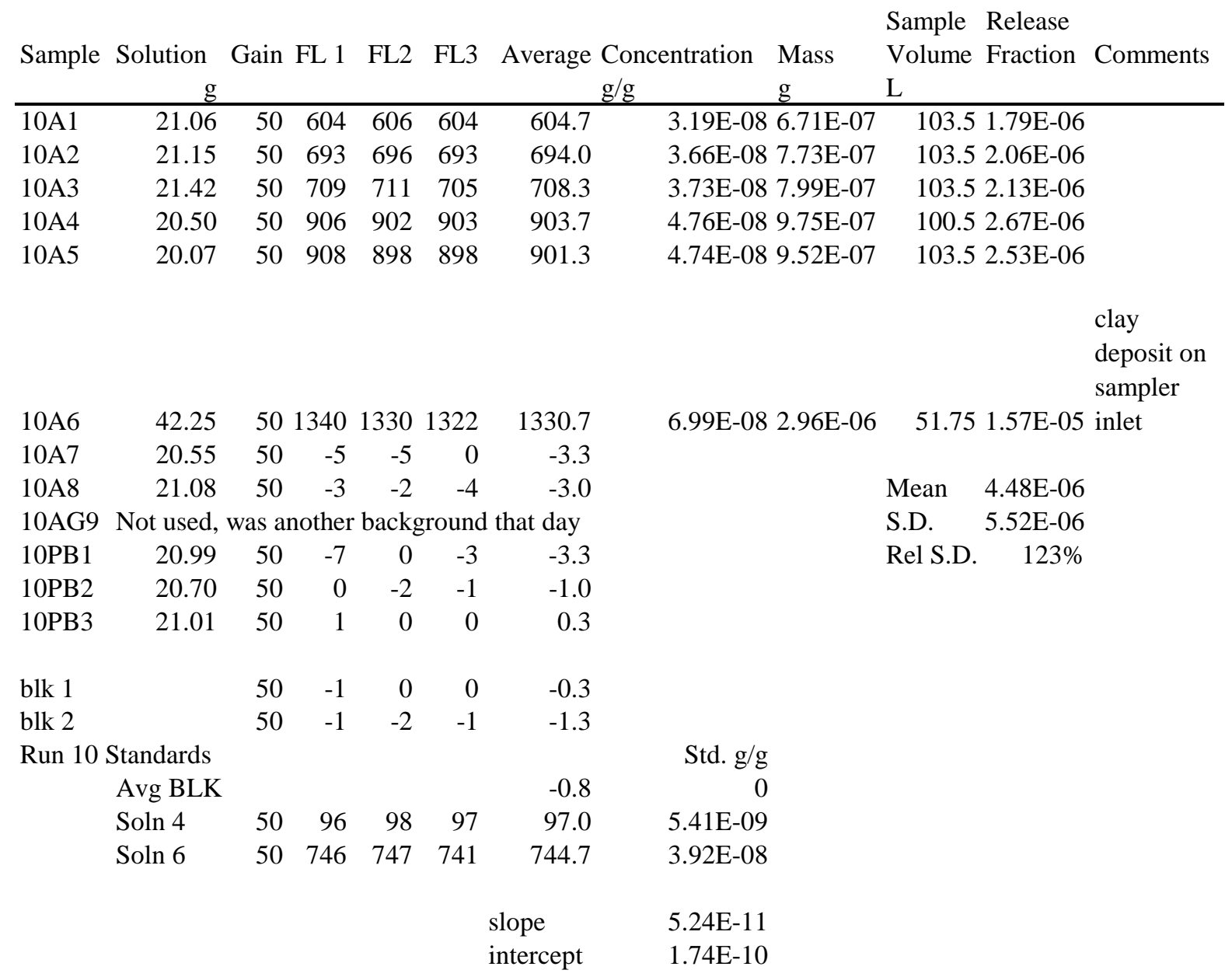


Table C.8. Run 11 Pipe discharge tests using slurry discharge at high flow rate

\section{2 in. nozzle $30 \mathrm{gpm}$}

Tank Volume 81530 liters

Dye $271.79 \mathrm{~g}$

\begin{tabular}{|c|c|c|c|c|c|c|c|c|c|c|c|}
\hline Sample & $\begin{array}{r}\text { Solution } \\
\mathrm{g}\end{array}$ & Gain & FL 1 & FL2 & FL3 & Average & $\begin{array}{l}\text { Concentration } \\
\mathrm{g} / \mathrm{g}\end{array}$ & $\begin{array}{l}\text { Mass } \\
\mathrm{g}\end{array}$ & $\begin{array}{l}\text { Sample } \\
\text { Volume } \\
\text { L }\end{array}$ & $\begin{array}{l}\text { Release } \\
\text { Fraction }\end{array}$ & Comments \\
\hline 11B1 & 21.19 & 50 & 103 & 107 & 105 & 105.0 & $5.75 \mathrm{E}-0 \mathrm{~s}$ & $1.22 \mathrm{E}-07$ & & 4 4.35E-07 & \\
\hline 11B2 & 20.57 & 50 & 383 & 384 & 383 & 383.3 & $2.06 \mathrm{E}-08$ & 4.23E-07 & 84 & 4 1.51E-06 & \\
\hline 11B3 & 21.11 & 50 & 412 & 409 & 410 & 410.3 & $2.20 \mathrm{E}-08$ & 4.64E-07 & 84 & 4 1.66E-06 & \\
\hline 11B4 & 21.07 & 50 & 526 & 526 & 525 & 525.7 & $2.81 \mathrm{E}-08$ & 5.93E-07 & 84 & 4 2.12E-06 & \\
\hline 11B5 & 21.07 & 50 & 381 & 396 & 395 & 390.7 & $2.10 \mathrm{E}-08$ & 4.42E-07 & & 4 2.45E-06 & \\
\hline 11B6 & 21.22 & 50 & 254 & 253 & 251 & 252.7 & $1.36 \mathrm{E}-08$ & 2.89E-07 & & 2 2.06E-06 & \\
\hline 11B7 & 20.05 & 50 & 3 & 0 & 0 & 1.0 & & & & & \\
\hline 11B8 & 21.05 & 50 & 2 & 1 & 0 & 1.0 & & & & & \\
\hline 11BG9 & 20.15 & 50 & 0 & 0 & 3 & 1.0 & $2.18 \mathrm{E}-1 \mathrm{C}$ & 4.39E-09 & & 0 2.20E-08 & \\
\hline 11PB1 & 19.99 & 50 & 0 & 0 & 3 & 1.0 & & & & & \\
\hline 11PB2 & 20.15 & 50 & -1 & 4 & 0 & 1.0 & & & & & \\
\hline \multirow[t]{2}{*}{ 11PB3 } & 20.01 & 50 & 2 & 0 & 0 & 0.7 & & & Mean & $1.71 \mathrm{E}-06$ & \\
\hline & & & & & & & & & S.D. & 7.08E-07 & \\
\hline blk 1 & & 50 & 0 & -2 & 1 & -0.3 & & & Rel S.D. & ). $42 \%$ & \\
\hline
\end{tabular}

Run 11 Standards

Std. g/g

Avg BLK + Process blanks $\quad 0.6$

$\begin{array}{llllll}\text { Soln } 4 & 50 & 95 & 90 & 98 & 94.3\end{array}$

Soln $6 \quad 50 \quad 743 \quad 731 \quad 728 \quad 734.0$

5.41E-09

3.92E-08

$\begin{array}{ll}\text { slope } & 5.32 \mathrm{E}-11 \\ \text { intercept } & 1.65 \mathrm{E}-10\end{array}$


Table C.9. Run 12 Pipe transfer tests of slurry discharge at high flow rate

\section{2 in. nozzle 126 gpm}

Tank Volume 81530 liters

Dye $275.73 \mathrm{~g}$

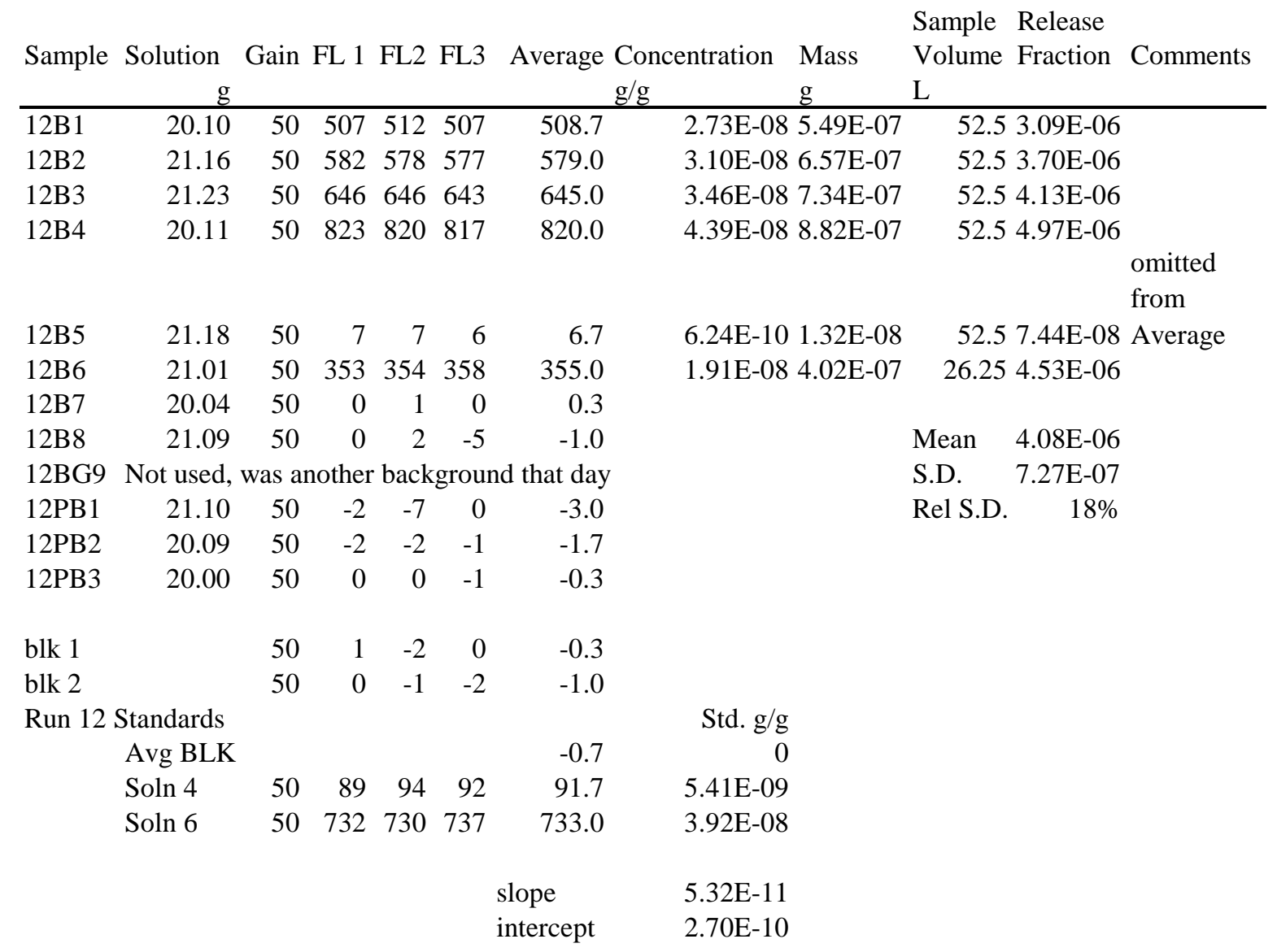


Table C.10. Process water samples

Process water samples

\begin{tabular}{|c|c|c|c|c|c|c|c|c|c|c|c|c|}
\hline Sample & $\begin{array}{r}\text { D.I water } \\
\mathrm{g}\end{array}$ & $\begin{array}{l}\text { Solution } \\
\mathrm{g}\end{array}$ & Gain & GL1 & FL2 & FL3 & Average & $\begin{array}{l}\text { Solution } \\
\mathrm{g} / \mathrm{g}\end{array}$ & $\begin{array}{l}\text { Process } \\
\text { Water } \\
\text { g/g }\end{array}$ & $\begin{array}{l}\text { Process } \\
\text { Water Used } \\
\text { In Run } \\
\text { g }\end{array}$ & $\begin{array}{l}\text { Dye } \\
\text { Exposed } \\
\text { in Run } \\
\mathrm{g}\end{array}$ & \multirow[t]{5}{*}{ Comment } \\
\hline Run 2 & 30.4955 & 30.9114 & 1 & 589 & 586 & 579 & 584.7 & $1.29 \mathrm{E}-06$ & 9.62E-05 & $2.86 \mathrm{E}+06$ & 275.40 & \\
\hline Run 5 & 31.2173 & 31.7116 & 1 & 762 & 762 & 760 & 761.3 & $1.68 \mathrm{E}-06$ & $1.08 \mathrm{E}-04$ & $2.86 \mathrm{E}+06$ & 308.27 & \\
\hline Run 7 & 30.3107 & 30.6687 & 1 & 459 & 458 & 454 & 457.0 & $1.02 \mathrm{E}-06$ & 8.71E-05 & $1.77 \mathrm{E}+05$ & 15.38 & \\
\hline Run 8 & 29.9810 & 30.2078 & 1 & 261 & 260 & 260 & 260.3 & 5.89E-07 & 7.85E-05 & $1.48 \mathrm{E}+05$ & 11.60 & \\
\hline Run 10 & 29.0415 & 29.6414 & 1 & 953 & 952 & 950 & 951.7 & 2.09E-06 & 1.03E-04 & $2.86 \mathrm{E}+06$ & 295.97 & \multirow{3}{*}{$\begin{array}{c}\begin{array}{c}\text { Probably contained some clay, } \\
\text { although centrifuged before } \\
\text { analysis }\end{array} \\
\end{array}$} \\
\hline Run 11 & 29.0411 & 29.3979 & 1 & 519 & 520 & 519 & 519.3 & 1.15E-06 & 9.50E-05 & $2.86 \mathrm{E}+06$ & 271.79 & \\
\hline Run 12 & 29.7669 & 30.1634 & 1 & 573 & 572 & 570 & 571.7 & $1.27 \mathrm{E}-06$ & $9.64 \mathrm{E}-05$ & $2.86 \mathrm{E}+06$ & 275.73 & \\
\hline 10PB1 & & & 1 & 0 & 0 & 0 & 0.0 & & & & & \\
\hline 10РB2 & & & 1 & 0 & 0 & 0 & 0.0 & & \multirow{3}{*}{\multicolumn{2}{|c|}{$\begin{array}{l}\text { 9.08E-05 Mean } \\
\text { 1.42E-05 S.D. } \\
\text { 16\% Rel S.D. }\end{array}$}} & & \\
\hline 10PB3 & & & 1 & 0 & 0 & 0 & 0.0 & & & & & \\
\hline City water & & & 1 & 0 & 0 & 0 & 0.0 & & & & & \\
\hline \multicolumn{8}{|c|}{ Batch Standards } & Std. g/g & & & & \\
\hline \multicolumn{7}{|c|}{ Avg BLK + city water + process b] } & 0.0 & 0 & & & & \\
\hline & & Soln 3 & 1 & 932 & 929 & 927 & 929.3 & $2.04 \mathrm{E}-06$ & & & & \\
\hline & & Soln 7 & 1 & 157 & 155 & 156 & 156.0 & 3.90E-07 & & & & \\
\hline \multirow{2}{*}{\multicolumn{8}{|c|}{$\begin{array}{l}\text { slope } \\
\text { intercept }\end{array}$}} & 2.18E-09 & & & & \\
\hline & & & & & & & & $2.30 \mathrm{E}-08$ & & & & \\
\hline
\end{tabular}


Table C.11. Run 8 Solids analysis from cutting jet impacting simulant at low pressure

High pressure jet on simulant -- 300 psig

Tank Volume $\quad 81530$ liters
Clay

\begin{tabular}{|c|c|c|c|c|}
\hline Sample & $\begin{array}{l}\text { Weight Sample } \\
\text { Change Volume } \\
\text { mg }\end{array}$ & & $\begin{array}{l}\text { release } \\
\text { raction }\end{array}$ & Comment \\
\hline 12B1 & 0.0 & 57 & $0.00 \mathrm{E}+00$ & omitted from fluorometry and here \\
\hline 12B2 & 0.1 & 57 & 3.18E-05 & \\
\hline 12B3 & 0.0 & 57 & $0.00 \mathrm{E}+00$ & omitted zeroes \\
\hline 12B4 & 0.0 & & & did not run, omitted \\
\hline 12B5 & 0.0 & & & did not run, omitted \\
\hline 12B6 & 0.2 & 28.5 & $1.27 \mathrm{E}-04$ & \\
\hline 12B7 & 0.0 & & & \\
\hline 12B8 & 0.0 & & 7.96E-05 & Mean \\
\hline 12BG9 & 0.1 & & $\begin{array}{r}6.76 \mathrm{E}-05 \\
85 \%\end{array}$ & $\begin{array}{l}\text { S.D. } \\
\text { Rel S.D. }\end{array}$ \\
\hline
\end{tabular}

Table C.12. Run 9 Solids analysis from cutting jet impacting simulant at high pressure

High pressure jet on simulant -- 1200 psig

Tank Volume 81530 liters

Clay $\quad 11839 \mathrm{~g}$

\begin{tabular}{lrrr} 
Sample & $\begin{array}{c}\text { Weight Sample } \\
\text { Change Volume } \\
\text { mg }\end{array}$ & \multicolumn{2}{c}{$\begin{array}{l}\text { Release } \\
\text { Fraction }\end{array}$ Comment } \\
& 0.5 & 52.5 & $6.56 \mathrm{E}-05$ \\
\hline 12B1 & 0.5 & 52.5 & $6.56 \mathrm{E}-05$ \\
12B2 & 0.6 & 52.5 & $7.87 \mathrm{E}-05$ \\
12B3 & 0.3 & 52.5 & $3.94 \mathrm{E}-05$ \\
12B4 & 0.3 & 52.5 & $3.94 \mathrm{E}-05$ \\
12B5 & 0.1 & 26.25 & $2.62 \mathrm{E}-05$ \\
12B6 & -0.2 & & \\
12B7 & -0.3 & & 5.25E-05 Mean \\
12B8 & N.A. & & 2.03E-05 S.D. \\
12BG9 & & & 39\% Rel S.D.
\end{tabular}

C.13 
Table C.13. Run 10 Solids analysis from transfer jet slurry discharge

\section{9/16 nozzle with slurry}

\begin{tabular}{|c|c|c|c|c|}
\hline \multirow{4}{*}{ Sample } & \multicolumn{2}{|c|}{ Tank Volume } & \multicolumn{2}{|c|}{81530 liters } \\
\hline & \multicolumn{2}{|c|}{ Weight Sample } & \multirow{3}{*}{$\begin{array}{l}\text { Release } \\
\text { Fraction }\end{array}$} & \multirow{3}{*}{ Comment } \\
\hline & Change & Volume & & \\
\hline & $\mathrm{mg}$ & $\mathrm{L}$ & & \\
\hline 12B1 & 0.0 & 103.5 & $0.00 \mathrm{E}+0 \mathrm{c}$ & omitted zeroes \\
\hline 12B2 & -0.1 & 103.5 & $-1.71 \mathrm{E}-0 \mathrm{\epsilon}$ & omitted zeroes \\
\hline 12B3 & 0.0 & 103.5 & $0.00 \mathrm{E}+0 \mathrm{C}$ & omitted zeroes \\
\hline 12B4 & 0.2 & 100.5 & $3.52 \mathrm{E}-0 \mathrm{E}$ & \\
\hline 12B5 & 0.4 & 103.5 & 6.84E-0€ & \\
\hline 12B6 & 1.3 & 51.75 & $4.45 \mathrm{E}-05$ & clay deposit on sampler inlet \\
\hline 12B7 & -0.1 & & & \\
\hline 12B8 & -0.1 & & $1.83 \mathrm{E}-05$ & Mean \\
\hline 12BG9 & N.A. & & $\begin{array}{r}2.28 \mathrm{E}-05 \\
124 \%\end{array}$ & $\begin{array}{l}\text { S.D. } \\
\text { Rel S.D. }\end{array}$ \\
\hline
\end{tabular}




\section{Distribution}

No. of

Copies

OFFSITE

1 DOE/Office of Scientific and Technical

Information and Information Release

\section{ONSITE}

5 Hanford Site

D. J. Carrell H6-03

P. C. Miller R1-51

L. L. Penn (2) H6-03

W. T. Thompson S7-65

5 Pacific Northwest National Laboratory

M. Y. Ballinger BSRC

J. A. Bamberger (2) K7-15

J. A. Glissmeyer K3-54

T. A. Michener K7-15

Distr. 1 